April 8, 2009

\title{
Recovery Before Redemption: A Theory of Delays in Sovereign Debt Renegotiations
}

\author{
David Benjamin* \\ State University of New York, Buffalo \\ Mark L. J. Wright* \\ University of California, Los Angeles
}

\begin{abstract}
Negotiations to restructure sovereign debts are protracted, taking on average almost 8 years to complete. In this paper we construct a new database (the most extensive of its kind covering ninety recent sovereign defaults) and use it to document that these negotiations are also ineffective in both repaying creditors and reducing the debt burden countries face. Specifically, we find that creditor losses average roughly 40 per-cent, and that the average debtor exits default more highly indebted than when they entered default. To explain this apparent large inefficiency in negotiations, we present a theory of sovereign debt renegotiation in which delay arises from the same commitment problems that lead to default in the first place. A debt restructuring generates surplus for the parties at both the time of settlement and in the future. However, a creditor's ability to share in the future surplus is limited by the risk that the debtor will default on the settlement agreement. Hence, the debtor and creditor find it privately optimal to delay restructuring until future default risk is low, even though delay means some gains from trade remain unexploited. We show that a quantitative version of our theory can account for a number of stylized facts about sovereign default, as well as the new facts about debt restructurings that we document in this paper. Finally, we argue that our findings shed light on the existence of delays in bargaining in a wider range of contexts.
\end{abstract}

*We thank Lee Ohanian, Christoph Trebesch, Vivian Yue, numerous seminar participants, as well as participants at the 2007 Society for Economic Dynamics meetings in Prague, for comments. Further comments welcome. Benjamin: db64@buffalo.edu. Wright: mlwright@econ.ucla.edu. 


\section{Introduction}

In many economic environments, agents appear to have trouble reaching mutually advantageous agreements. In this paper, we document that this phenomenon is especially severe in the case of debt restructuring negotiations between a sovereign country in default and its international creditors. Using a new database of sovereign debt restructuring outcomes, the most extensive of its kind covering ninety recent sovereign defaults, we show that the average default takes more than 7 years to resolve, results in creditor losses (or "haircuts") of roughly 40 per-cent, and leaves the sovereign country more highly indebted than when they entered default. To explain this apparent inefficiency, we present a theory of sovereign borrowing, default, and debt restructuring in which delays in debt restructuring are the result of the same commitment problems that lead to default in the first place. As a debt restructuring agreement produces gains for the debtor country both in the period of the settlement, and in the future, the country would like to promise a share of these future gains as part of a settlement. However, there is a risk that the country will default on such a promise. As a result, both the country and its creditors find it privately optimal to delay restructuring until future default risk is low. We show that a quantitative version of the theory can account for a number of stylized facts about sovereign default, as well as the new facts on debt restructurings that we document in this paper. Finally, we use the theory to examine the efficacy of bailouts by multilateral institutions as a tool for both providing insurance to debtor countries, and for encouraging a prompt restructuring.

We begin by presenting our database of sovereign debt restructuring outcomes. Drawn from a variety of sources, the database covers 90 defaults by 73 countries that were settled during the period 1989 to 2006, and contains data on the occurrence of default and settlement, the outcomes of negotiations, as well as measures of economic performance and indebtedness. In addition to the three facts introduced above, we emphasize three facts about the relationship of these outcomes to economic activity, and to each other, that motivate the development of our theory below. Specifically, we find that longer defaults are correlated with larger haircuts, and that there is a modest (but only a modest) tendency for countries to enter default when output is relatively low, and to emerge from default once output has recovered to its trend. Finally, we also establish that longer defaults and larger haircuts are more likely when 
economic conditions in the defaulting country are weak at the time of default.

We then present our theory of sovereign borrowing, default and debt restructuring. In the theory, international debt markets are incomplete so that default offers the sovereign country partial (and costly) insurance against adverse economic outcomes. While in default, and until it has settled with its creditors, output in the country is reduced, and access to international financial markets is limited. As a result, surplus is wasted while the country is in default, and the country and its creditors bargain over shares of this surplus. Bargaining takes place under complete information, with the bargaining power of the parties fluctuating over time. A settlement consists of a transfer of current resources as well as a new debt issue which serves to share the future surplus generated by a settlement. The value of a settlement to creditors, therefore, depends on the market value of the new debt issue, which is in turn limited by the fact that the country may default on these debts. Delay arises as both the country and creditor find it optimal to wait until the value of any debt issued as part of a settlement has recovered before agreeing on a settlement and redeeming the old debts.

We next take the theory to the data and show that it is capable of matching the new debt restructuring facts above, as well as a number of facts about sovereign borrowing and default stressed in previous studies. Calibrating bargaining power in our model to the relationship between default and economic activity in the data, we generate some defaults when output is high as a result of a favorable bargaining position for the debtor. Other defaults occur following a sequence of low income levels. In such cases, the possibility of a settlement leads creditors to lend even when default risk is high, supporting higher levels of borrowing (at face value) at higher interest rates than in previous models. Defaults occur when the ability to raise debt levels in response to another negative income shock is limited. When debt levels are high, settlements consist largely of new debt issues, and occur only after significant improvements in economic circumstances or bargaining conditions that raise the value of new debt issues. This is the source of delay in our model. Likewise, when the face value of the defaulted debt is high we get large haircuts, generating a positive correlation between delay and haircuts. Since countries exit default when circumstances have improved, they are able to borrow more than they could just prior to default. Thus, debt levels often rise upon exit from default. The volatility of sovereign spreads is increased by both volatility 
in the size of the expected settlement, and the greater variability in debt levels.

Our paper contributes to a number of literatures. We believe we are the first to characterize the empirical relationship between delay, haircuts and debt levels for sovereign countries in default, while our characterization of creditor losses for ninety defaults triples the number of estimates previously available (e.g. Cline 1995 and Sturzenegger and Zettelmeyer 2007). Our theory contributes to the recent literature on debt and default in both an international (Arellano 2007, Kovrijnykh and Szentes 2007, Yue 2007, and Mendoza and Yue 2008) and domestic (Chatterjee et al 2007) context. Unlike all of these papers, our theory generates delays in bargaining, and does so without appealing to collective action problems among creditors (unlike Pitchford and Wright 2007, 2008), and while simultaneously explaining the evolution of debt during the default restructuring process (unlike Bi 2008 and d'Erasmo 2008). Finally, we view our work as a contribution to the broader literature on delays in bargaining. Our finding that delays are predictable leads us to focus on commitment problems with complete information, and abstract from the role of asymmetric information (unlike the work surveyed by Ausubel, Cramton, and Deneckere 2002). Our approach extends the abstract bargaining environment of Merlo and Wilson (1995) by allowing for outside options, flow payoffs, and an endogenous terminal payoff.

The rest of this paper is organized as follows. Section 2 describes our database of sovereign debt restructuring outcomes and presents our empirical findings. Section 3 presents our theory, first analyzing the debt restructuring process taking borrowing outcomes as given, before analyzing borrowing outcomes taking the debt restructuring process as given. We then combine the restructuring environment with the borrowing environment and provide a proof of existence of an equilibrium for the overall model. Section 4 shows that a calibrated version of the model can match the facts introduced in Section 2, while Section 5 evaluates the effect of supranational bailout policies. Section 6 concludes by reinterpreting the phenomenon of worldwide sovereign debt crises in the light of our results, and considering the theories implications for negotiations in other contexts. An appendix collects tables and figures, proofs of theorems, and provides further details on our database. 


\section{Sovereign Debt Restructuring Facts}

In this section we describe our database of sovereign defaults and debt renegotiation outcomes, and present our empirical findings.

\section{A Data Sources and Construction}

In setting the limits of our database, we restrict attention to defaults on sovereign debts owed to private sector creditors, like banks and bondholders. The reason is that, in our model of debt restructuring below, creditors bargain with a view to maximizing the value of their settlement, while official creditors like the International Monetary Fund and creditor country governments are arguably motivated by broader concerns of equity. We define sovereign debts to include debts owed either directly by a country's national government, or owed indirectly by virtue of a government guarantee. The most comprehensive and widely used source of data on the dates of defaults on sovereign debts owed to private sector creditors, as well as the dates of settlements of these defaults, is published by the ratings agency Standard and Poors (Beers and Chambers 2006). Standard and Poors (S\&P) defines a default on a debt contract to have occurred if a payment is not made within any grace period specified in the contract, or if debts are rescheduled on terms less favorable than those specified in the original debt contract. S\&P defines the end of a default as occurring when a settlement occurs, typically in the form of an exchange of new debt for old debt, and when they conclude that "no further near-term resolution of creditors claims is likely" (page 22). Defining a default to have begun when debts are rescheduled on unfavorable terms, which is also related to the definition of a settlement, may result in an underestimate of actual delays in bargaining. Standard and Poors record only the year in which a default started and ended, and so we supplement these dates with data from Arteta and Hale (2007), Pitchford and Wright (2007) and Trebesch (2008), as well as a range of primary sources, to come up with the month, and in some cases the day, in which a default started and ended.

The most novel part of our dataset lies in its estimates of creditor losses, or haircuts, for a large number of defaults. Until now, there has existed only a small number of estimates

produced by different researchers using different methods for largely non-overlapping sam- 
ples of defaults ${ }^{1}$. In order to obtain the largest sample possible, and to ensure consistency of treatment, we base our measures on the World Bank's estimates of debt stock reduction, interest and principal forgiven, and debt buybacks, as published in Global Development Finance (GDF). We combine the World Bank's estimates of the reduction in the face value of the debt with estimates of the forgiveness of arrears on interest and principle. As the World Bank data do not make any distinction between forgiveness of debts by private creditors and forgiveness by official creditors, we scale the amount of forgiveness using estimates of the total amount of debt renegotiated, and on the proportion owed to private creditors, from both GDF and Institute for International Finance (2001). Losses in different years were added together and discounted back to the time of the default using a ten per-cent discount rate, following the practice of the OECD Development Assistance Committee and the World Bank (Dikhanov 2006). As shown in Appendix C, our estimates correlate closely with those of other studies.

The resulting series on private creditor haircuts covers ninety defaults and renegotiations by seventy-three separate countries that were completed after GDF data on debt forgiveness first became available in 1989 and that ended prior to 2006. Our data on default dates and haircuts were then combined with data on various indicators of economic activity taken from the World Bank's World Development Indicators publication, and with data on the stock of long term sovereign debt outstanding from GDF. Short term debt is not included because it is not available disaggregated by type of creditor.

\section{B The Facts}

Table 1 presents some summary statistics on the length of time taken to settle a default, which we refer to as delay, and on average haircuts weighted by the level of outstanding debt. There are three instances of defaults being contiguous in time, in the sense that S\&P dates a default by a country as ending in the same year, or year before, another default begins ${ }^{2}$. We present results treating these defaults both as separate events ("delay 1"), and treating them

\footnotetext{
${ }^{1}$ We have uncovered estimates of haircuts in 27 defaults, constructed by four different authors using five different methods. All of the estimates are tabulated for the purposes of comparison in Appendix C.

${ }^{2}$ The three episodes are: Ecuador, who S\&P treat as being in default from 1999 to 2000, and again from 2000 to 2001; Russia, in default from 1991 to 1997, and from 1998 to 2000; and Venezuela, in default from 1995 to 1997, and in 1998.
} 
as a single default episode ("delay 2"). Treating contiguous defaults as distinct defaults, there are ninety defaults in our sample lasting an average of 7.4 years. Delays rise to an average of 7.6 years if contiguous defaults are treated as a single default event. In our sample, delay is slightly higher than found in other studies, such as Pitchford and Wright (2008), who record an average delay of 6.5 years for a larger sample of defaults in the modern era. This leads to our first result:

Fact 1: sovereign defaults are time consuming to resolve, taking almost eight years on average in our sample.

Table 1 also presents evidence on the average size of haircuts, where the average is weighted by the value of outstanding debts for the case of contiguous defaults. As shown in the Table, the average creditor experienced a haircut of roughly 40 per-cent of the value of the debt. Further information on the sizes of haircuts and delays is presented in Figure 1 which contains a scatter plot of haircuts and delays for each of the ninety settlements contained in our sample. As shown in the Figure, haircuts in our sample have ranged from approximately zero all the way up to ninety per-cent of the value of creditors claims in the case of some African defaults. Likewise, there is a great deal of variation in delays with many defaults being settled almost immediately while others are settled in excess of two decades. There is also a noticeable positive relationship between the amount of delay in renegotiation and the size of the haircut, with the correlation coefficient between the two series equalling 0.66. This gives rise to our next two results:

Fact 2: creditor losses (or haircuts) are substantial, with the average creditor experiencing a reduction in the value of their claim of forty-four per-cent.

Fact 3: longer defaults are associated with larger haircuts, with a correlation between the length of the renegotiation process and the size of the creditor haircut of two-thirds.

One possible explanation for Fact 3 is that there is a common factor driving both longer defaults and larger haircuts. To examine this, Table 1 also presents evidence on the relationship between delays and haircuts and the level of economic activity in the year of the default. In particular, the third column shows that the larger is the decline in output in the 
year of default, the longer the delay and the larger the haircut, on average. The relationship is only modest, however, never rising above 0.3 in absolute value, with the correlation to haircuts barely different from zero. The fourth column Table 1 presents the relationship between delays and haircuts and the growth of output in the two years surrounding the default and finds a stronger negative relationship with haircuts. This leads to our fourth fact:

Fact 4: larger output declines in the year of default are associated with modestly longer defaults and larger haircuts, with correlation coefficients around -0.25

Table 2 provides further evidence on the relationship between defaults, settlements and output. As shown in the first column, there is a broad tendency for default to be associated with adverse economic conditions, with a mean level of output roughly one-half of one percent below trend ${ }^{3}$, while output in non-default periods is above trend by an equal amount on average. Economic adversity is particularly likely in the first year of a default, when output was on average 1.3 per-cent below trend, and tends to have dissipated by the time a country settles with its creditors when output is on average only $0.2 \%$ below trend. Nonetheless, there is a great deal of variation across country experiences so that the overall relationship between output and default is quite weak. In almost one-third of cases, a country defaults with output above trend. This confirms the earlier finding of Tomz and Wright (2007) for a larger sample of defaults, and leads to our fifth result:

Fact 5: defaults are somewhat more likely to occur when output is below trend, and settlements tend to occur when output has returned to trend, with $64 \%$ of defaults beginning when output is below trend, and $49 \%$ ending when output is above trend. The average deviation of output from trend is $-1.3 \%$ in the first year of a default, and $-0.2 \%$ in the year of the settlement.

Table 2 also explores the relationship between defaults and debt levels for the defaulting country. As shown in the table, being in default is associated with levels of debt to GDP

\footnotetext{
${ }^{3}$ Deviations from trend are calculated using a Hodrick-Prescott filter with smoothing parameter 6.25 for annual data (see the discussion in Ravn and Uhlig 2002). Tomz and Wright (2007) establish that these facts are robust to different filtering methods.
} 
that are more than seventy per-cent higher than for when a country is not in default, bearing in mind that our sample of countries is conditioned upon having defaulted once during this period. Strikingly, the table reveals that the average country exits default with levels of debt that are 25 per-cent higher than they possessed when they entered default. This figure is accentuated by some outlier countries, but even the median country exits default with 5 per-cent more debt. From this we conclude that renegotiations are ineffective at reducing the indebtedness of a debtor country. This leads to our sixth result:

Fact 6: default resolution is not associated with decreased country indebtedness, with the median and average country exiting default with a debt to GDP ratio 5 and 25 per-cent higher than before they entered default, respectively.

Finally, Table 1 also shows that delays and haircuts are essentially unrelated to the initial level of indebtedness of a country. In our theory, which we begin to outline in the next section, we therefore do not focus upon differences in debt levels as a major factor in negotiations.

\section{A Theory of Sovereign Debt, Default, and Debt Restructuring}

In this section, we present our theory of sovereign borrowing and default. We begin by first describing the decisions facing a sovereign country that is in good standing with its creditors, before moving on to a description of international credit markets, and then to the debt restructuring environment, devoting the most detail to the latter.

\section{A The Borrowing and Default Environment}

\section{The Sovereign Borrower}

Consider a world in which time is discrete and lasts forever. In each period $t=0,1, \ldots$, a sovereign country receives an endowment of the single non-storable consumption good $e(s)$ that is a function of the exogenous state $s$ which takes on values in the finite set $S$. Thus, the endowment also takes on only a finite number, $N_{e}$, of values. The state $s$ summarizes all sources of uncertainty in the model and evolves according to a first order Markov process with transition probabilities given by a transition matrix with representative element $\pi\left(s^{\prime} \mid s\right)$. Below, the evolution of the state $s$ will also govern the evolution of the country's bargaining position with creditors. 
The sovereign country is represented by an agent that maximizes the discounted expected value of its utility from consuming state contingent sequences of the single consumption good $\left\{c_{t}\left(s^{t}\right)\right\}$ according to

$$
\sum_{t=0}^{\infty} \beta^{t} \sum_{s^{t} \mid s_{0}} \pi\left(s^{t} \mid s_{0}\right) u\left(c_{t}\left(s^{t}\right)\right) .
$$

Here, the felicity function $u$ is twice continuously differentiable, strictly increasing and strictly concave so that the country is averse to fluctuations in its consumption. The notation $s^{t} \mid s_{0}$ is used to denote a history of the state that begins with state $s_{0}$, while $\pi\left(s^{t} \mid s_{0}\right)$ is the product of the associated one-period ahead conditional probabilities. The discount factor $\beta$ lies between zero and one and is assumed to imply a discount rate in excess of the world interest rate. As a result, international borrowing may be motivated by both a desire to smooth consumption, as well as a desire to tilt a country's consumption profile forward in time.

A sovereign country that is not in default enters a period with a new value of the state $s$, and a level of international debt $b$. It is assumed that $b$ must lie in the set of debt levels, $B$, which is finite with cardinality $N_{b}$, and contains both negative and positive elements, as well as the zero element, where negative elements are interpreted as savings by the country. We let $V(b, s)$ denote the value function of a country of that enters the period with debt $b$ and state $s$, before the country has decided whether or not to default, which is an $N_{e}$ by $N_{b}$ vector of real numbers.

The sovereign's first decision is whether or not to default on its debts. If the sovereign defaults, they receive a payoff given by $\tilde{V}^{D}(b, s)$, which is a $N_{e}$ by $N_{b}$ vector of real numbers, and which will be determined below when we describe the process by which a country in default bargains with its creditors. If we let $V^{R}(b, s)$ denote the value function of a country that enters the period with debt $b$ and state $s$, after it has decided to repay it's debts, which is an $N_{e}$ by $N_{b}$ vector of real numbers, then the value function $V(b, s)$ satisfies

$$
V(b, s)=\max \left\{V^{R}(b, s), \tilde{V}^{D}(b, s)\right\}
$$

If the sovereign country repays its debts, it must decide how much to consume $c$ and how much debt $b^{\prime} \in B$ to take into the next period. The value function associated with the 
repayment of debt, $V^{R}$, is defined by

$$
V^{R}(b, s)=\max _{c, b^{\prime} \in B} u(c)+\beta \sum_{s^{\prime} \in S} \pi\left(s^{\prime} \mid s\right) V\left(b^{\prime}, s^{\prime}\right)
$$

subject to

$$
c-q\left(b^{\prime}, s\right) b^{\prime} \leq e(s)+b .
$$

Here, $q\left(b^{\prime}, s\right)$ is a $N_{e} \times N_{b}$ vector of prices today of a bond that pays one unit tomorrow as long as the country does not default, and that depends on the current state $s$ and total borrowing $b^{\prime}$. It is determined by competition in international credit markets, which we describe next.

\section{International Credit Markets}

We assume that international credit markets are populated by a large number of risk neutral creditors that behave competitively. The opportunity cost of funds for a creditor is given by the world interest rate $r^{w}$, which we assume is constant. Competition in the international credit market ensures that creditors expect to earn the world interest rate from their investments in the sovereign borrower's bonds.

To understand the determinants of the price of a country's bonds, suppose the country issues a total of $b$ claims, each of which pays one unit tomorrow as long as the country does not default. If a creditor were to buy one unit of the country's bonds at price $q(b, s)$, then competition ensures that they must expect to receive $\left(1+r^{w}\right) q(b, s)$ on average tomorrow. The actual return they receive has two components. First, with some probability $1-p(b, s)$ the country is expected to repay-in-full which yields a total of one unit. Second, with probability $p(b, s)$ the country defaults. In this case, the country will commence bargaining with its creditors and the creditor will receive a one-in- $b$ share of any returns from this bargaining process. If we let $\tilde{W}\left(b, s^{\prime}\right)$ be a $N_{e} \times N_{b}$ vector of the total expected discounted values of any settlement on a default on $b$ bonds in state $s^{\prime}$ tomorrow, viewed from the perspective of tomorrow, then the equilibrium bond price must satisfy

$$
q(b, s)=\frac{1-p(b, s)+p(b, s) \sum_{s^{\prime} \in S} \pi\left(s^{\prime} \mid s\right) \tilde{W}\left(b, s^{\prime}\right) / b}{1+r^{w}} .
$$


The total expected discounted value of any settlement, viewed from tomorrow, $\tilde{W}\left(b, s^{\prime}\right)$ will be determined along with the $N_{e} \times N_{b}$ vector of values to the country from default $\tilde{V}^{D}(b, s)$, as a result of the bargaining process which we describe in the next section. For now, we assume that $\tilde{W}\left(b, s^{\prime}\right)$ is bounded below by zero and above by $b$, which in turn ensures that the bond price function takes values in the interval $\left[0,1 /\left(1+r^{w}\right)\right]$; we prove that $\tilde{W}$ has these properties below. We let $\mathcal{Q}(B \times S)$ be the set of all functions on $B \times S$ taking values in $\left[0,1 /\left(1+r^{w}\right)\right]$.

It remains to describe the probability of default $p(b, s)$, which is determined by the sovereign's decision to default described in (1) above. For most values of $(b, s)$, the sovereign country will strictly prefer defaulting over repaying, or repaying over defaulting. However, it is possible that for some values of $(b, s)$ that the country is indifferent. To deal with this possibility, we define an indicator correspondence for default with debt $b$ in state $s, \Phi(b, s)$, as

$$
\Phi(b, s)=\left\{\begin{array}{ccc}
1 & \text { if } & \tilde{V}^{D}(b, s)>V^{R}(b, s) \\
0 & \text { if } & \tilde{V}^{D}(b, s)<V^{R}(b, s) \\
{[0,1]} & \text { if } & \tilde{V}^{D}(b, s)=V^{R}(b, s)
\end{array} .\right.
$$

From this we can define the default probability correspondence for debt $b$ and state $s, P(b, s)$, as the set of all $p(b, s)$ constructed as

$$
p(b, s)=\sum_{s^{\prime} \in S} \phi\left(b, s^{\prime}\right) \pi\left(s^{\prime} \mid s\right)
$$

for some $\phi(b, s) \in \Phi(b, s)$.

\section{Debt Restructuring Negotiations}

In this subsection, we specify the process by which a sovereign country in default bargains with its creditors over a settlement. We abstract from the coordination problems in debt restructuring negotiations studied by Pitchford and Wright (2007, 2008), and assume that creditors are able to perfectly coordinate in bargaining with the country. Hence, our restructuring negotiations are modeled as a game between two players: the sovereign borrower in default, and a single creditor. 
Environment We assume that the country is in autarky in the period in which the default actually occurs. Hence, the relationship between the total value to creditors from a settlement $\tilde{W}\left(b, s^{\prime}\right)$ and the value to the country from default $\tilde{V}^{D}(b, s)$, that we introduced above, and the $N_{e} \times N_{b}$ vectors of outcomes of bargaining that we derive below, $W\left(b, s^{\prime}\right)$ and $V^{D}(b, s)$, is given by

$$
\begin{aligned}
\tilde{W}(b, s) & =\delta E\left[W\left(b, s^{\prime}\right)|s|\right] \\
\tilde{V}^{D}(b, s) & =u\left(e^{\operatorname{def}}(s)\right)+\beta E\left[V^{D}\left(b, s^{\prime}\right) \mid s\right] .
\end{aligned}
$$

Here, $\delta=1 /\left(1+r^{w}\right)$ while $e^{\text {def }}(s)$ is used to denote the possibility that the endowment process may be lower in the event of a default (reflecting any direct costs of default). The output loss, combined with one period of autarky, ensure that there is always some cost to default, and deter the country from continually renegotiating its debts.

The timeline of actions is described in Figure 3. Negotiations begin with a sovereign country that has previously entered default with a level of debt $b$. At stake is the ability of the country to re-access credit markets. The value to the country of settling today in state $s$ with its creditors and re-accessing capital markets with a new level of debt $b^{\prime}$ is given by $\sum_{s^{\prime} \in S} \pi\left(s^{\prime} \mid s\right) V\left(b^{\prime}, s^{\prime}\right)$, where $V$ was described above and is treated as exogenous for the purposes of bargaining.

Neither player is able to commit to a split of surplus beyond the current period. Instead, the players can only agree to a current transfer of resources that may be partially (or wholly) financed by the issue of new debt securities. The ability to share future surplus is therefore limited by the fact that the country may default on these new debt securities in the future. Delay can occur as both the creditor and the debtor wait for an improvement in the terms under which new debt securities can be issued. Importantly, the same commitment problem that leads to default also drives the outcome of the renegotiation.

If no agreement is reached this period, the bargaining game continues with a new state $s^{\prime}$ and the same level of debt $b$. The assumption that the amount of debt in default, $b$, is unchanged throughout negotiations captures the fact that for most of the period under study, 
interest on missed payments was not a part of default settlements ${ }^{4}$.

Negotiations between the creditors and the debtor are efficient, in the sense that agreements are optimal for the two parties subject to the constraints on negotiations implied by future default risk. To capture this fact, we say that negotiations are privately optimal ex post. Nonetheless, delay may be said to be socially wasteful ex post, as the country is unable to access capital markets while in default, and thus forfeits potential gains from trade in tilting and smoothing its consumption.

Timing and Actions Bargaining occurs according to a randomly alternating offer bargaining game with an outside option available to the debtor. The timing is illustrated in Figure 2. At any point, the debtor country has the option of paying off the defaulted debt in full, using any desired mix of current transfers and new debt securities issued at the market price. We refer to this action as the outside option of the debtor, although we stress that this is strictly only an outside option for the game conditional on default, and not for the entire borrowing environment. In addition to being a feature of the actual environment governing sovereign debt renegotiations, this assumption guarantees that the total value of the settlement never exceeds $b$ which serves to bound our bond price function.

In every period and in each state of the world $s$, either the sovereign borrower or the creditor is selected to be the proposer who is then allowed to make a settlement offer. A proposal consists of a transfer of resources $\tau$ to the creditor in the current period, and an issue of new debt securities $b^{\prime}$. The proposer's action is therefore given by an offer of two values $\left(\tau, b^{\prime}\right) \in \mathbb{R} \times B$. We do not place any additional bounds on the issue of new debt, although debt issues will continue to be limited by the price that new creditors will be prepared to offer for these new bonds. Importantly, we allow for the possibility that the settlement may contain an amount of "new money" in which case the country receives a positive flow of the consumption good in the period in which they settle (this corresponds to a negative $\tau$ ).

Once a proposal is made, the non-proposing agent chooses to either accept or reject the current proposal. If the proposal is accepted, or if the debtor country's outside option is

\footnotetext{
${ }^{4}$ In cases that went to court, the courts did not award interest on missed payments until 1997 as part of the legal proceedings involving Elliott Associated and Peru.
} 
taken, the bargaining concludes and the country emerges from default with the new negotiated debt level. If the proposal is rejected and the outside option is not taken, the game continues to the next period, and we say that there has been delay in bargaining. In the next period, the realization of the state determines the identity of the proposer, and the timing repeats with the next proposer suggesting an offer.

A history of the bargaining game is a list of all previous actions and states that have occurred after a country's most recent default. That is, we are assuming that each debt restructuring is not affected by previous borrowing, default or debt restructurings, except insofar as these decisions have determined the debt level $b$. If no offer has been accepted, and if $t$ indexes stages, a history up to the beginning of stage $t$ is defined by the sequence of realizations for the state variable and the sequence of rejected offers:

$$
h^{t}=\left\{s^{t}=\left(s_{0}, s_{1}, \ldots, s_{t-1}\right),\left(\tau, b^{\prime}\right)^{t}=\left(\left(\tau_{0}, b_{0}^{\prime}\right),\left(\tau_{1}, b_{1}^{\prime}\right), \ldots,\left(\tau_{t-1}, b_{t-1}^{\prime}\right)\right)\right\}
$$

We let $H^{t}$ denotes the set of all histories to stage $t$.

Strategies Strategies map the level of the defaulted debt $b$ and the history into a choice of actions. The current state determines the identity of the current proposer, and the set of feasible actions depends on which player is the proposer. A strategy for the creditor when they are the proposer is a function $\sigma^{C, P}: B \times H^{t} \times S \rightarrow \mathbb{R} \times B$. The situation is more complicated when the debtor is the proposer due to the fact that the debtor may elect to take the outside option. In particular, a strategy for the debtor when they are the proposer is a function $\sigma^{D, P}: B \times H^{t} \times S \rightarrow \mathbb{R} \times B \times\{0,1\}$, where the third element takes on the value one if the debtor takes the outside option; whether or not the debtor takes the outside option, there is an associated transfer and new debt level $\left(\tau, b^{\prime}\right)$. A strategy for the creditor when they are not the proposer depends on whether or not the debtor has taken the outside option. If the debtor has not taken the outside option, a strategy for a non-proposing creditor is a function $\sigma^{C, N P}: B \times H^{t+1} \rightarrow\{0,1\}$ where 0 denotes rejection of the proposal, and 1 acceptance of the proposal. If the debtor has taken the outside option, the creditor has no choice but to accept the proposed settlement and so a strategy for a non-proposing creditor is a function 
$\sigma^{C, N P}: B \times H^{t+1} \rightarrow\{1\}$. A strategy for the debtor when they are not the proposer is a function $\sigma^{D, N P}: B \times H^{t+1} \rightarrow\{0\} \cup\{1\} \cup\{2\} \times\left\{\left(\tau, b^{\prime}\right) \in \mathbb{R} \times B: \tau+q\left(b^{\prime}, s_{t+1}\right) b^{\prime} \geq b\right\}$ where the first element 0 indicates a rejection, 1 indicates acceptance, and the third element indicates that the outside option was chosen with associated transfer and new debt levels $\left(\tau, b^{\prime}\right)$. A strategy profile is a pair of strategies, one for each player.

Payoffs and Equilibrium Next we discuss outcomes and payoffs and define an equilibrium. An outcome is a termination of negotiations plus the final accepted offer. That is, an outcome of the bargaining game is a stopping time $t^{*}$ and the associated proposal $\left(\tau, b^{\prime}\right)$. At any history, a strategy profile induces an outcome and hence a payoff for each player. The payoff to the debtor given outcome $\varphi=\left\{t^{*},\left(\tau, b^{\prime}\right)\right\}$ after history $s^{t^{*}}$ is

$$
V^{D}\left(t^{*}, s^{t^{*}},\left(\tau, b^{\prime}\right)\right)=\sum_{r=0}^{t^{*}-1} \beta^{r} u\left(e^{\text {def }}\left(s_{r}\right)\right)+\beta^{t^{*}}\left\{u\left(e^{\text {def }}\left(s_{t^{*}}\right)-\tau\right)+\beta E\left[V\left(b^{\prime}, s_{t^{*}+1}\right) \mid s_{t^{*}}\right]\right\},
$$

while to the creditor it is given by

$$
W\left(t^{*}, s^{t^{*}},\left(\tau, b^{\prime}\right)\right)=\delta^{t^{*}}\left\{\tau+q\left(b^{\prime}, s_{t^{*}}\right) b^{\prime}\right\} .
$$

Let $G\left(b, h^{t}\right)$ denote the game from date $t$ onwards starting from history $h^{t}$. Let $\mid h^{t}$ denote the restriction to the histories consistent with $h^{t}$. Then $\sigma \mid h^{t}$ is a strategy profile on $G\left(b, h^{t}\right)$. We let $\varphi\left(\sigma \mid h^{t}\right)$ be the outcome generated by the strategy profile $\sigma \mid h^{t}$ in game $G\left(b, h^{t}\right)$. A strategy profile is subgame perfect (SP) if, for every history $h^{t}, \sigma \mid h^{t}$ is a Nash equilibrium of $G\left(b, h^{t}\right)$. That is

$$
\begin{aligned}
W\left(\varphi\left(\sigma \mid h^{t}\right)\right) & \geq W\left(\varphi\left(\sigma^{D}\left|h^{t}, \sigma^{C \prime}\right| h^{t}\right)\right), \\
V^{D}\left(\varphi\left(\sigma \mid h^{t}\right)\right) & \geq V^{D}\left(\varphi\left(\sigma^{D \prime}\left|h^{t}, \sigma^{C}\right| h^{t}\right)\right),
\end{aligned}
$$

for all $\sigma, t$, and $h^{t}$.

As is customary in the literature, we impose the restriction of stationarity. A strategy profile is stationary if the actions prescribed at any history depend only on the current state 
and proposal. That is a stationary strategy profile satisfies:

$$
\begin{aligned}
\sigma^{D}\left(b, h^{t}, s_{t}\right) & =\sigma^{D}\left(b, s_{t}\right) \\
\sigma^{C}\left(b,\left(h^{t},\left(s_{t},\left(\tau_{t}, b_{t}^{\prime}\right)\right)\right)\right) & =\sigma^{C}\left(b, s_{t},\left(\tau_{t}, b_{t}^{\prime}\right)\right),
\end{aligned}
$$

for all $h^{t}$ and all $t$ when $s_{t}$ is such that the debtor proposes, and

$$
\begin{aligned}
\sigma^{C}\left(b, h^{t}, s_{t}\right) & =\sigma^{C}\left(b, s_{t}\right) \\
\sigma^{D}\left(b,\left(h^{t},\left(s_{t},\left(\tau_{t}, b_{t}^{\prime}\right)\right)\right)\right) & =\sigma^{D}\left(b, s_{t},\left(\tau_{t}, b_{t}^{\prime}\right)\right),
\end{aligned}
$$

for all $h^{t}$ and all $t$ when $s_{t}$ is such that the creditor proposes. A stationary subgame perfect equilibrium (SSP) outcome and payoff are the outcome and payoff generated by an SSP strategy profile. We define a stationary outcome as $\left((B \times S)^{\mu}, \mu\right)$, where $\mu=\left(\tau, b^{\prime}\right)$ and where $(B \times S)^{\mu}$ is the set of debt levels $b$ and states $s$ on which an agreement occurs or the outside option is taken, and where $(B \times S) \backslash(B \times S)^{\mu}$ is the disagreement set.

\section{B Solution to the Bargaining Model}

The solution to the overall model involves solving a fixed point problem. First, taking as given the solution to the bargaining problem, we solve for the solution to the debtor countries default problem and update the market price of debt. Second, we take the market price of debt and the debtor's value function from repayment and then use these to solve the bargaining problem. An equilibrium is a fixed point of the composition of the two operators. In this section, we focus on the bargaining model, taking as given the form of the solution to the borrowing problem.

\section{Recursive Problem Statement}

For this section, we take the solution to the borrowing problem as given. That is, the debtor country's value of accessing capital markets $V(b, s)$ is assumed to be a fixed element of the set all real valued $N_{e}$ by $N_{b}$ vectors, and the equilibrium bond price function $q(b, s)$ is assumed to be a fixed element of $\mathcal{Q}(B \times S)$. Given these assumptions, we then show that the SSP values of the bargaining game are fixed points of a particular functional equation. 
As is usual, the key to the approach is that we focus directly on SSP payoffs, rather than on the SSP itself.

Our approach is recursive, and relies upon the following operator $\hat{T}$. Given any pair of functions $\left(f_{1}, f_{2}\right)$ with $f_{i}: B \times S \rightarrow \mathbb{R}$ for $i=1,2$, we define the mapping $\hat{T}$ such that: If $s$ is such that the debtor is the proposer

$\hat{T} f_{1}(b, s)=\max \left\{\begin{array}{c}\max _{\tau, b^{\prime}} u\left(e^{\operatorname{def}}(s)-\tau\right)+\beta E\left[V\left(b^{\prime}, s^{\prime}\right) \mid s\right] \\ \text { s.t } \tau+b^{\prime} q\left(b^{\prime}, s\right) \geq \min \left\{b, \delta E\left[f_{2}\left(b, s^{\prime}\right) \mid s\right]\right\}\end{array}, u\left(e^{\operatorname{def}}(s)\right)+\beta E\left[f_{1}\left(b, s^{\prime}\right) \mid s\right]\right\}$

and

$$
\hat{T} f_{2}(b, s)=\min \left\{b, \delta E\left[f_{2}\left(b, s^{\prime}\right) \mid s\right]\right\}
$$

while if $s$ is such that the creditor is the proposer

$$
\hat{T} f_{2}(b, s)=\max \left\{\min \left\{\begin{array}{c}
\max _{\tau, b^{\prime}} \tau+b^{\prime} q\left(b^{\prime}, s\right) \\
b, \text { s.t } u\left(e^{\operatorname{def}}(s)-\tau\right)+\beta E\left[V\left(b^{\prime}, s^{\prime}\right) \mid s\right] \\
\geq u\left(e^{\operatorname{def}}(s)\right)+\beta E\left[f_{1}\left(b, s^{\prime}\right) \mid s\right]
\end{array}\right\}, \delta E\left[f_{2}\left(b, s^{\prime}\right) \mid s\right]\right\}
$$

and

$$
\hat{T} f_{1}(b, s)=\max \left\{u\left(e^{\operatorname{def}}(s)\right)+\beta E\left[f_{1}\left(b, s^{\prime}\right) \mid s\right], \quad \begin{array}{cc}
\max _{\tau, b^{\prime}} u\left(e^{\operatorname{def}}(s)-\tau\right)+\beta E\left[V\left(b^{\prime}, s^{\prime}\right) \mid s\right] \\
\text { s.t } \tau+b^{\prime} q\left(b^{\prime}, s\right) \geq b
\end{array}\right\} .
$$

Intuitively, the $\hat{T}$ mapping yields the values from bargaining at a given stage with defaulted debt $b$ and current state $s$, given that the continuation values associated with not reaching agreement this period are determined by $f_{1}$, for the debtor, and $f_{2}$ for the creditor. To understand this mapping, note that if the debtor is the proposer, they have three options. First, they could make an offer which will not be accepted. In this case, the debtor consumes the autarky endowment level this period and moves on the next stage with defaulted debt still at $b$, new state $s^{\prime}$ and payoffs encoded in $f_{1}$, while the creditor receives nothing today and a future payoff encoded by $f_{2}$. This payoff is the right hand component of the debtor-proposer half of the operator, for both the debtor and the creditor.

Second, the debtor could take the outside option, in which case the creditor receives 
the value of the defaulted debt $b$, and the debtor receives the maximum value achievable while still delivering a payoff of $b$ to the creditor. This corresponds to the left hand side of the creditors part of the debtor-proposer half of the operator, and to the left hand side of the debtor's part of the operator given the constraint on creditor utility defined by $b$.

Third, the debtor could make an offer that is accepted. In this case, since the debtor makes the offer, the creditor receives none of the surplus from the agreement, and hence receives the same payoff as if the offer was not accepted (the right hand side of the creditor part of the debtor-proposer half of the operator). The debtor, on the other hand, receives the maximum value that can be achieved while delivering this value to the creditor (the left hand side of the debtor's part of the operator with the constraint defined by the reservation payoff of the creditor). Since the debtor would never take the outside option when it can do better by making an offer that is accepted, the minimum over the value of the debt and the creditors reservation value is the relevant determinant of the constraint.

Similar logic underlies the half of the operator that applies to states in which the creditor is the proposer, noting that the creditor will extract all of the surplus from an accepted proposal up to a maximum value of $b$ at which level the debtor will take the outside option.

The following theorem, which can be thought of as a version of the principle of optimality for our problem, establishes an equivalence between SSP payoffs and fixed points of the $\hat{T}$ operator.

Theorem 1. The functions $f=\left(f_{1}, f_{2}\right)$ are SSP payoffs if and only if $\hat{T} f=f$. Proof. See Appendix B.

This operator forms the basis for our theoretical and numerical analysis of the bargaining problem below. In the next subsection we establish existence of an equilibrium bargain, and provide a sufficient condition under which this bargain is unique, by studying the properties of the $\hat{T}$ operator.

\section{Existence and Uniqueness of Symmetric Subgame Perfect Equilibria}

Next we show that an SSP equilibrium exists, by demonstrating that our $\hat{T}$ mapping operates on a bounded space of functions, and is monotone. The details are relegated to the 
appendix.

Theorem 2. An SSP equilibrium exists.

Proof. See Appendix B.

The uniqueness of the values of the equilibrium bargain could be easily established if $\hat{T}$ is a contraction mapping. However, as in many multi-agent problems, this is not straightforward. The difficulty results from two issues. First, changes in one agent's continuation value function will affect the result of the operator on the other agents continuation value function, because continuation values act as constraints on the proposals that will be accepted. Second, and more importantly, the rates at which changes in one agent's continuation value affect the operator on the other agents continuation value can vary when payoffs are non-linear functions of outcomes.

To understand this difficulty, it is instructive to consider how these issues appear in an attempt to establish Blackwell's sufficient conditions for a contraction mapping, and in particular by affecting the proof of the discounting condition. Suppose we change the value of the creditor's and debtor's continuation values by a small constant amount. The discounting property requires that the operator produce functions that are bounded by the modulus of the contraction mapping, which is strictly less than one. Since the country's felicity function is non-linear, it is possible that a small increase in the creditor's continuation value, which would lead to a small change in the settlement value, could lead to a large change in the country's payoff if the marginal utility of consumption was high near the solution of the debtor's problem in the debtor's half of the $\hat{T}$ operator. Moreover, it is also possible that a small change in the debtor's continuation value could result in a large change in the value of the settlement (and hence also a large change in creditor payoffs) if the marginal utility of consumption is low near the solution of the creditor's problem in the creditor's half of the $\hat{T}$ operator.

The following theorem states a condition that is sufficient to prove uniqueness, by imposing bounds on the rate at which resources can be transformed into utility, and the rate at which utility can be transformed into resources. As a consequence of the fact that we have imposed few restrictions on the shape of the $V$ and $q$ functions, the condition is stated in terms 
of bounds on the slope of the utility function of the debtor. In our numerical work below, as in much of the quantitative literature on sovereign debt and default, we focus on discount factors for the country that are substantially less than one, reflecting political economy problems in developing countries that lead to impatient policy making. For sufficiently low $\beta$, we can typically show that the sufficient condition is satisfied.

Theorem 3. Let $u: \mathbf{R} \rightarrow \mathbf{R}$ be differentiable. If there exists $K_{L}>\beta$ and $K_{U}<1 / \delta$ such that $K_{L} \leq u^{\prime}(c) \leq K_{U}$, for all $c$, then the SSP equilibrium values are unique.

Proof. See Appendix B.

\section{C Solution to Borrowing Model}

In the previous section, we establish the existence and uniqueness of a solution to the debt restructuring bargaining problem, taking as given the value to the country from re-accessing capital markets with new debt $b^{\prime}, E\left[V\left(b^{\prime}, s^{\prime}\right) \mid s\right]$, and the value of new debt to creditors $q\left(b^{\prime}, s\right)$. In this section, we take as given the solution to the bargaining model, and hence the value to the country and the creditor from being in default, and then establish existence of a solution to the borrowing problem. That is, we take as given the $N_{e} \times N_{b}$ vectors of payoffs to the country, $\tilde{V}^{D}(b, s)$, and the creditor, $\tilde{W}(b, s)$, in default, that are elements of $\mathcal{B}(B \times S)$.

The solution of the borrowing problem is established as the composition of two operators. The first takes a value to the country from default and an equilibrium bond price function, and then solves the country's problem to obtain a value to the country for access to capital markets, and a default policy function, which is a selection from a default policy correspondence. The second takes the default policy function and combines it with the value to the creditors from default to obtain a new bond price function. Existence of a solution follows from the monotonicity of the composition of these operators.

Theorem 4. Given $\left(\tilde{V}^{D}(b, s), \tilde{W}(b, s)\right) \in \mathcal{B}(B \times S)$ and $q(b, s) \in \mathcal{Q}(B \times S)$, there exists a value function for the country, $V(b, s)$, and an equilibrium bond price function $q(b, s) \in$ $\mathcal{Q}(B \times S)$, that solve the borrowing problem.

Proof. See Appendix B. 
Given the result of this Theorem, it is tempting to try to prove existence of an equilibrium for our entire model by iterating successively on the $T^{V}, T^{q}$ and $\hat{T}$ operators. However, this approach need not converge. Specifically, although iterating on the $T^{V}$ and $T^{q}$ operators produces a monotone operator, when combined with the bargaining operator, the compounded operator need not be monotone. Intuitively, it can be the case that a high value to the creditor in default, and a low value to debtor, leads to a high bond price, which in turn leads to a high value to the country from repayment. This high value to repayment can lead to a high value from default, which then leads to a low bond price in the next iteration. That is, we cannot rule out cycles in the successive application of these operators. In the next section, we describe an alternative method for proving existence.

\section{D Existence of Equilibrium}

In this section, we establish the existence of a recursive equilibrium for our economy. First, we define an equilibrium for our economy.

Definition 1. An equilibrium for our economy is a value function for the country from borrowing $V(b, s)$, a value function for the country in default $V^{D}(b, s)$, a value function for the creditor in default $W(b, s)$ and a bond price function $q(b, s)$ such that:

1. Given the bond price function $q(b, s)$ and the value to the country from re-accessing capital markets $V(b, s)$, the country and the creditor optimally bargain over re-access to financial markets. That is, $V^{D}$ and $W$ are fixed points of the inside default operator $\hat{T}$;

2. Given the value to the country and from default $V^{D}(b, s)$, and the bond price $q(b, s)$, the country makes optimal borrowing and default decisions. That $i s, V(b, s)$ is a fixed point of $T^{V}$ with associated default policy correspondence $\Phi(b, s)$

3. Given the payoff to the creditor in default $W$ and the optimal default policy correspondence, the bond price function $q(b, s)$ satisfies the no arbitrage condition for creditors. That is, $q(b, s)$ is a fixed point of the operator $T^{q}$.

The latter two conditions may equivalently be written as: Given $V^{D}(b, s)$ and $W(b, s)$, $V(b, s)$ and $q(b, s)$ are a fixed point of the outside default operator, which is the composition 
of the $T^{V}$ and $T^{q}$ operators.

We prove existence by using the operators defined above to construct a new mapping from the space of value functions for the country and creditor in default, and the space of bond price functions, into itself, and establishing that it possesses a fixed point. Specifically, define the mapping $H$ from $\mathcal{B}(B \times S) \times \mathcal{Q}(B \times S)$ into itself as follows. First, given $V^{D}, W$ and $q$, iterate on the outside default operator to convergence to obtain a new bond price function $q^{\prime}(b, s)$. Second, given $V^{D}$ and $q$, iterate on the $T^{V}$ operator to convergence to produce a value function $V$. Then, given the old $q$ and this $V$, iterate on the $\hat{T}$ operator to convergence to find new $V^{D^{\prime}}$ and $W^{\prime}$. We establish that the combination of these operators defines an upper hemi-continuous correspondence with non-empty and convex values. Then, noting that $\mathcal{B}(B \times S) \times \mathcal{Q}(B \times S)$ is a compact and convex space of functions, the result then follows by application of the Kakutani-Fan-Glicksberg fixed point theorem.

Theorem 5. There exists an equilibrium of our borrowing economy.

Proof. See Appendix B.

\section{Calibration and Numerical Results}

In this section, we present results from several numerical solutions of the model that vary only in the calibration of the bargaining power process for the debtor and creditor. These examples are used to illustrate some comparative static properties of the model, and to build intuition for the elements of the model that produce delay. We then present our benchmark case in which the parameters of the model governing bargaining power are calibrated to some aspects of the relationship between default and output observed in the data. The model is then assessed according to it's ability to match the other facts discussed in the introduction.

\section{A Calibration}

The first step in calibrating the model is the choice of a period length. On the one hand, as debt contracts in our theory are one period in duration, calibration to a long period length is necessary in order to match the maturity of observed debt issues. A long period length is also desirable given that the information on which bargaining positions are formed is revealed at best quarterly, and in some cases only annually. On the other hand, the bargaining 
process plausibly operates at a high frequency, suggesting that we should calibrate to a shorter period length. To balance these concerns, and given that most other studies in the literature calibrate to quarterly data, we adopt a quarterly calibration.

In some cases, our data is only available at an annual frequency. To construct annual outcomes, we simulate on a quarterly calendar for 11000 periods beginning with the March quarter, and drop the first thousand periods to eliminate the effect of initial conditions. All model variables are treated identically to the data, with flow variables such as output being summed, and stock variables such as debt calculated as of the end of the year. Trend output is computed from the annualized data using a Hodrick-Prescott filter with smoothing parameter equal to 6.25 as in Ravn and Uhlig (2002). If a country exits and re-enters default in successive quarters, we count this as one default ${ }^{5}$. Since our data measures the start and end of a default at a high frequency, we calculate the duration of default in the model from the quarterly data. In comparing our annual data on output and debt to the timing of defaults and settlements, we follow the practice of S\&P and label a country as being in default in a given year if it was in default at any point in that year.

Most parameters in the model are held constant in every experiment and, as shown in Table 3, are set to values that are standard in the literature. Following Arellano (2007), Aguiar and Gopinath (2006), Yue (2007), and Tomz and Wright (2007), the world interest rate is set to $1 \%$ per quarter, and the coefficient of relative risk aversion is set to two. The income process is assumed to follow a log normal $\mathrm{AR}(1)$ process, which is chosen to match Argentinean output data. One non-standard parameter value is the discount factor, which in the rest of the literature often takes on values as low as 0.8 for quarterly data implying annual discount factors around 0.4. Although a low value can be plausibly motivated by political economy considerations that lead developing country governments to act myopically, we view a choice of 0.8 as too extreme and use a more modest 0.945 at our quarterly frequency.

\footnotetext{
${ }^{5}$ This is conventional. Standard and Poors classify periods in which a country has engaged in a series of successive renegotiations as one default episode. For example, S\&P defines Mexico to have defaulted once in the past three decades, starting in 1982 and ending in 1990, despite the fact that Arteta and Hale (2008) record 3 separate negotiations and 23 separate rescheduling agreements for commercial bank debt during this period. Likewise, Beim and Calomiris (2001, p.35) treat defaults occurring within five years of each other as one default episode. By only merging defaults that occur within one quarter of each other, our estimates of delay are conservative.
} 
The remaining parameters describe the evolution of the proposer identity during bargaining, and the loss of output experienced by the country during default. For our benchmark case, these parameters are calibrated to the features of the data summarized in Table 4. First, we calibrate the output loss during default to match the observed average ratio of debt to GDP; higher output costs support higher borrowing levels. In matching model data on debt to the World Bank data on debt, we must confront a measurement issue, raised earlier and described in more detail in Appendix C. The issue is that the World Bank reports debt at face values, which is defined as the undiscounted sum of all future amortization payments. However, two equivalent debts (that is, two debts with exactly the same streams of debt service) will have different face values if debt service is divided into principal and interest in different ways. In our presentation of the theory, all debt is issued at a discount without a coupon, so the face value of the debt is given by the state variable $b$. However, these zerocoupon bonds with face value $b$ are equivalent to par bonds with face value equal to their market value, $q(b, s) b$, and with total coupons worth $b-q(b, s) b$. We calibrate the output cost of default so that a $2: 1$ weighted average of face value and market value debt matches the average debt-to-GDP level of $65 \%$, reported by the World Bank. This produces an output cost of $1 \%$ of GDP, which is about half the level assumed by other studies.

Finally, we need to choose values for the parameters governing the evolution of the identity of the proposer in bargaining. Obviously, the ability to make today's offer can be thought of as giving the proposer more bargaining power. Less obviously, the agent's expectations about who will propose offers in the future has the strongest effect on bargaining power because it determines the reservation value of the non-proposing agent. Hence, we refer to these probabilities as "bargaining power" parameters. Since the economics literature provides little guidance as to how to set these parameters, we experiment with a number of alternatives.

In our benchmark case, we calibrate bargaining power to some aspects of the relationship between default and income in the data. Specifically, we divide output realizations equally into 'high', 'medium' and 'low' levels, and describe the evolution of proposer identity in terms of the probability that the debtor proposes conditional on the output level and identity of the proposer in the previous period. This leaves us six probabilities to calibrate. 
We assume a limited form of symmetry to set two of these parameters; we assume that the probability that the creditor proposes tomorrow given that they proposed today and output was high (low) is equal to the probability that the debtor will propose tomorrow given that they proposed today and output was low (high). The remaining probabilities are set to match the first four moments in Table 4, with the resulting probabilities tabulated in Table 5.

In order to build intuition for the effect of bargaining power on the outcomes of the model, we also present numerical results for five stylized example processes for bargaining power. The economics literature that considers bargaining typically assumes that bargaining power is constant (for example, when the cooperative Nash bargaining solution is imposed, as in Yue (2007) in her study of sovereign debt restructuring). To capture this case, we present results for two examples in which the identity of the proposer is i.i.d., and which differ only as to whether it is the creditor (probability 0.99) or debtor (probability 0.55) who is always likely to propose, and hence who has most of the bargaining power. We follow these i.i.d. cases with a "persistent" regime where the proposer today is very likely (probability 0.99) to remain proposer tomorrow, so that there will be random cycles in bargaining power.

Last, we present two examples in which the bargaining power of the agents depends on economic conditions in the country. In the first case, which we follow the international relations literature in referring to as "strength through weakness", the likelihood that the country is able to make offers in the future is higher when output is low, so that the debtors bargaining power is greatest when the economy is weak. This case attempts to capture the idea that in countries with weak economies, the politicians negotiating the debt restructuring are too weak politically at home to propose significant concessions to its lenders, which acts as a form of bargaining power. In the second - "strength through strength" - the debtor country has more bargaining power when output is high, capturing the idea that strong economic performance insulates a political leader from domestic political pressures. In both of these cases, the agent that has higher bargaining power when output in the debtor country is high proposes with a probability greater than one half (probability 0.96). Inspection of the calibrated probabilities in Table 5 reveals that the benchmark case possesses elements of the "persistent" and "strength through weakness" examples. 


\section{B Intuition For Delays in Bargaining}

Before turning to our results for the benchmark model, it is instructive to examine bargaining outcomes for two of the example bargaining power processes introduced above. We begin with an i.i.d. case in which the creditor is very likely to propose each period and hence has the greater bargaining power. As the likelihood of making future offers is constant,bargaining power is constant, and defaults are driven primarily by fluctuations in output. To see this, Figure 4 plots a sample time series of income levels for this case, along with the corresponding debt choices of the country at both face and market values. For the first two and one-half years (that is, the first nine periods), income levels are low and falling, on average, leading the country to increase its debt level to smooth consumption. Market and face values of debt move together reflecting a low and stable level of default risk. In the tenth period, income falls again and the risk of default rises, leading to a large rise in spreads (that is, fall in the bond price as shown in Figure 4) so that the country must now dramatically increase the face value of its debt in order to generate enough resources from foreign borrowing (the market value of debt) to smooth its consumption. When output falls again in period 11, the country enters default.

To help understand the motivation of the country, Figure 5 plots the probability that the country will default as a function of income and debt levels, as well as the corresponding bond price function. As shown, for low income levels, the probability of default rises quickly from zero to one in the neighborhood of the debt choices plotted in Figure 4. In much of the previous literature, where there is no possibility of a settlement, this would cause the price of new bonds issued by the country to drop to zero, curtailing borrowing at low levels with a low probability of default and low spreads over the risk free rate. However, in our model, the possibility of a debt settlement gives creditors the incentive to keep lending even when default risk is high, albeit at higher interest rates. It is this fact that enables our framework to produce greater borrowing levels at higher spreads than in the previous literature. To understand the dramatic rise in debt levels, the Figure also plots the market value of debt associated with a given face value of debt in this case, which shows that beyond a certain point bond prices fall as borrowing levels rise to keep the market value of debt roughly constant. As 
shown in the Figure, at high debt levels, the country correctly anticipates that the outcome of bargaining will not vary greatly with the face value of the debt, and so dramatically increases the face value issued, whereas the actual amount of resources borrowed increases only slightly. This is profitable for the creditor because it increases the settlement obtained in states where the outside option in bargaining is taken.

After nine and one-half years (that is, by period 45), both output and bond prices have reached levels significantly higher than when the country entered default (see Figure 4). This allows the country and creditor to agree on a settlement in which the creditor receives a substantial share of the surplus: as current income is high, a larger current transfer of resources is possible for a smaller utility cost to the country, while high bond prices make debt issues more valuable to the creditor. Note that, in the first full year after exiting default, debt levels at face value are higher than in periods 5 through 9 before entering default; likewise, at market values, the country exits default with more debt than when they entered default (although scaled by GDP, indebtedness falls).

In the previous example, delays in bargaining were caused solely by persistence in income levels. Next we consider a case in which there are persistent fluctuations in bargaining power. In this case, default may be driven by a change in bargaining power, and Figure 6 illustrates a simulation in which this outcome occurs. Although output is relatively high in the first two and one-half years of this simulation, and debt remains roughly constant, a shift in bargaining power in favor of the debtor causes a collapse in bond prices so that debts with the same face value would now raise a smaller amount of resources (they would have a lower market value), which in turn leads the country to default in period 11.

To see why this occurs, Figures 7and 8 plot the equilibrium objects for the persistence example. As these figures show, for this regime, changes in bargaining power have a dramatic effect on default likelihoods, whereas income has little effect. These differences also show up in the prices at which the country can issue debt, which are much higher when the creditor has the bargaining power. Even when default is certain, debt prices are positive as creditors expect a settlement. However, when the debtor has the bargaining power, they are likely to extract most of the surplus from such a settlement, and debt prices are lowest. Consequently, market values of debt tend to be much higher when creditors have the bargaining power 
(compare the 'kink' in the plots of the market values of debts when the creditor, as opposed to the debtor, makes the proposal). This means that the value of credit market access to the debtor, when they have the bargaining power, is low, and so default is the more attractive option. The Figures also show that expected settlements are large when the creditor has the bargaining power, explaining why bond prices are high. Default ends after roughly nine years when bargaining power switches back to the creditor, and the country's debt price recovers. This is in part because the debtor can issue more debt as part of a settlement, but mostly because capital market access is now more valuable to the debtor, making a settlement more attractive.

Finally, Figures 9 and 10 present the equilibrium objects for our benchmark case. Relative to the persistent example, bond prices in the benchmark vary more with income, while relative to the i.i.d. case they vary with bargaining power quite substantially at intermediate income levels. This is driven primarily by differences in default probabilities, although as

seen in Figure 10 changes in the expected settlement also play a role. The importance of intermediate income levels is driven by the fact that bargaining power is more persistent at these income levels. The benchmark regime also allows the face value of debt to vary more than in the persistent example, and allows the market value of debt to vary more than in the i.i.d. example. This can be seen by comparing the market value of debt panels in Figure 10, with the corresponding panels in Figures 5 and 8. The borrower optimally chooses a face value of debt at or near the kink in the market value figure; changes in bargaining power in the benchmark produce twice the change in market values possible in the i.i.d. regime (the height of the line in the figure), as well as much large changes in face values than the persistent regime (as seen by the horizontal location of the kink).

\section{C Results}

Tables 6 through 8 compare the performance of our benchmark model to the facts documented in Section 2. For comparison, we also collect the predictions of our various example bargaining power processes for debt restructuring outcomes. As shown in Table 6, our benchmark model produces exactly the same default probability as observed in our sample. At $4.4 \%$, this default probability is roughly twice the level $(2 \%)$ assumed in other 
studies on the basis of observed default over the entire 20th Century. In our view, this default probability is artificially low: the middle of the Century contains more than three decades in which capital flows were very small due to controls under Bretton-Woods and the adoption of inward-looking development policies in many developing countries. With little debt to default upon, little default was observed. Our $4.4 \%$ number describes the modern period, and also seems consistent with other periods of well functioning international capital markets, such as the Gold Standard era. For the benchmark output process, both i.i.d. regimes produced little delay; for the i.i.d. regimes only, we increased the variance of output innovations seven-fold in order to study the effect of longer delays in the creditor regime.

In examining our sample of debt restructuring outcomes in practice, we found that sovereign defaults were time consuming to resolve, taking almost eight years on average (Fact 1). Table 6 shows that our benchmark regime produces an average delay in excess of seven years, slightly less than the delay observed in our sample, and slightly more than the average for the modern era documented in Pitchford and Wright (2008) using a larger sample of defaults. This result follows from both the persistence in output fluctuations as well as the persistence in bargaining power.

We next documented that, in practice, debt restructurings were costly to creditors with the average restructuring generating creditor losses, or "haircuts", of roughly 40\% (Fact 2). Table 6 shows that our benchmark model is able to produce haircuts of $28 \%$; although this is less than the unweighted average haircut, is almost equal to the debt weighted average haircut of $30 \%$. Haircuts in many of our other example regimes are even larger, and in some cases total more than $75 \%$ of the value of creditors claims. Counterintuitively, average haircuts are largest in the i.i.d. regime where creditors have more bargaining power, because this regime supports higher debt levels; for a fixed debt level, haircuts are larger in the i.i.d. debtor regime, but in both regimes haircuts increase with debt levels.

In the data, we also found that longer defaults are associated with larger haircuts (Fact 3 ), with a correlation coefficient of 0.66 . This is almost exactly matched by our benchmark model, which produces a correlation coefficient of 0.7 . Both the i.i.d. regimes generate a negative correlation between delay and haircuts, because defaults in these regimes only occur at the lowest output levels: when output is very low, reversion to the mean output level is 
fast and settlements occur quickly; however, when output is low, haircuts are large. This also explains why there is a negative correlation between output declines and delay for the i.i.d. models, with the largest output declines being associated with the fastest reversion to the mean, and hence the shortest delays. The other example bargaining power regimes produce little or no relationship between output declines in the year of default and debt restructuring outcomes, in contrast to the data where larger output declines in the year of default are associated with longer defaults and larger haircuts (Fact 4). Our benchmark model produces negative correlations between the change in output and both haircuts and delays. The reason is that, in the benchmark model, defaults occur for two reasons: when bargaining power changes at intermediate income levels, defaults are resolved with little delay and small haircuts because creditors regain bargaining power relatively quickly; when income falls to low levels, defaults are resolved more slowly and with larger haircuts, because there is more persistence in the output process. In our other example regimes, only one effect is present so that time aggregation tends to reduce or eliminate the correlation between outcomes and output.

In calibrating the bargaining power process, we chose parameter values to match some aspects of the relationship between output and default in the data, although not the aspects that we had emphasized in Section 2, where we had confirmed the finding of Tomz and Wright (2007) that defaults are somewhat more likely to occur when output is below trend, and settlements tend to occur when output has returned to trend (Fact 5). Table 7 shows that our benchmark model also produces a weak relationship between output and default, as observed in the data, although settlements tend to occur before output returns to trend. The weak relationship between default and output is also a feature of each of our example bargaining regimes. However, whereas for many of our example regimes this is solely a product of time aggregation, for our benchmark regime it is also due to the role of switches in bargaining power in generating defaults. As shown in Table 8, at a quarterly frequency, all of our examples except for the strength-through-strength regime produce a near perfect negative relationship between default and output. Moving from quarterly to annual data not only weakens this pattern, but occasionally reverses it. By contrast, our benchmark regime displays a strong negative relationship in only the quarter of default, and almost no 
relationship with output in the preceding quarter.

Finally, we documented that in practice debt restructuring negotiations are ineffective at reducing country indebtedness (Fact 6) with the median country exiting default with $5 \%$ more debt (scaled by GDP) than when it entered default, and the mean country exiting with $25 \%$ more debt. Table 7 presents results on the evolution of indebtedness throughout default for each of the bargaining regimes. Data on debt is presented at both at face values and market values in order to bracket the World Bank data which, as discussed above and in Appendix $\mathrm{C}$, is an average of the two. Our benchmark regime predicts that a country should exit default with roughly the same level of indebtedness as when they entered default, regardless of which measure of the value of debt is used. This is because settlements tend to be associated with both improved economic conditions and more bargaining power for the creditor, which increase the country's ability to borrow.

To summarize, we conclude that our benchmark model is able to explain almost all of the delay observed in the data and more than two-thirds of observed haircuts, while also producing the relationships between bargaining outcomes and economic activity documented above in Section 2. In addition to matching these new facts, our model is also able to match the features of the data emphasized by the previous quantitative theoretical literature on sovereign default. Specifically, this literature has emphasized four facts, all established using quarterly (and chiefly Argentine) data; we collect these facts in Table 9. First, capital flows tend to be "procyclical", with net exports relatively high (and hence capital inflows small) when output is relatively low; the correlation coefficient in the quarterly Argentine data has been reported between -0.2 and -0.9 . Second, the difference between interest rates charged on developing country and developed country debts, typically referred to the 'spread' on developing country debt, is counter-cyclical, rising in recessions and falling in booms, with estimates of the correlation between spreads and output for Argentina ranging from -0.1 to -0.9 . Third, high spreads are associated with capital outflows, with correlation coefficients between spreads and net exports reported between 0.05 and 0.85 . Fourth and finally, consumption in many developing countries is more volatile than output, with the standard deviation of consumption roughly 10 percentage points higher than the standard deviation of output. 
Table 9 documents the performance of both our benchmark model and our expository examples along these dimensions and compares them to results reported in a sample of other studies. All moments were calculated from the quarterly model data. Our benchmark model, like some of the leading previous studies, produces consumption that is almost exactly $10 \%$ more volatile than output. This arises due to the large movements in consumption that are predicted in both the year of default and the year of settlement. All regimes, except for strength-through-strength, produce countercyclical spreads, with the benchmark model producing a correlation between spreads and income that is almost exactly in the center of the range of published targets. Likewise, the benchmark model also produces procyclical capital flows with the correlation between income and capital flows the same as that produced by Arellano (2007). All of the regimes produce a positive relationship between spreads and capital flows, with the benchmark model producing a stronger relationship, closer to that observed in the data, than any of the alternative studies.

Finally, a number of studies have emphasized the inability of quantitative models of sovereign debt to produce spreads with the same level, and volatility, as observed in the data (see, for example, Arellano and Ramnarayan 2008, Chatterjee and Eyigungor 2008, and Hatchondo and Martinez 2008). In assessing the ability of this class of models to match data on spreads, it is important to note that the available data on spreads are limited. Prior to the early 1990s, most developing country borrowing took the form of bank loans that were not traded on liquid markets. Moreover, many developing countries spent the decade of the 1980s in default, so that the data on spreads in the 1990s should be viewed as being conditional on a recent settlement of a default. In the case of Argentina, spreads in the 1990s should also be viewed as conditional on being in the lead-up to another default ${ }^{6}$. Bearing these caveats in mind, a coarse summary of the Argentine data over this period shows that Argentine spreads averaged 5 percentage points during the 1990s, peaking near 15 percentage points in the middle of 1995 and again just prior to the default at the end of 2001. The benchmark calibration of our theory produces spreads on the order of those observed in the Argentine

\footnotetext{
${ }^{6}$ In recognition of this problem, most authors follow Arellano (2007, p.22) and restrict attention to simulations that are less than eighty quarters in length and terminate just prior to a default, so as to match the available quarterly data for Argentina. As shown in her Figure 5, the spreads generated by her model for this period are typically zero, and exceed the spreads observed in the data at only four data points.
} 
data. In the quarter that a default occurs, spreads average $20 \%$, while a country emerges from a default with spreads at roughly $8 \%$.

\section{$5 \quad$ Policy Analysis and Welfare}

Third party organizations such as creditor country governments and supranational institutions often attempt to influence the sovereign debt restructuring process by providing direct financial transfers to countries involved in restructuring negotiations. Some of these transfers appear large; for example, the IMF negotiated a bailout with Argentina in 2001 that was valued at a total of $\$ 40$ billion, or nearly $15 \%$ of Argentine GDP, although this number overstates the size of the transfer to the extent that it is in the form of a loan that is eventually repaid. Such "bailouts" can affect restructuring outcomes and welfare in numerous ways. On the one hand, by transferring resources to a country when its output is low, bailouts might facilitate smoothing of consumption. In addition, to the extent that bailouts are conditional on agreement to a settlement, bailouts may encourage prompt restructuring. On the other hand, the possibility of a future bailout may encourage countries to default, or to delay a restructuring until a bailout is offered. Finally, the effect of bailouts on borrowing rates, and hence on borrowing levels, depends on the effect they have on default probabilities relative to the effect they have on settlement values if creditors can extract part of the settlement amount. In this Section, we first examine the effect of bailouts on countries with different borrowing histories. We then evaluate the net cost of making bailouts available to a wide group of countries.

We implement bailouts stochastically. This captures an important feature of bailouts in practice where, at the time of default and during early negotiations, there is much uncertainty about the timing, and even the existence, of future bailouts. At the end of every period of bargaining, there is positive probability that a bailout will be "placed on the table" in the next period so that when a subsequent agreement is reached additional resources will be transferred to the country. Once on the table, the bailout remains on the table until settlement is reached. We assume that bailouts amount to 1.44 per-cent of the average income of a country, which is Jeanne and Zettelemeyer's (2001) estimate of the subsidy implicit in an average IMF bailout loan. We assume that the probability of a bailout is 20 per-cent per 
quarter, implying that it takes 15 months on average for a bailout to be put on the table. We examine the sensitivity of our results to this probability below.

We examine the welfare consequences of introducing the possibility of a future bailout. Let $V_{B}(b, s, D)$ denote the welfare of a country with debt level $b$, in state $s$, either in default $(D=1)$ or out of default $(D=0)$, when a bailout is possible, but is currently not on the table; let $V(b, s, d)$ denote welfare when there is no possibility of a future bailout. When there is no bailout possible, a country in this position would be prepared to give up the fraction

$$
x(b, s, D)=1-\left(\frac{V(b, s, D)}{V_{B}(b, s, D)}\right)^{1 /(1-\gamma)},
$$

of its expected future consumption stream for the possibility of a bailout in the future (under the assumption that preferences display a constant coefficient of relative risk aversion $\gamma$ ). Later, when we compare costs to benefits, it will be convenient to value this stream of payments from the perspective of the third party. We assume that the third party providing the bailouts discounts the future at the world interest rate, and so define the present value of expected benefits as

$$
E B(b, s, D)=x(b, s, D) E\left[\sum_{t=0}^{\infty}\left(1+r^{w}\right)^{-t} c_{B t} \mid(b, s, D, 0)\right]
$$

where $c_{B t}$ denotes the consumption of a country at time $t$, which is in turn a function of its debt level $b$, state $s$, default status $D$ and bailout status $B$. The overall expected benefit is independent of $B$ because it is assumed all countries begin without a bailout on the table.

Figures 11 and 13 plot the function $E B$ as a function of debt levels for different states $s$ (one income level is low relative to the mean and one is exactly the mean) and default states $D$. The Figures show that, if a firm has low income and high debt levels, there is little difference in the welfare effect of a possible future bailout regardless of whether the country firm is currently in default. The reason is that the country is likely to enter default in the near future regardless of whether or not there is the possibility of a bailout. In both cases, welfare increases. However for countries with more moderate incomes and lower debt levels, the prime effect of the bailout is too encourage more default, which limits a country's ability 
to borrow to smooth consumption in the future and results in more direct costs of default being paid. For these countries the presence of future bailouts lowers welfare.

Next, we compare these benefits to the cost of providing bailouts. We denote the expected discounted cost to the third party of providing bailouts to such a country by $E C(b, s, D, B)$, where $B$ takes the value one when a bailout is on the table, and is zero otherwise. Figures 12 and 14 show that expected costs tend to be monotonic in the current debt level and income level, as countries with low levels of income and high levels of debt can be expected to require more bailouts.

Finally, we examine the cost of implementing a bailout program more widely. In particular, we consider a world with many country's that has no possibility of a bailout. Over time, the world distribution of country types $(b, s, d)$ will converge to its invariant distribution, which we denote by $\Lambda(b, s, d)$. We then calculate the average expected net benefit by comparing the costs and benefits computed above and then integrating with respect to the invariant distribution for the world without a bailout. As the developed countries account for more than $80 \%$ of world income (at market exchange rates) we assume that world interest rates are unaffected by this policy.

Expressing the result as a fraction of the present value (discounted at the world interest rate) of the world's lifetime consumption stream, we obtain

$$
\frac{\int[E B(b, s, D)-E C(b, s, D)] \Lambda(s, b, D)}{\int E\left[\sum_{t=0}^{\infty}\left(1+r^{w}\right)^{-t} c_{B t} \mid(b, s, D, B)\right] \Lambda_{B}(s, b, D, B)} .
$$

The results for our benchmark case are presented in Table 10, which shows that the costs of bailouts dominate the benefits producing a welfare loss equivalent to just over one-tenth of lifetime consumption. On average, country welfare falls only slightly, with any benefit from resource transfers offset by the fact that they now spend $75 \%$ of their time in default. The cost to the third party providing the bailout amounts to about $0.11 \%$ of lifetime consumption, so that the overall net effect is that the world loses roughly $0.13 \%$ of lifetime world consumption. Table 11 shows that the result that net benefits are negative is quite robust to variations in the average time it takes to implement a bailout. The reason is that the possibility of a bailout producing a substantial amount of moral hazard. With the possibility of a future 
bailout, many countries borrow and default repeatedly. Treating neighboring defaults as one default episode, for moderate bailout probabilities, the average country remains in perpetual default. As the probability of a bailout rises to $50 \%$ per quarter, the net cost of bailouts rises to $0.25 \%$ of lifetime consumption.

\section{Conclusion and Future Work}

In this paper, we documented that negotiations to restructure sovereign debts are both time consuming and costly, leading to creditor losses in excess of forty per-cent and leaving the defaulting country more highly indebted than when they entered default. We also documented the relationships between these outcomes, as well as their relationship to economic activity. We then proposed a theory of these delays in which the very same risk of default that gave rise to these negotiations is also the factor that leads to negotiations being prolonged. Intuitively, the conclusion of a debt restructuring negotiation generates surplus to be shared at both the time of the settlement and in the future. However, the debtor country cannot be trusted to honor promises to share future surplus. Hence, both the creditor and the country find it optimal to wait until a future time period in which the risk of default is low; low default risk facilitates the sharing of future surplus, and is also directly associated with a greater amount of surplus to be shared as access to capital markets by the country is more valuable. We show that our model is capable of explaining the bulk of the observed delay in reaching a settlement, as well as about two-thirds of the observed creditor losses. We then use the model to examine the effect of multinational bailout policies, and show that the negative effect of bailouts on default incentives outweigh any benefits from both greater risk sharing and a greater incentive to reach a settlement.

Our theory also suggests a reinterpretation of the modern history of worldwide sovereign default crises in which multiple countries default at the same time. The phenomenon of concurrent defaults has often been explained by appealing to common negative economic shocks. However, this is hard to reconcile with the modest declines in output observed at the time of default. Our alternative emphasizes changes in the institutional structure governing negotiations over sovereign debt restructuring with all countries. The rise in sovereign borrowing in the late 1970s coincides with the weakening of the "absolute view" of sovereign immunity and 
movement to a more "restrictive view" which allowed suit against a sovereign in default, and weakened the bargaining position of debtors. In the mid 1980's, the IMF's policy of "lending into arrears" combined with the weak financial position of international banks, strengthened the position of debtors in default, and it was not until these banks improved their financial position, and hence their bargaining power, that the crisis was resolved ${ }^{7}$. Similarly, the rise of litigious "vulture creditors" in the 1990s has been associated with fewer and shorter defaults. Such an interpretation suggests that current efforts to curtail legal action by creditors, such as the introduction of collective action mechanisms into bond contracts, may lead to more default, and lower borrowing levels, in the future.

We intend to pursue two extensions of this project in future work. First, our model makes predictions about the behavior of secondary market prices for sovereign bonds while a country is in default. We have begun the collection of data on secondary market prices to evaluate these predictions. Second, as discussed in length in the paper, we calibrated the model on a quarterly frequency. Although this is standard when examining the timing of investment decisions in macroeconomics, it is arguably too long a time horizon when thinking about the frequency with which parties may make proposals in bargaining. However, shortening the time horizon also limits the set of assets available to the country; calibrated to a monthly frequency, the country can only issue thirty-day treasury bills. Adding more assets, however, expands the dimension of the state vector for the model, and hence requires greater computational power. In future work we intend to explore the approach of Hatchondo and Martinez (2008), Arellano and Ramnarayan (2008) and Chatterjee and Eyigungor (2008) to computing models with multiple debt maturities.

Finally, we argue that our findings may be useful in understanding the presence of delays in other bargaining contexts. As one, but by far from the only, possibility, consider bargaining between a firm and its workers in which changes in current work practices are sought in return for future wage and pension benefits. If firm profits are currently low

\footnotetext{
${ }^{7}$ In 1987, John Reed, chairman of Citicorp wrote that "Through building up their reserves and capital, U.S. banks' exposure to troubled debtor nations now accounts for a much smaller portion of capital and earnings than it did in $1982 \ldots$. [and that this] increases the strength of the banks and is putting a great strain on the bank restructuring process. Banks are now more able to lend new money, but they are also more able to 'walk away' from the process entirely" (Reed 1987 p.427).
} 
(or negative) the firms' workers may delay agreeing to changes in work practices that are potentially mutually beneficial, if they anticipate that the firm will declare bankruptcy in the future in order to avoid honoring these future benefits.

\section{References}

[1] Aguiar, Mark and Gita Gopinath. 2006. "Defaultable Debt, Interest Rates and the Current Account." Journal of International Economics, 69:1, pp. 64-83.

[2] Aliprantis, Charalambos D. and Kim C. Border. 2006. Infinite Dimensional Analysis: A Hitchhikers Guide. Berlin: Springer-Verlag, 3rd Edition.

[3] Arellano, Cristina. 2006. "Default Risk and Income Fluctuations in Emerging Economies." University of Minnesota Working Paper.

[4] Arteta, Carlos and Galina Hale. 2008. "Sovereign debt crises and credit to the private sector." Journal of International Economics, 74:1, pp. 53-69.

[5] Ausubel, Lawrence M., Peter Cramton, and Raymond J. Deneckere. 2002. "Bargaining with incomplete information," in Handbook of Game Theory with Economic Applications: Elsevier, pp. 1897-945.

[6] Beers, David T. and John Chambers. 2006. "Default Study: Sovereign Defaults At 26Year Low, To Show Little Change In 2007". Standard 86 Poor's CreditWeek, September 18.

[7] Beim, David O., and Charles W. Calomiris, 2000, Emerging Financial Markets (New York: McGraw Hill/Irwin).

[8] Bi, Ran. 2008. "Beneficial' Delays in Debt Restructuring Negotiations." IMF Working Paper, 08:38.

[9] Chatterjee, Satyajit, Dean Corbae, Makoto Nakajima, and Jose-Victor Rios-Rull. 2007. "A Quantitative Theory of Unsecured Consumer Credit with Risk of Default." Econometrica, 75:6, pp. 1525-89.

[10] Chatterjee, Satyajit and Burcu Eyigungor. 2008. "Maturity, Indebtedness and Default Risk." Unpublished Paper, Federal Reserve Bank of Philadelphia.

[11] Cline, William R. 1995. International Debt Re-examined. Washington, DC: Institute for International Economics.

[12] D'Erasmo, Pablo. 2007. Government Reputation and Debt Repayment in Emerging Economies. Unpublished Paper, University of Texas at Austin.

[13] Dikhanov, Yuri. 2006. "Historical Present Values of Debt in developing Countries, 19802002." World Bank Working Paper.

[14] Eaton, Jonathan and Mark Gersovitz. 1981. "Debt with potential repudiation: Theoretical and empirical analysis." Review of Economic Studies, 48:2, pp. 289-309. 
[15] Global Committee of Argentina Bondholders. 2004. Investor Roadshow Presentation. Global Committee of Argentina Bondholders: New York.

[16] Hatchondo, Juan Carlos and Leonardo Martinez. 2008. "Long-duration bonds and sovereign defaults." Unpublished Paper, Federal Reserve Bank of Richmond.

[17] Institute for International Finance. 2001. Survey of Debt Restructuring by Private Creditors. Institute for International Finance: Washington, D.C.

[18] Jeanne, Olivier and Jeromin Zettelmeyer. 2001. "International Bailouts, Moral Hazard and Conditionality." Economic Policy, 16:33, pp. 409-32.

[19] Kovrijnykh, Natalia and Balázs Szentes. 2007. "Equilibrium Default Cycles." Journal of Political Economy, 115:3, pp. 403-46.

[20] Mendoza, Enrique G. and Vivian Z. Yue. 2007. "Solving the Country Risk - Business Cycle Disconnect: Endogenous Output Collapse in a Model of Sovereign Default." Unpublished Paper, University of Maryland.

[21] Merlo, Antonio and Charles Wilson. 1995. "A Stochastic Model of Sequential Bargaining with Complete Information." Econometrica, 63:2, pp. 371-99.

[22] Pitchford, Rohan and Mark L. J. Wright. 2008. "Restructuring the Sovereign Debt Restructuring Mechanism." UCLA Working Paper.

[23] Pitchford, Rohan and Mark L. J. Wright. 2008. "Holdouts in Sovereign Debt Restructuring: A Theory of Negotiation in a Weak Contractual Environment." UCLA Working Paper.

[24] Ravn, Morten O. and Harald Uhlig. 2002. "On Adjusting the Hodrick-Prescott Filter for the Frequency of Observations." Review of Economics and Statistics, 84:2, pp. 371-76.

[25] Reed, John S. 1987 "The Role of External Private Capital Flows", in Vittorio Corbo, Morris Goldstein and Mohsin Khan (eds.) Growth Oriented Adjustment Programs, The World Bank: Washington, D.C.

[26] Sturzenegger, Federico and Jeromin Zettelmeyer. "Haircuts: Estimating investor losses in sovereign debt restructurings, 1998-2005." Journal of International Money and Finance, In Press, Corrected Proof.

[27] Tomz, Michael and Mark L. J. Wright. 2007. "Do Countries Default in 'Bad Times'?" Journal of the European Economic Association, 5:2-3, pp. 352-60.

[28] Trebesch, Christoph. 2008. "Delays in Sovereign Debt Restructuring: Should We Really Blame the Creditors?" Unpublished Paper, Free University of Berlin.

[29] World Bank. various. Global Development Finance. World Bank: Washington, D.C.

[30] Yue, Vivian Z. 2006. "Sovereign Default and Debt Renegotiation." New York University Working Paper. 


\section{Appendix A: Tables and Figures}

Table 1: Delays and Haircuts

\begin{tabular}{l|ccccc}
\hline \hline & Mean & Median & $\begin{array}{c}\text { Correlation with } \\
\left(e_{T}-e_{T-1}\right) / e_{T-1}\end{array}$ & $\begin{array}{c}\text { Correlation with } \\
\left(e_{T+1}-e_{T-1}\right) / e_{T-1}\end{array}$ & $\begin{array}{c}\text { Correlation with } \\
\text { Debt } / G D P\end{array}$ \\
\hline Delay 1 & 7.4 years & 6.0 years & -0.26 & -0.21 & 0.03 \\
Delay 2 & 7.6 years & 6.7 years & -0.26 & -0.21 & 0.03 \\
Haircut 1 & $38 \%$ & $42 \%$ & -0.25 & -0.23 & 0.02 \\
Haircut 2 & $38 \%$ & $42 \%$ & -0.25 & -0.23 & 0.02 \\
\hline \hline
\end{tabular}

Table 2: Output and Debt Levels Around Default

\begin{tabular}{l|cccc}
\hline \hline & $\begin{array}{c}\text { mean \% deviation } \\
\text { from trend e }\end{array}$ & $\begin{array}{c}\text { \% of years } \\
\text { e below trend }\end{array}$ & \multicolumn{2}{c}{ Debt/GDP (\%) } \\
Mean & Median \\
\hline years in default & -0.4 & 54 & 87 & 61 \\
years out of default & 0.4 & 43 & 51 & 33 \\
year before default & 1.0 & 39 & 52 & 40 \\
year of default & -1.3 & 64 & 58 & 45 \\
year of settlement & -0.2 & 51 & 73 & 50 \\
year after settlement & 0.1 & 48 & 72 & 47 \\
\hline \hline
\end{tabular}

Figure 1: The Relationship Between Delays and Haircuts

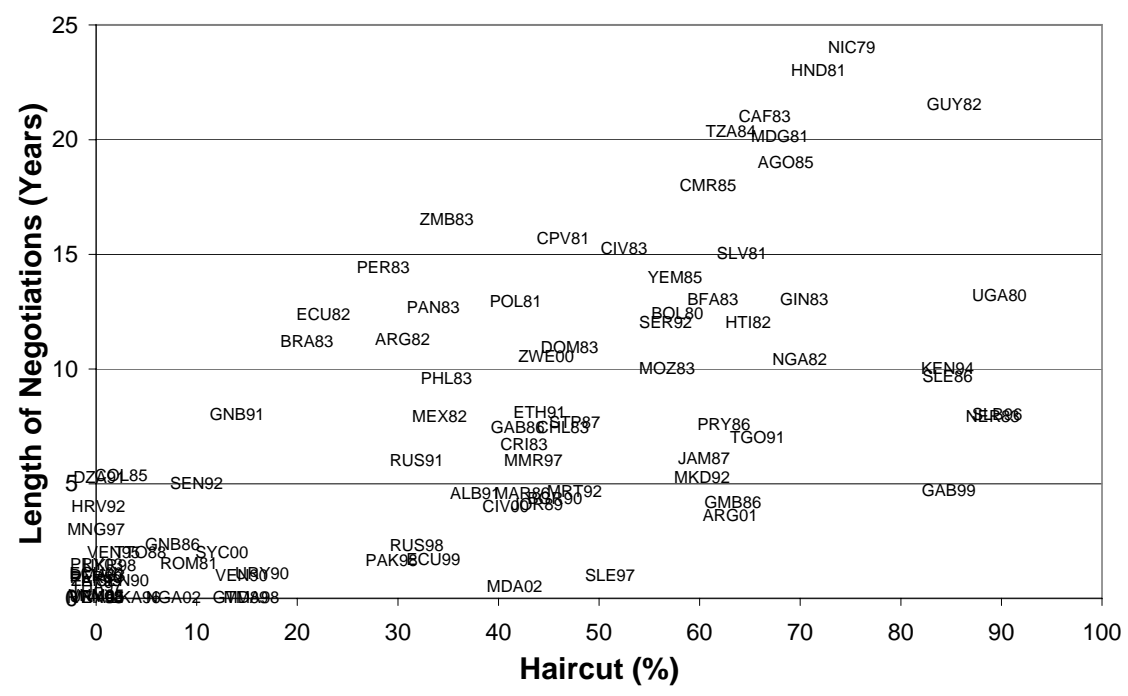


Figure 2: Timeline of Decisions Outside Default

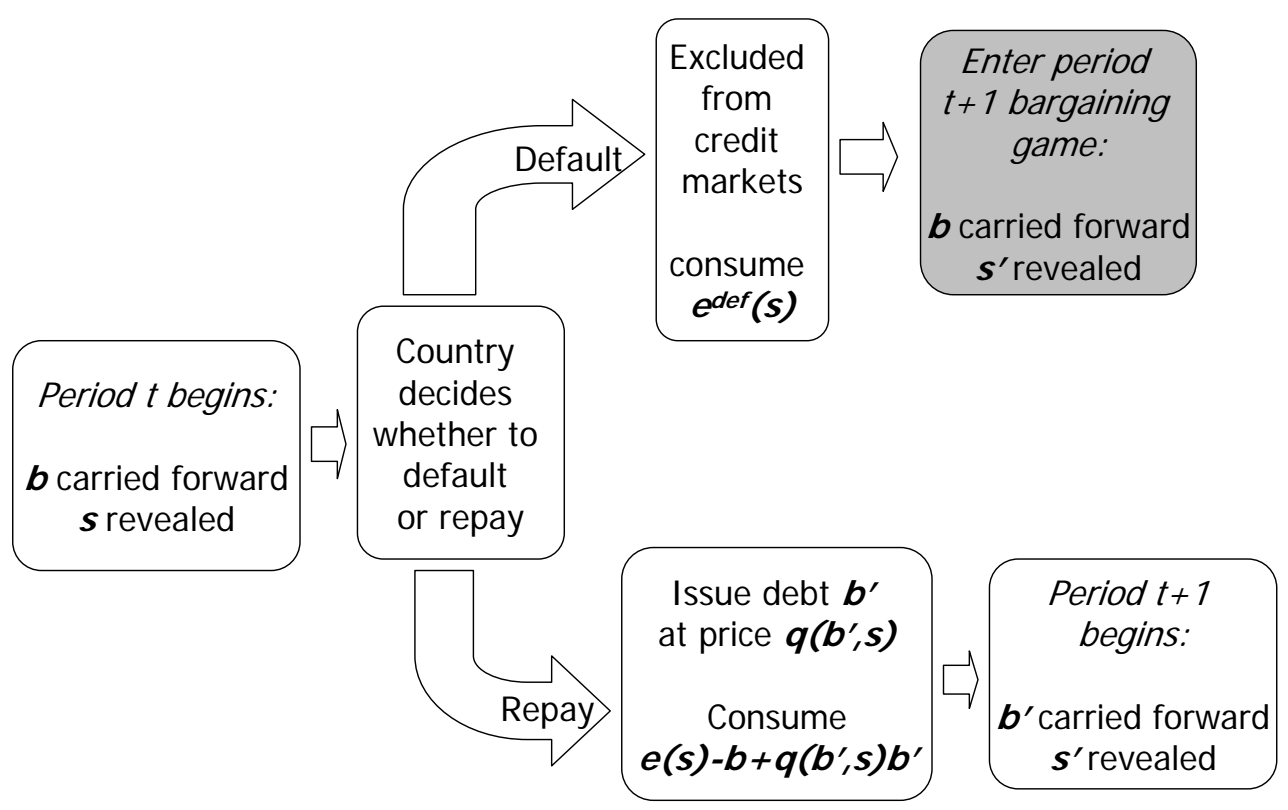

Figure 3: Timeline of Decisions Inside Default

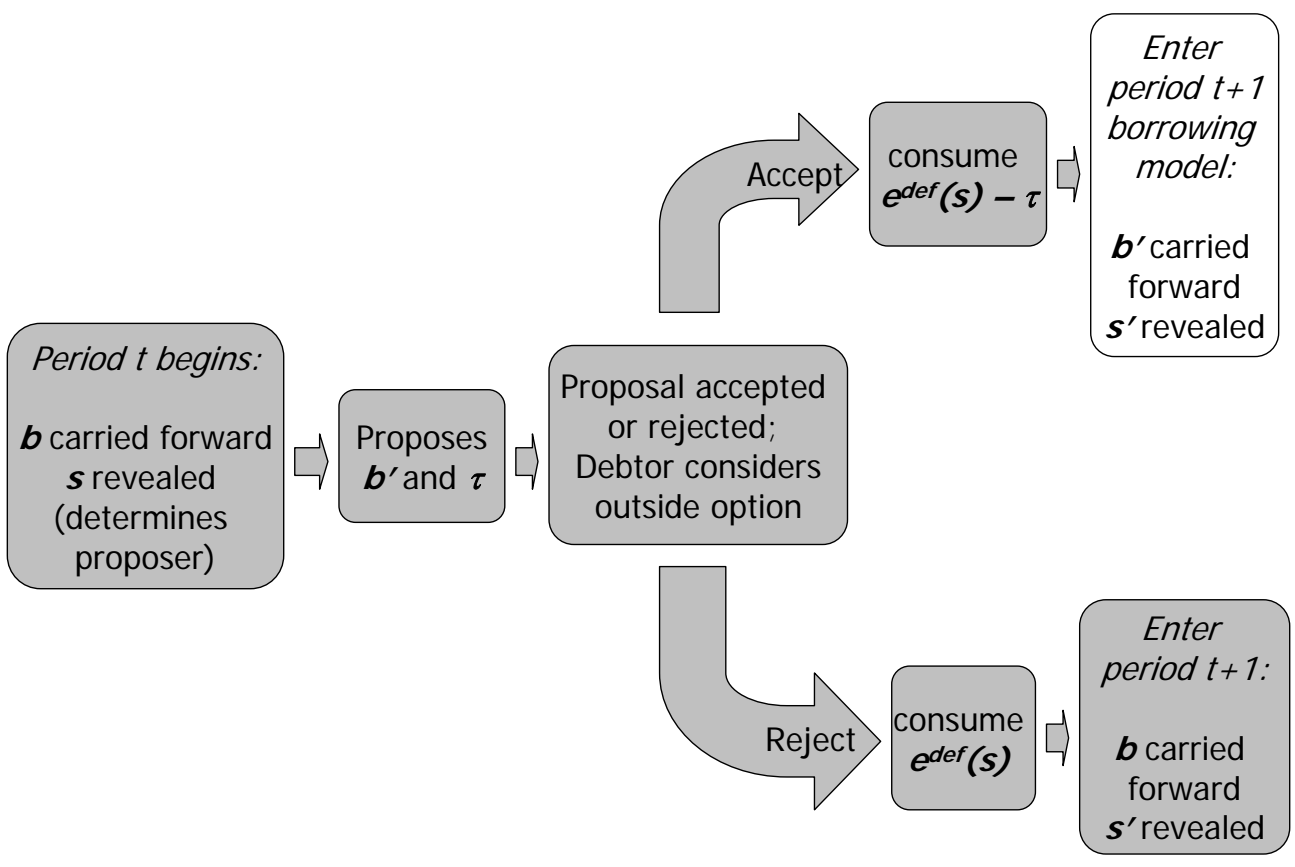


Table 3: Parameter Values for Calibration

\begin{tabular}{c|c|c}
\hline \hline Name & Meaning & Value \\
\hline$\beta$ & Discount factor & 0.945 \\
$1+r^{w}$ & World Interest rate & 1.01 \\
$\gamma$ & CRRA & 2 \\
$\rho_{e}$ & Persistence & 0.945 \\
$\sigma_{\epsilon}$ & Std Dev & 0.02 \\
\hline \hline
\end{tabular}

Table 4: Calibration Targets

\begin{tabular}{c|c|c}
\hline \hline Target & Data & Model Outcome \\
\hline mean $\left(\left(e_{t}-e_{t}^{\text {trend }}\right) / e_{t}^{\text {trend }} \mid t\right.$ is period before default $)$ & 0.01 & 0.01 \\
$\operatorname{mean}\left(\left(e_{t+1}-e_{t}\right) / e_{t} \mid t+1\right.$ is period default ends $)$ & 0.004 & 0.005 \\
$\operatorname{prob}\left(e_{t}<e_{t}^{\text {trend }} \mid t\right.$ is period in default $)$ & $54 \%$ & $54 \%$ \\
$\operatorname{mean}\left(\left(e_{t}-e_{t-1}\right) / e_{t-1} \mid t\right.$ is period in default $)$ & -0.0016 & -0.0014 \\
mean(debt to gdp $)$ & 0.65 & 0.65 \\
\hline \hline
\end{tabular}

Table 5: Parameters Calibrated to Match Targets

\begin{tabular}{l|c}
\hline \hline Name & Value \\
\hline$\pi(D \mid D, e(s)$ low $)$ & 0.86 \\
$\pi(D \mid D, e(s)$ medium $)$ & 0.93 \\
$\pi(D \mid D, e(s)$ high $)$ & 0.61 \\
$\pi(D \mid C, e(s)$ medium $)$ & 0.05 \\
Output Cost & 0.01 \\
\hline \hline
\end{tabular}


Figure 4: Simulation of i.i.d. Creditor Example
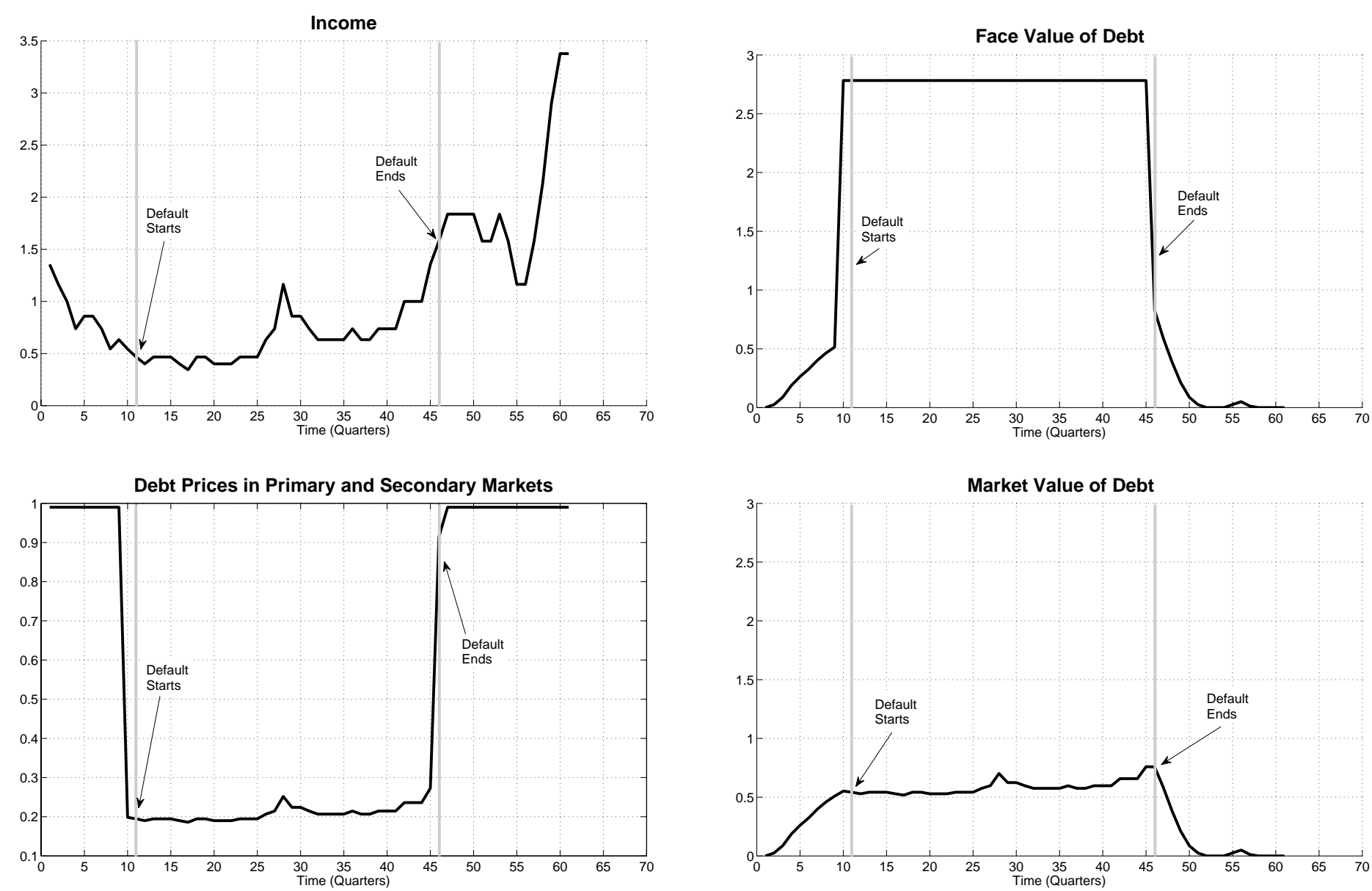
Figure 5: Equilibrium Objects in i.i.d. Creditor Example
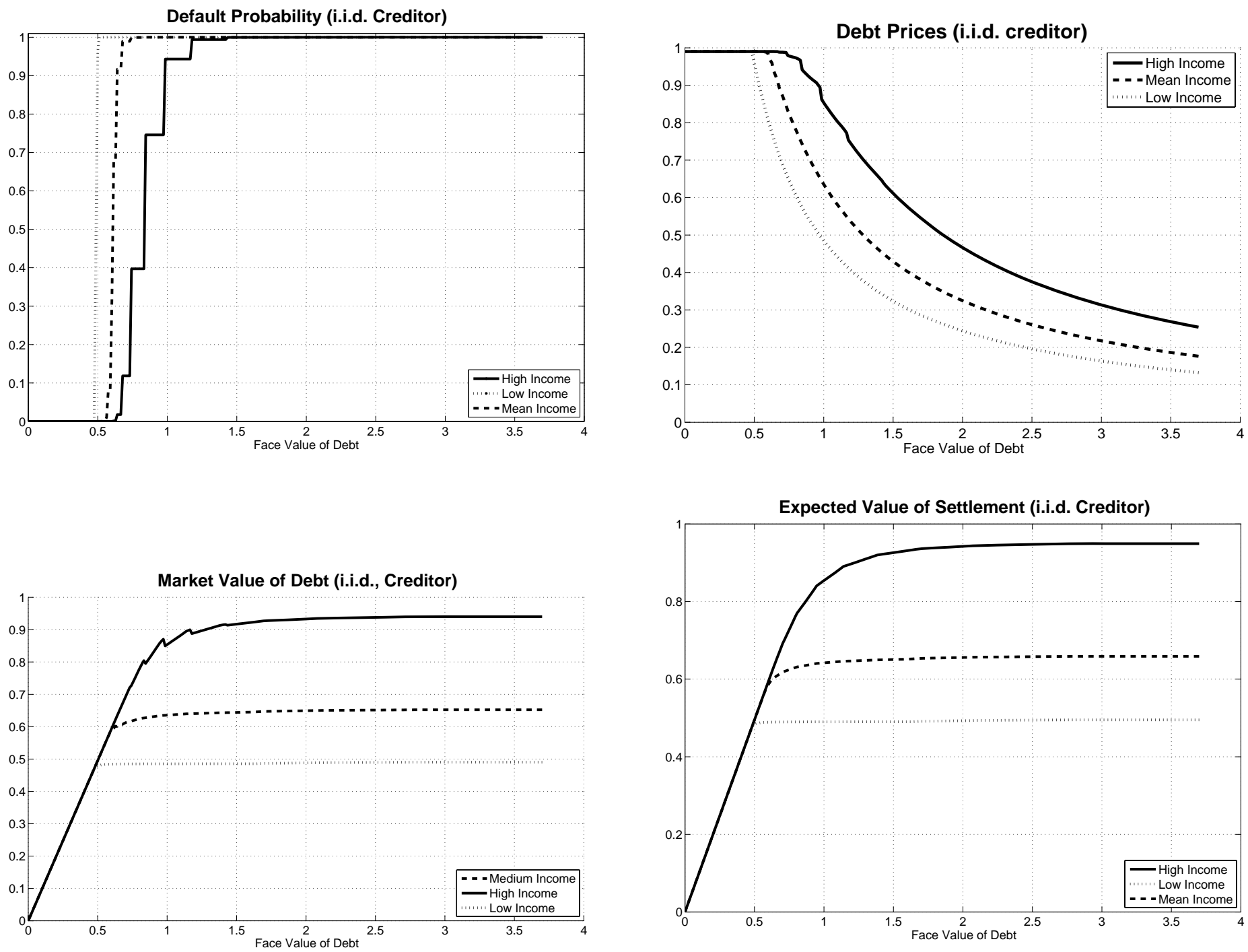
Figure 6: Simulation of Persistent Example
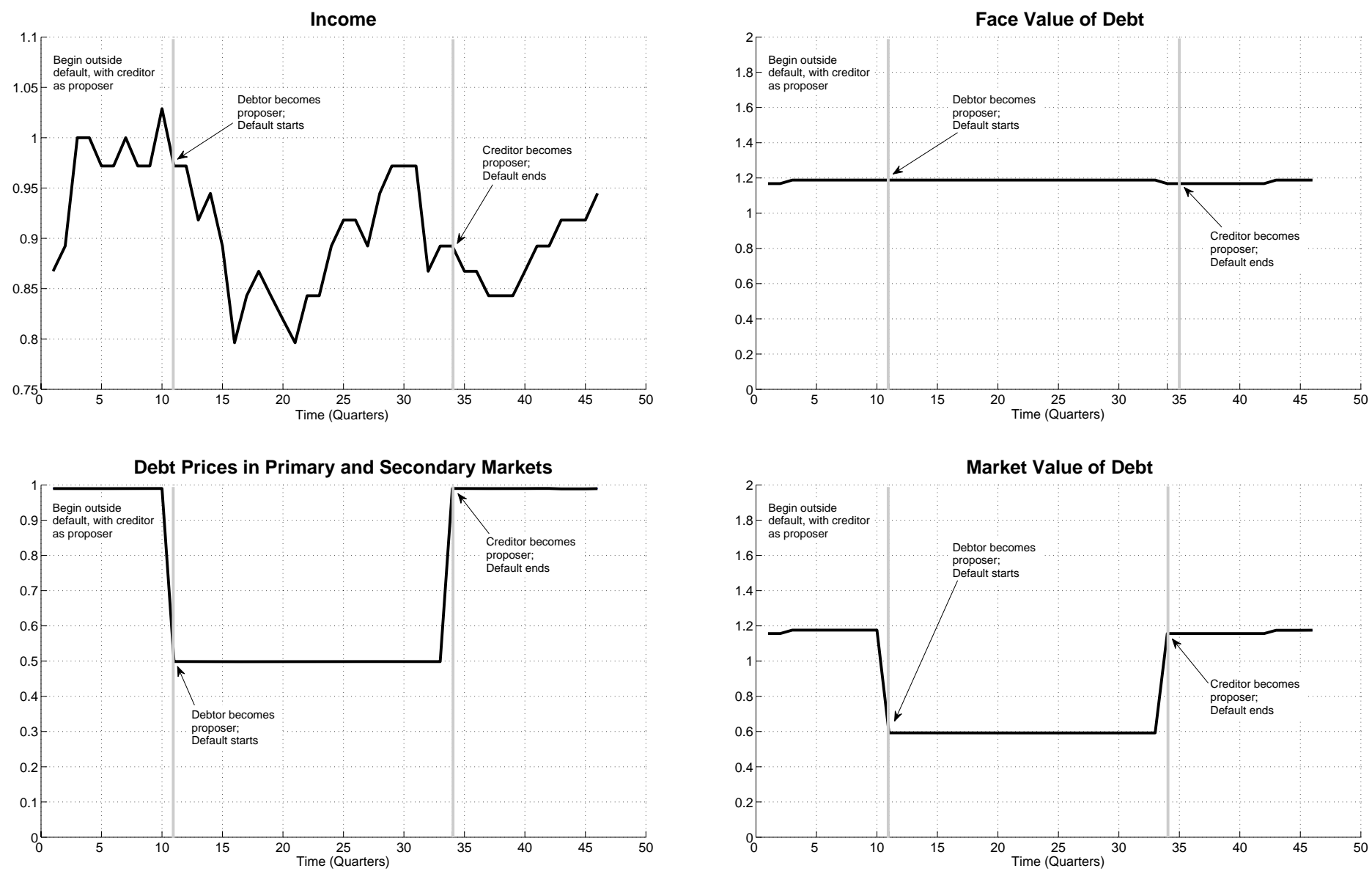
Figure 7: Equilibrium Objects in Persistent Example: Part I
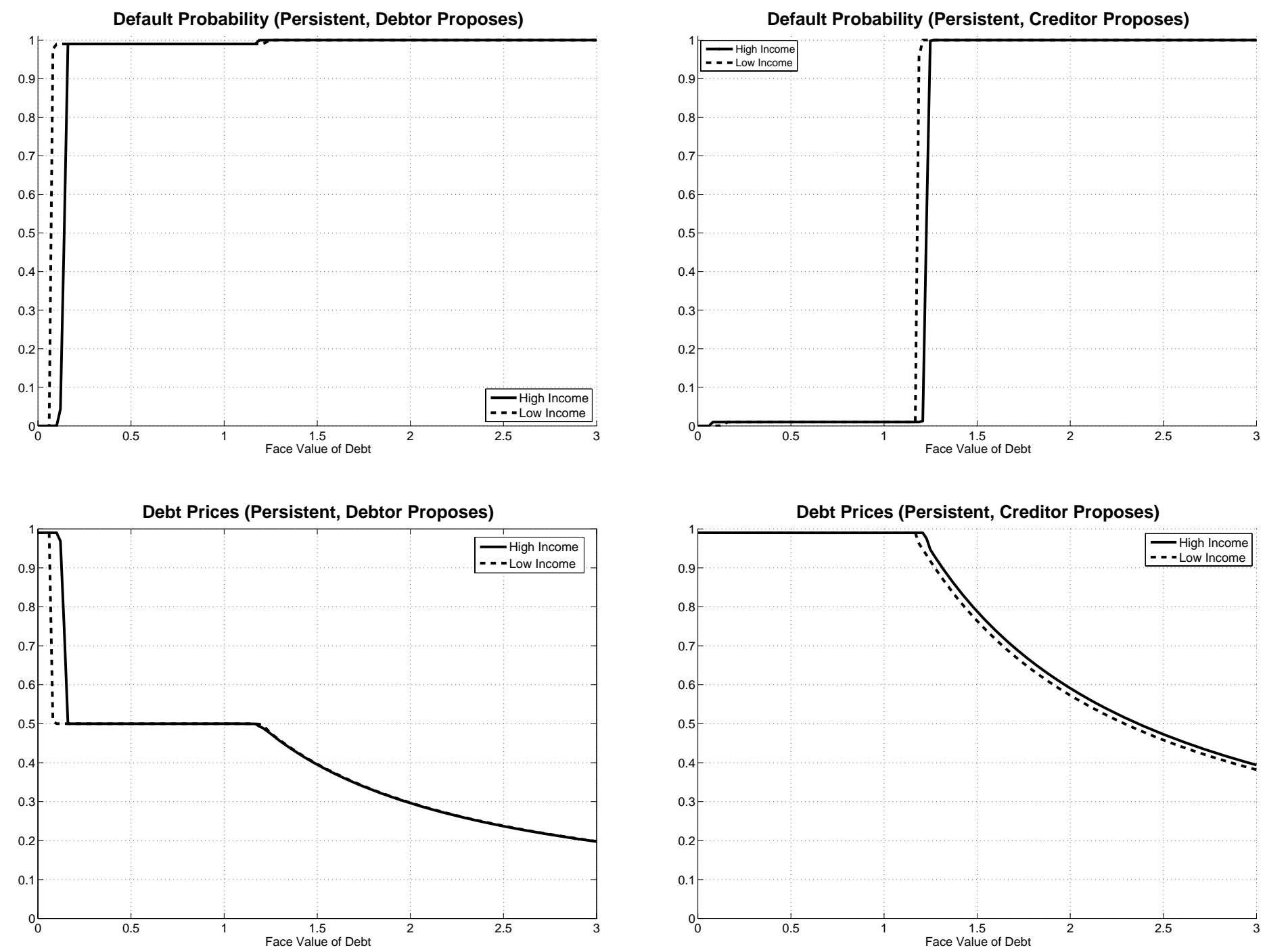
Figure 8: Equilibrium Objects in Persistent Example: Part II
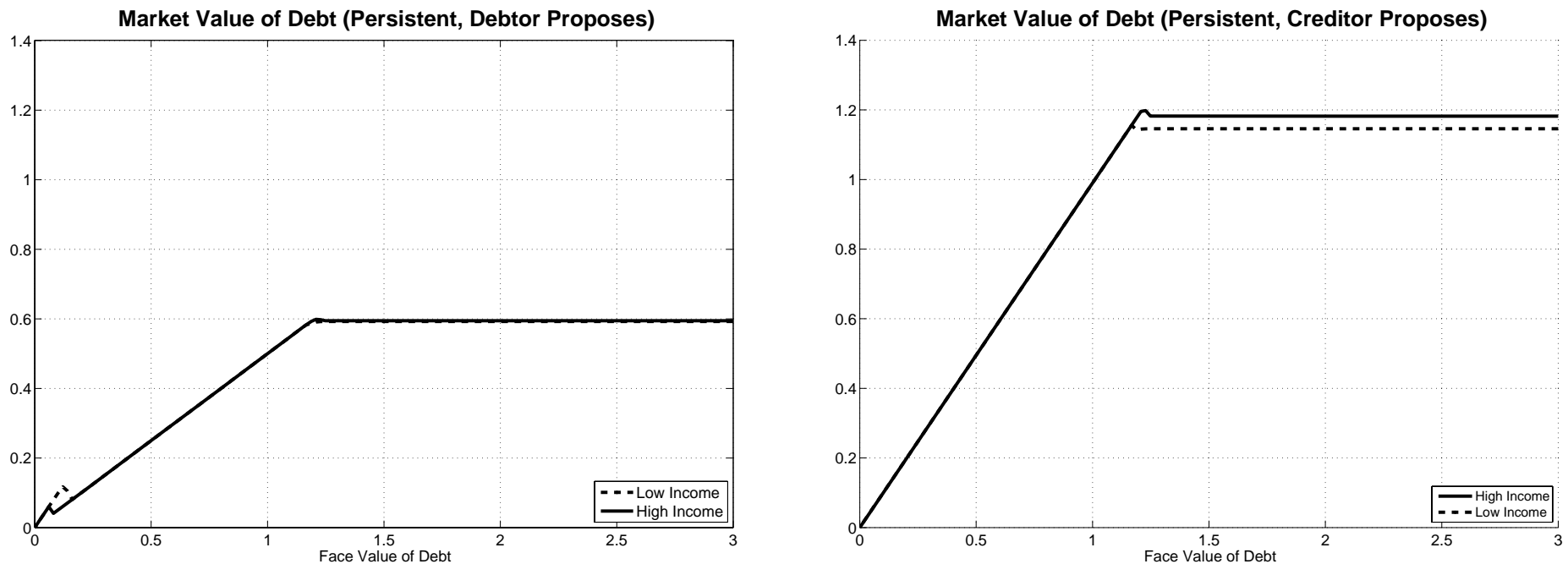

Expected Value of Settlement (Persistent, Debtor Proposes)
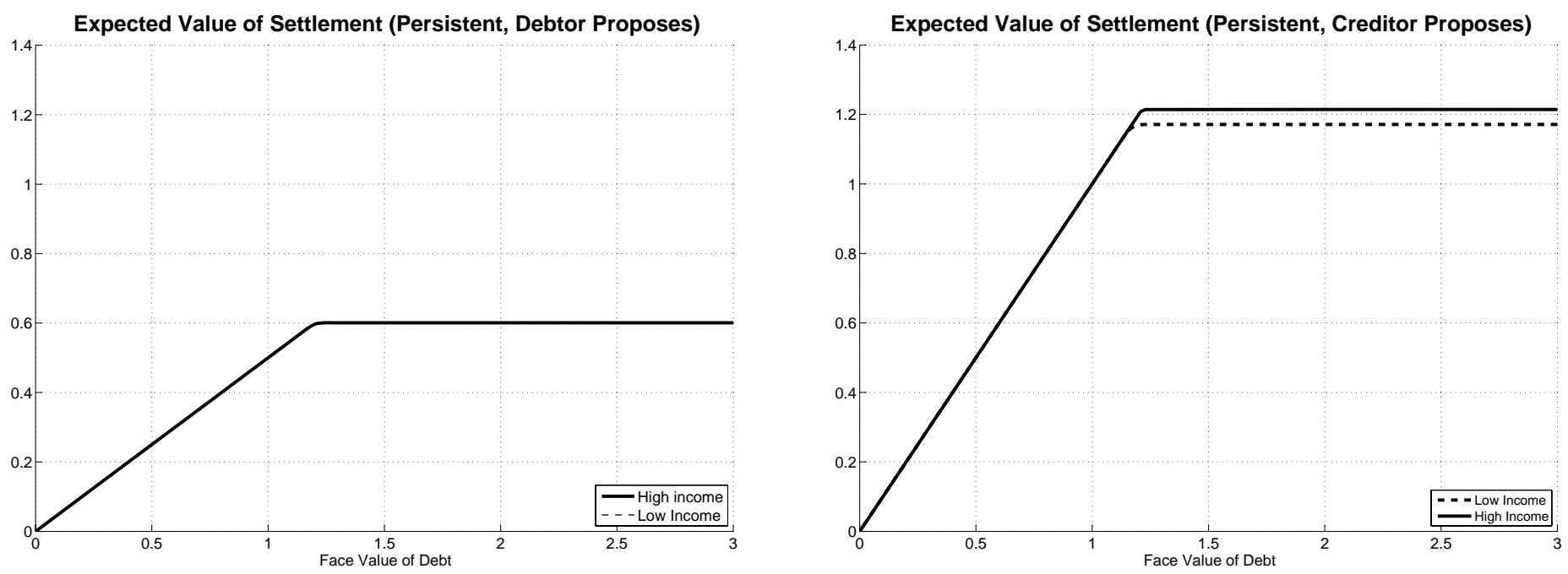
Figure 9: Equilibrium Objects of the Benchmark Model I
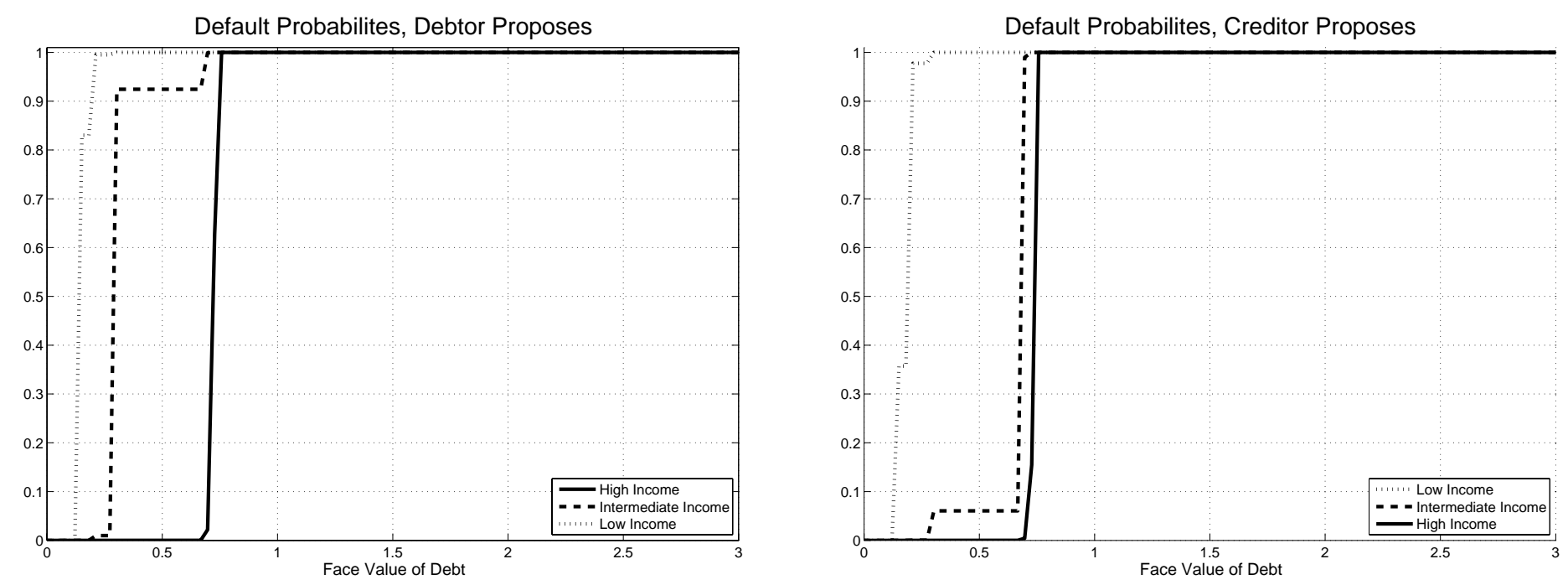

Debt Prices, Debtor Proposes

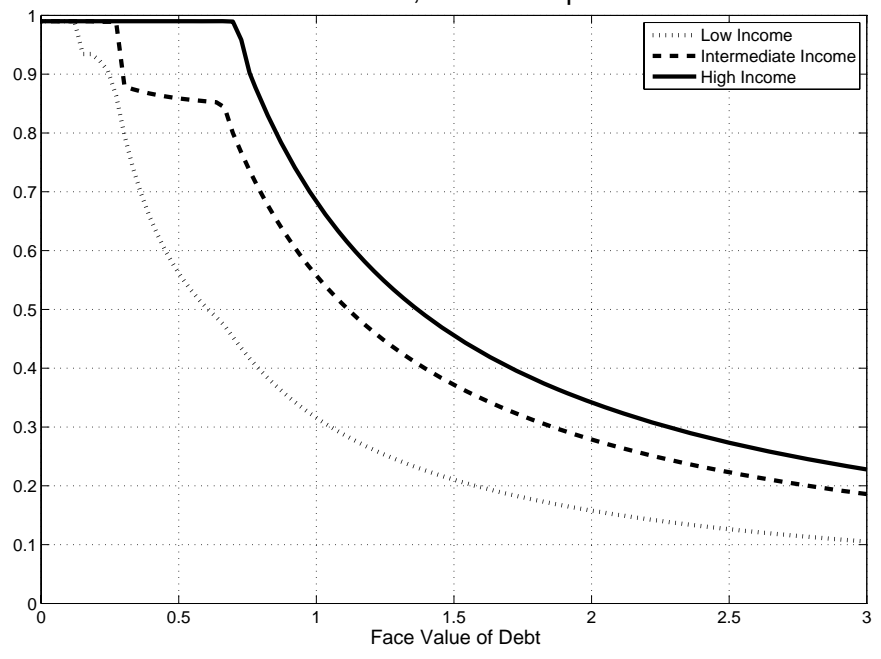

Debt Prices, Creditor Proposes

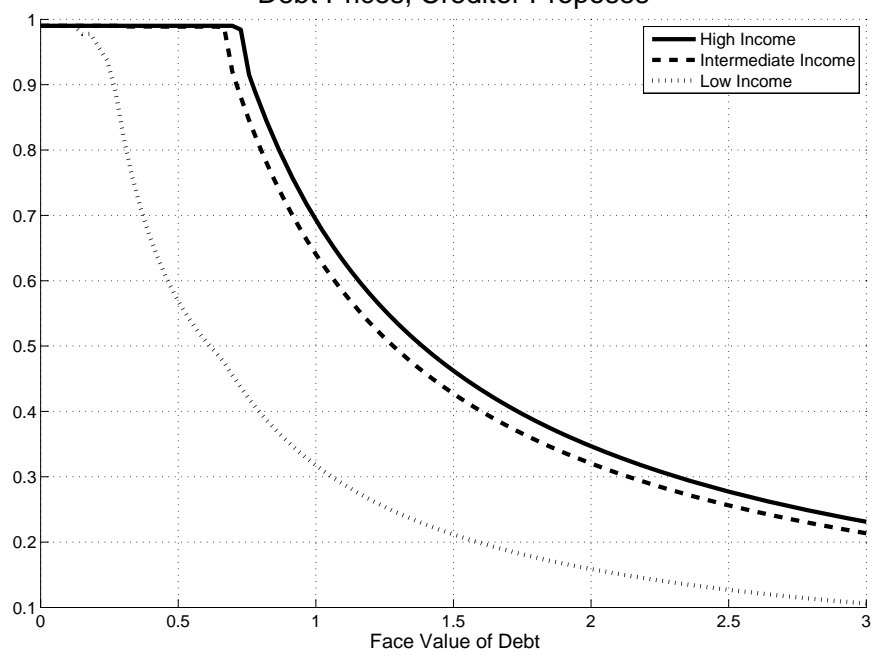


Figure 10: Equilibrium Objects of the Benchmark Model II
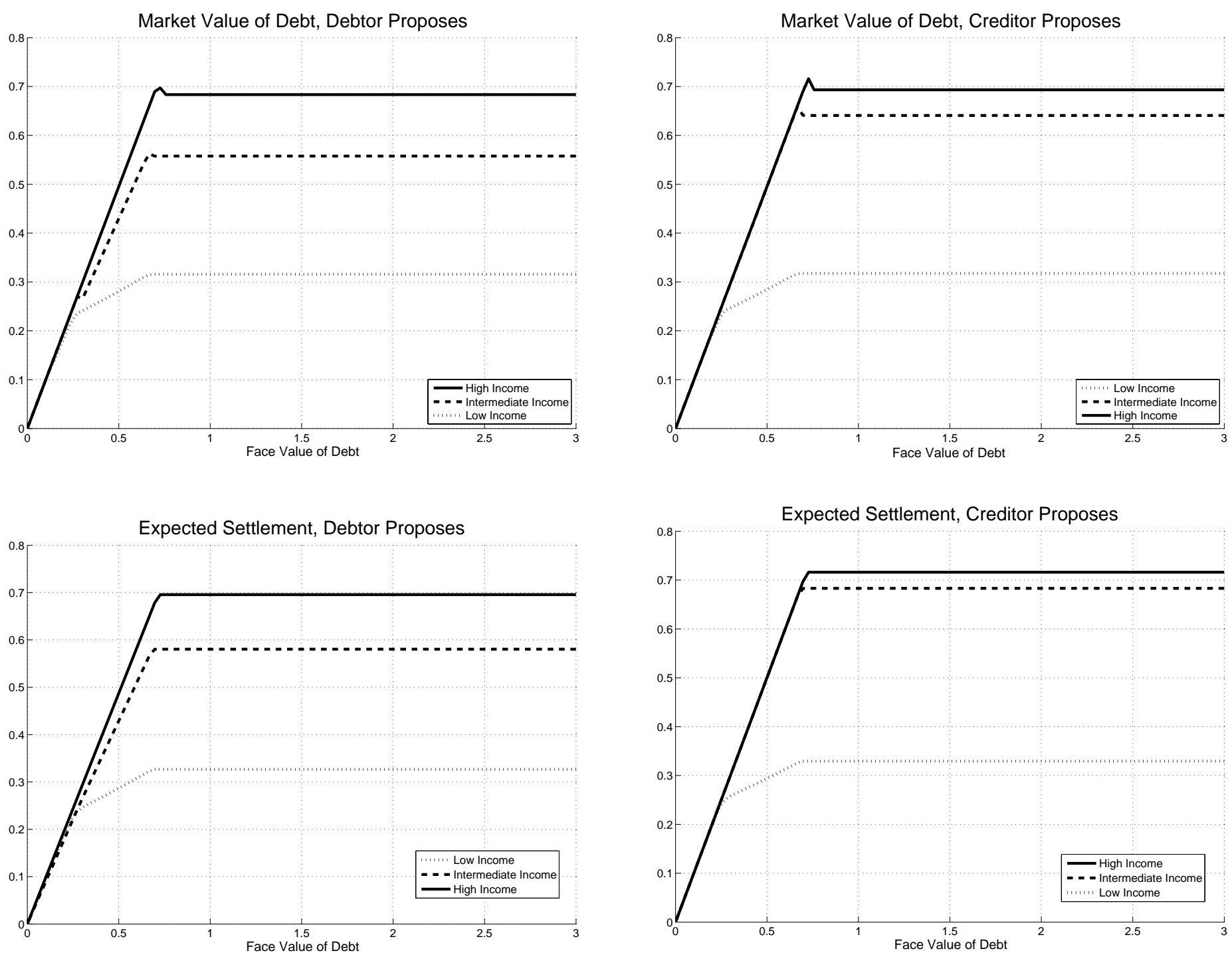
Table 6: Numerical Results for Delays and Haircuts

\begin{tabular}{c|c|c|c|c|c|c}
\hline \hline & Probability & Mean & Mean & \multicolumn{3}{|c}{ Correlation } \\
\cline { 5 - 7 } & of Default & Delay & Haircut & Delays \& & \multicolumn{2}{c}{$\left(e_{T}-e_{T-1}\right) / e_{T-1} \&$} \\
\cline { 5 - 7 } & $(\%)$ & (Years) & $(\%)$ & Haircuts & Delays & Haircuts \\
\hline i.i.d creditor & 3.9 & 6.7 & 84 & -0.21 & -0.03 & 0.01 \\
i.i.d debtor & 4.4 & 1.0 & 68 & -0.18 & -0.06 & 0.06 \\
strength through strength & 3.6 & 5.0 & 63 & 0.44 & 0.02 & -0.05 \\
strength through weakness & 3.9 & 6.7 & 78 & 0.89 & -0.05 & 0.10 \\
persistent & 4.0 & 10.7 & 35 & 0.54 & 0.22 & 0.27 \\
benchmark & 4.4 & 7.2 & 28 & 0.70 & -0.15 & -0.08 \\
data & & & & & & \\
\hline \hline
\end{tabular}

Table 7: Numerical Results on Default, Debt and Economic Activity

\begin{tabular}{|c|c|c|c|c|c|c|}
\hline & \multicolumn{2}{|c|}{$\begin{array}{l}\text { \% Countries Below } \\
\text { Trend in Year of: }\end{array}$} & \multicolumn{2}{|c|}{$\begin{array}{l}\text { Mean Trend Deviation } \\
\text { of Output in Year of: }\end{array}$} & \multicolumn{2}{|c|}{$\begin{array}{l}\text { Change in Indebtedness: } \\
\frac{\text { Debt/GDP Y ear After Settlement }}{\text { Debt/GDP Year of Default }}\end{array}$} \\
\hline i.i.d debtor & 47 & 53 & 2.9 & -0.6 & 0.79 & 0.95 \\
\hline i.i.d creditor & 48 & 60 & 2.8 & -4.9 & 0.56 & 0.85 \\
\hline strength through strength & 49 & 50 & 0.1 & 0.6 & 0.72 & 0.80 \\
\hline strength through weakness & 49 & 62 & 0.2 & -1.1 & 0.70 & 0.81 \\
\hline persistent & 39 & 66 & 0.2 & -0.3 & 0.99 & 1.08 \\
\hline benchmark & 53 & 76 & -0.3 & -0.8 & 0.97 & 1.03 \\
\hline $\begin{array}{c}\text { data (mean) } \\
\text { data (median) }\end{array}$ & 64 & 52 & -1.3 & -0.2 & & $\begin{array}{l}1.24 \\
1.04\end{array}$ \\
\hline
\end{tabular}


Table 8: Numerical Results on the Proportion of Countries Below Trend

\begin{tabular}{c|cccc}
\hline \hline Regime & $\begin{array}{c}\text { Period Before } \\
\text { Default }\end{array}$ & $\begin{array}{c}\text { Period Of } \\
\text { Default }\end{array}$ & $\begin{array}{c}\text { Period Of } \\
\text { Settlement }\end{array}$ & $\begin{array}{c}\text { Period After } \\
\text { Settlement }\end{array}$ \\
\hline i.i.d debtor & 97 & 99 & 87 & 84 \\
i.i.d creditor & 99 & 97 & 52 & 56 \\
strength through strength & 1 & 5 & 42 & 40 \\
strength through weakness & 98 & 99 & 57 & 53 \\
persistent & 60 & 89 & 89 & 58 \\
benchmark & 46 & 90 & 73 & 19 \\
i.i.d debtor & 4 & 47 & 53 & 86 \\
i.i.d creditor & 3 & 48 & 60 & 55 \\
strength through strength & 96 & 49 & 50 & 40 \\
strength through weakness & 3 & 49 & 62 & 40 \\
persistent & 15 & 39 & 66 & 62 \\
benchmark & 25 & 53 & 76 & 29 \\
data & 40 & 64 & 52 & 49 \\
\hline \hline
\end{tabular}

Table 9: Numerical Results on Spreads, Income and Capital Flows: Quarterly Data

\begin{tabular}{|c|c|c|c|c|c|c|c|c|}
\hline \multirow{2}{*}{\multicolumn{2}{|c|}{ Model }} & \multicolumn{5}{|c|}{ Correlation Between } & \multirow{3}{*}{$\begin{array}{c}\text { Std Dev }(\mathrm{C}) / \\
\text { Std Dev }(\mathrm{Y})\end{array}$} & \multirow{3}{*}{$\begin{array}{c}\text { Face Value } \\
\text { of Debt/ } \\
\text { Income }\end{array}$} \\
\hline & & \multicolumn{3}{|c|}{ Spreads \& } & \multicolumn{2}{|c|}{ Income \& } & & \\
\hline & & & & & & & & \\
\hline Arellano (2007) & & & 0.43 & -0.29 & & -0.25 & 1.10 & 6 \\
\hline Aguiar \& & Trend Stat & -0.21 & & 0.51 & -0.33 & & 0.99 & 27 \\
\hline Gopinath (2007) & Diff. Stat. & 0.11 & & -0.03 & -0.19 & & 0.98 & 19 \\
\hline Yue (2007) & & & 0.54 & -0.18 & & -0.14 & 1.03 & 10 \\
\hline Bi (2008) & & & & -0.51 & 0.12 & & 0.99 & 9 \\
\hline i.i.d debtor & & 0.23 & & -0.24 & 0.19 & & 0.99 & 49 \\
\hline i.i.d creditor & & 0.12 & & -0.45 & 0.27 & & 0.98 & 246 \\
\hline strength through & strength & 0.17 & & 0.31 & -0.20 & & 1.27 & 51 \\
\hline strength through & weakness & 0.19 & & -0.51 & 0.24 & & 1.09 & 66 \\
\hline persistent & & 0.25 & & -0.09 & 0.01 & & 1.03 & 83 \\
\hline benchmark & & 0.32 & & -0.44 & -0.24 & & 1.09 & 69 \\
\hline data range & min (abs. val.) & 0.05 & 0.49 & -0.12 & -0.17 & -0.64 & 1.03 & 65 \\
\hline & $\max$ (abs. val.) & 0.86 & 0.70 & -0.88 & -0.89 & -0.88 & 1.19 & \\
\hline
\end{tabular}

Sources: Arellano (2007) Tables 1 and 4. Aguiar and Gopinath (2007) Tables 1 and 3. Yue (2008) Table 4. Bi (2008) Table 4. 
Figure 11: The Benefits of Bailouts: Low Output
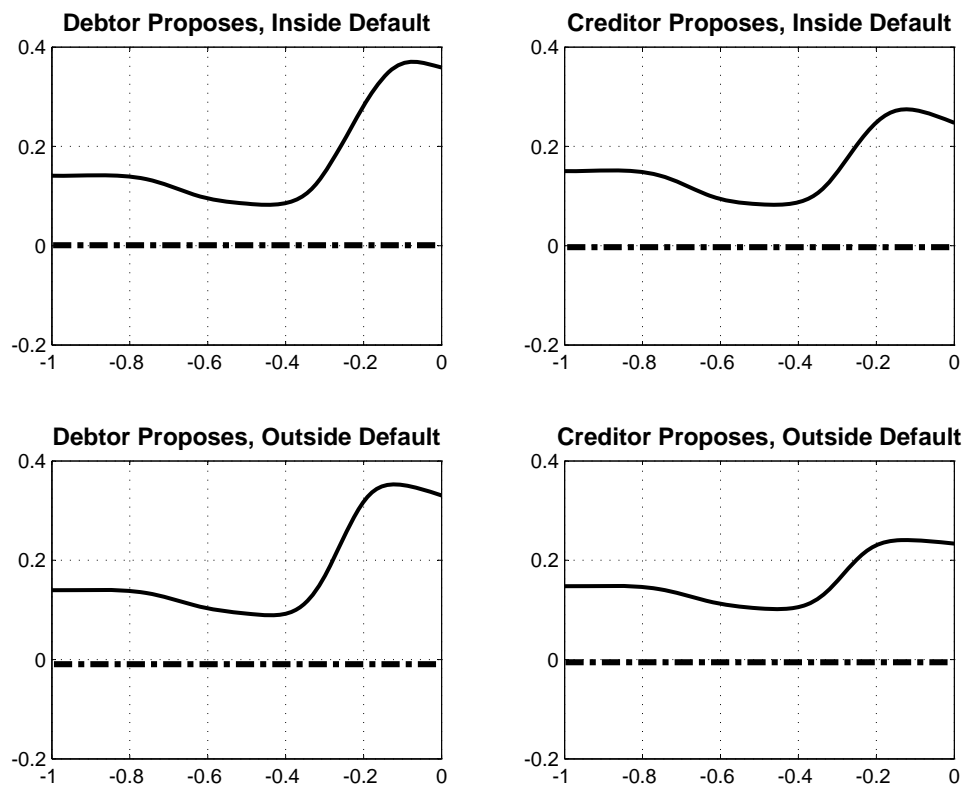

Figure 12: The Costs of Bailouts: Low Output
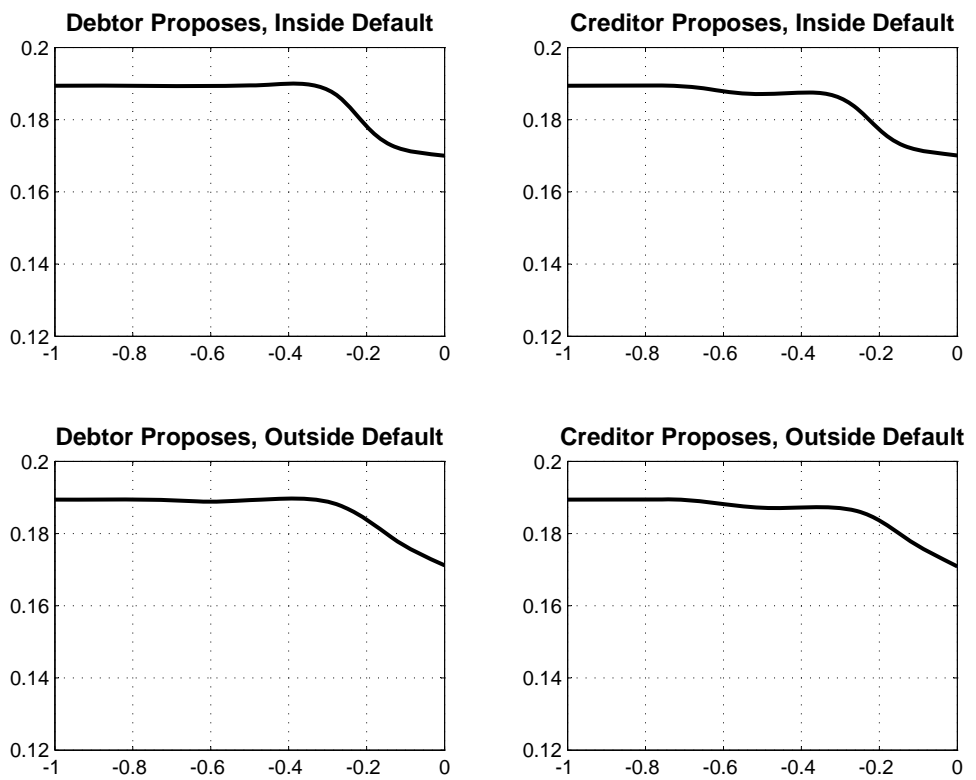
Figure 13: The Benefits of Bailouts: Mean Output
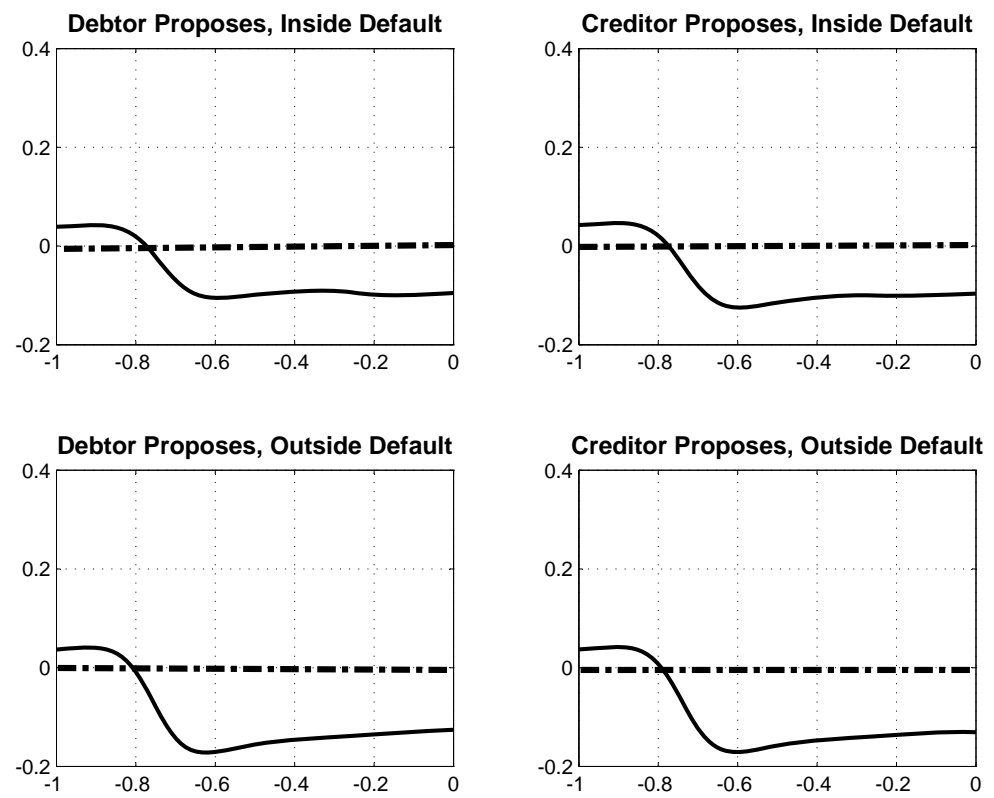

Figure 14: The Costs of Bailouts: Mean Output
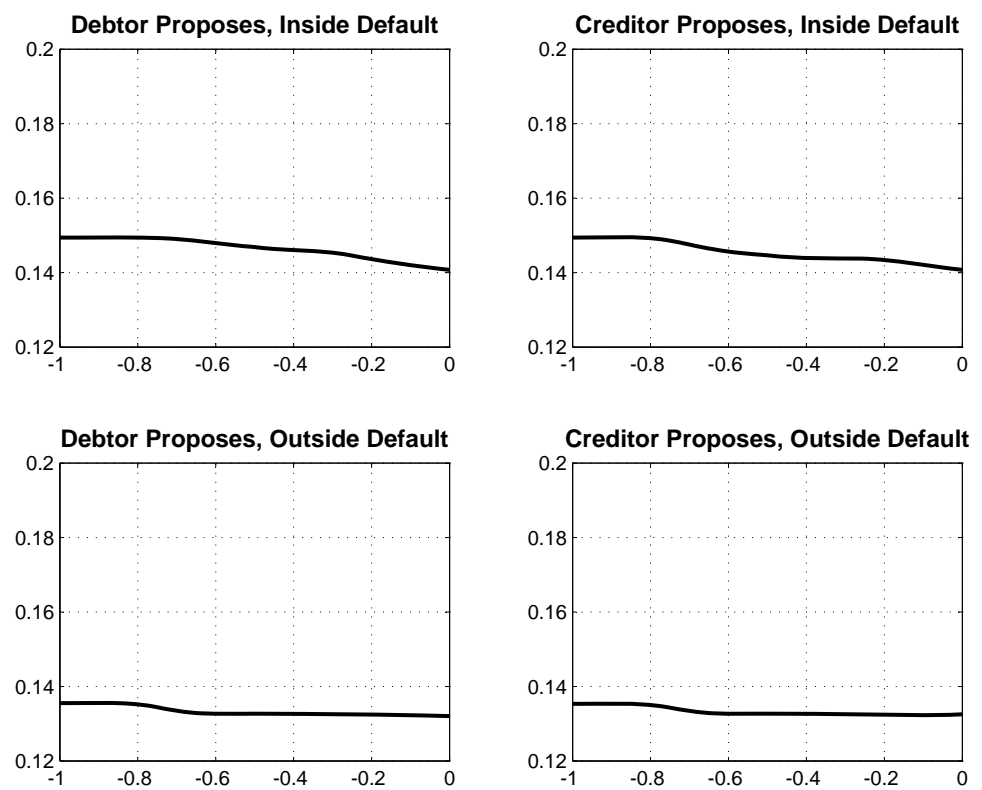
Table 10: The Effect of Bailouts

Benchmark Case

\begin{tabular}{c|cc}
\hline \hline & No Bailout & Bailout \\
\hline Length of Default (years) & 7.2 & 11.1 \\
Time in Default (\%) & 44 & 75 \\
Average Benefit & & \\
$(\%$ lifetime consumption) & & \\
Average Cost \\
$(\%$ lifetime consumption) & 0.02 \\
$\begin{array}{c}\text { Average Net Benefit } \\
(\% \text { lifetime consumption) }\end{array}$ & & \\
\hline \hline
\end{tabular}

Table 11: Probability of a Bailout

Sensitivity Analysis

\begin{tabular}{c|ccccccccccc}
\hline $\begin{array}{c}\text { Prob of Bailout } \\
\text { (per quarter) }\end{array}$ & 0.00 & 0.05 & 0.10 & 0.15 & 0.20 & 0.25 & 0.30 & 0.35 & 0.40 & 0.45 & 0.50 \\
\hline $\begin{array}{c}\text { Time in } \\
\text { Default (\%) }\end{array}$ & 44 & 43 & 74 & 75 & 75 & 75 & 100 & 96 & 100 & 100 & 100 \\
$\begin{array}{c}\text { Ave Net Benefit } \\
(\% \text { of life consn) }\end{array}$ & 0.00 & -0.04 & -0.05 & -0.11 & -0.13 & -0.10 & -0.17 & -0.15 & -0.19 & -0.20 & -0.24 \\
\hline \hline
\end{tabular}

\section{Appendix B: Proofs of Theorems}

\section{A Solution to the Bargaining Model}

\section{Recursive Problem Statement}

In this section, we prove the equivalence between SSP payoffs and fixed points of the $\hat{T}$ operator defined in the text. This requires some notation, and an intermediate Lemma.

Take the SSP outcome, which consists of a set of states in which acceptance occurs and the proposal that is accepted in that state, $\left((B \times S)^{\mu}, \mu\right)$, as given. We can define the value of this outcome as follows. First, fix the value of the defaulted debt to $b$. Then, given a sequence of realizations of the state, define the stopping time for an agreement by $t^{*}$ where $\left(b, s_{t^{*}}\right) \in(B \times S)^{\mu}$ and $\left(b, s_{t}\right) \in(B \times S) \backslash(B \times S)^{\mu}$ for all $t=0, \ldots, t^{*}-1$. Then we can define the value of this outcome in state $s$ as

$$
\begin{aligned}
& v^{\mu}(b, s) \equiv\left(\begin{array}{c}
v_{\mu}^{\mu}(b, s) \\
v_{2}^{\mu}(b, s)
\end{array}\right) \\
= & \left(\begin{array}{l}
E\left[\sum_{t=0}^{t^{*}-1} \beta^{t} U\left(e^{\text {def }}\left(s_{t}\right)+\beta^{t^{*}}\left\{U\left(e^{\text {def }}\left(s_{t^{*}}\right)-\tau\left(s_{t^{*}}\right)\right)+\beta V\left(b\left(s_{t^{*}}\right), s_{t^{*}}\right)\right\} \mid s\right]\right. \\
E\left[\delta^{t^{*}}\left\{\tau\left(s_{t^{*}}\right)+b\left(s_{t^{*}}\right) q\left(b\left(s_{t^{*}}\right), s_{t^{*}}\right)\right\} \mid s\right]
\end{array}\right) .
\end{aligned}
$$

First, we establish that the value function $v^{\mu}(b, s)$ is the unique function defined on 
$B \times S$ taking values in $\mathbb{R}^{2}$ satisfying a particular functional equation. The proof relies on the following mapping which is defined for an arbitrary stationary outcome. Specifically, consider the mapping $T$ on the set of functions $f: B \times S \rightarrow \mathbb{R}^{2}$ into itself defined by:

$$
T f_{1}(b, s)=\left\{\begin{array}{lc}
u\left(e^{\text {def }}(s)-\tau(b, s)\right)+\beta E\left[V\left(b^{\prime}(b, s), s^{\prime} \mid s\right)\right] & \text { if }(b, s) \in(B \times S)^{\mu} \\
u\left(e^{\operatorname{def}}(s)\right)+\beta E\left[f_{1}\left(b, s^{\prime}\right) \mid s\right] & \text { if }(b, s) \in(B \times S) \backslash(B \times S)^{\mu}
\end{array}\right.
$$

and

$$
T f_{2}(b, s)=\left\{\begin{array}{lr}
\tau(b, s)+b^{\prime}(b, s) q\left(b^{\prime}(b, s), s\right) & \text { if }(b, s) \in(B \times S)^{\mu} \\
\delta E\left[f_{2}\left(b, s^{\prime}\right) \mid s\right] & \text { if }(b, s) \in(B \times S) \backslash(B \times S)^{\mu}
\end{array}\right.
$$

The first operator applies to the payoff of the debtor country, and simply states that if $(b, s)$ is in the set $(B \times S)^{\mu}$, which is the set of debt levels and states in which either the outside option is taken or a proposal is accepted, then the payoff to the country is found by evaluating the value of that proposal. Conversely, if $(b, s)$ is not in the acceptance set, the debtor country consumes its endowment in default today and the discounted value of the expected payoff from continuing the bargaining game tomorrow. The second operator is similar and applies to the payoff of the creditors.

Lemma B. 1. Given an outcome $\left((B \times S)^{\mu}, \mu\right)$ where $\mu=(\tau, b)$, $v^{\mu}$ is the unique function defined on $B \times S$ taking values in $\mathbb{R}^{2}$ for which

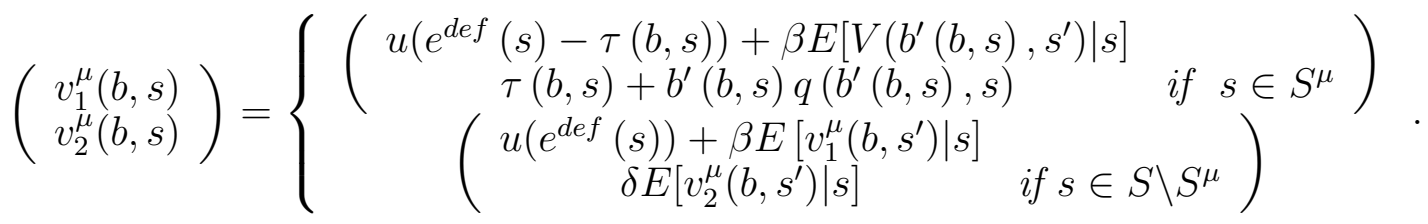

Proof. The proof requires us to show that $v^{\mu}$ is a fixed point of the operator $T$, and that the operator $T$ has a unique fixed point. First, to see that $v^{\mu}$ is a fixed point, note that if $\left(b, s_{0}\right) \in(B \times S)^{\mu}$ then

$$
T v^{\mu}\left(b, s_{0}\right)=\left(\begin{array}{c}
u\left(e^{\operatorname{def}}\left(s_{0}\right)-\tau\left(b, s_{0}\right)\right)+\beta E\left[V\left(b^{\prime}\left(b, s_{0}\right), s_{1} \mid s_{0}\right)\right] \\
\tau\left(b, s_{0}\right)+b^{\prime}\left(b, s_{0}\right) q\left(b^{\prime}\left(b, s_{0}\right), s_{0}\right)
\end{array}\right),
$$

which is precisely the definition of $v^{\mu}$ on states for realizations in which the stopping time is zero. Alternatively, suppose that $\left(b, s_{0}\right) \in(B \times S) \backslash(B \times S)^{\mu}$. Then by definition of $T$ we have

$$
T\left(\begin{array}{c}
v_{1}^{\mu}\left(b, s_{0}\right) \\
v_{2}^{\mu}\left(b, s_{0}\right)
\end{array}\right)=\left(\begin{array}{c}
u\left(e^{\text {def }}\left(s_{0}\right)\right)+\beta E\left[v_{1}^{\mu}\left(b, s_{1}\right) \mid s_{0}\right] \\
\delta E\left[v_{2}^{\mu}\left(b, s_{1}\right) \mid s_{0}\right]
\end{array}\right) .
$$

Define a stopping time $t^{*}$,such that if $\left(b, s_{0}\right)$ is the initial state, $t^{*}$ is the period in which agreement is reached. That is, $\left(b, s_{t^{*}}\right) \in(B \times S)^{\mu}$ and $\left(b, s_{t}\right) \in(B \times S) \backslash(B \times S)^{\mu}$ for all 
$t<t^{*}$. Then iterating on the operator $T$ we have

$$
\begin{aligned}
& T\left(\begin{array}{c}
v_{1}^{\mu}\left(b, s_{0}\right) \\
v_{2}^{\mu}\left(b, s_{0}\right)
\end{array}\right) \\
= & \left(\begin{array}{c}
u\left(e^{\operatorname{def}}\left(s_{0}\right)\right)+\beta E\left[v_{1}^{\mu}\left(b, s_{1}\right) \mid s_{0}\right] \\
\delta E\left[v_{2}^{\mu}\left(b, s_{1}\right) \mid s_{0}\right]
\end{array}\right) \\
= & \left(\begin{array}{c}
u\left(e^{\operatorname{def}}\left(s_{0}\right)\right)+\beta E\left[\sum_{t=1}^{t^{*}-1} \beta^{t} u\left(e^{\operatorname{def}}\left(s_{t}\right)\right)+\beta^{t^{*}} E\left[v_{1}^{\mu}\left(b, s_{t^{*}}\right) \mid s_{1}\right] \mid s_{0}\right] \\
\delta\left[E\left[E\left[\delta^{t^{*}} v_{2}^{\mu}\left(b, s_{t^{*}}\right) \mid s_{1}\right]\right] \mid s_{0}\right]
\end{array}\right) \\
= & \left(\begin{array}{c}
\left.E\left[\sum_{t=0}^{t^{*}-1} \beta^{t} U\left(e^{\operatorname{def}}\left(s_{t}\right)\right)+\beta^{t^{*}}\left\{U\left(e^{d e f}\left(s_{t^{*}}\right)-\tau\left(b, s_{t^{*}}\right)\right) V\left(b^{\prime}\left(b, s_{t^{*}}\right), s_{t^{*}}\right)\right\} \mid s\right]\right)=v^{\mu} . \\
E\left[\delta^{t^{*}}\left\{\tau\left(b, s_{t^{*}}\right)+b^{\prime}\left(b, s_{t^{*}}\right) q\left(b^{\prime}\left(b, s_{t^{*}}\right), s_{t^{*}}\right)\right\} \mid s\right]
\end{array}\right)
\end{aligned}
$$

Second, to show that $T$ has a unique fixed point it is sufficient to show that $T$ is a contraction on the metric space of functions defined on $B \times S$ taking values in $\mathbb{R}^{2}$ endowed with the sup (or in this case, the max) norm. That is, we require that if $f^{1}$ and $f^{2}$ are each functions mapping $B \times S$ into $\mathbb{R}^{2}$, then

$$
\left\|T\left(f^{1}\right)-T\left(f^{2}\right)\right\|_{\infty} \leq \delta\left\|f^{1}-f^{2}\right\|_{\infty} .
$$

To see this, note that if $(b, s) \in(B \times S)^{\mu}$, then $T f$ is independent of the function $f$ and hence

$$
\left|T f^{1}(b, s)-T f^{2}(b, s)\right|=\max \left\{\left|T f_{1}^{1}(b, s)-T f_{1}^{2}(b, s)\right|,\left|T f_{2}^{1}(b, s)-T f_{2}^{2}(b, s)\right|\right\}=0 .
$$

Otherwise,

$$
\begin{aligned}
& \left|T f^{1}(b, s)-T f^{2}(b, s)\right| \\
= & \max \left\{\left|\beta E\left[f_{1}^{1}\left(b, s^{\prime}\right) \mid s\right]-\beta E\left[f_{1}^{2}\left(b, s^{\prime}\right) \mid s\right]\right|,\left|\delta E\left[f_{2}^{1}\left(b, s^{\prime}\right) \mid s\right]-\delta E\left[f_{2}^{2}\left(b, s^{\prime}\right) \mid s\right]\right|\right\} \\
= & \beta \max \left\{\left|E\left[f_{1}^{1}\left(s^{\prime}\right)-f_{1}^{2}\left(s^{\prime}\right) \mid s\right]\right|,\left|E\left[f_{2}^{1}\left(s^{\prime}\right)-f_{2}^{2}\left(s^{\prime}\right) \mid s\right]\right|\right\} \\
\leq & \beta\left\|f^{1}-f^{2}\right\|_{\infty},
\end{aligned}
$$

where we have exploited our assumption that $\beta<\delta<1$. But then

$$
\left\|T f^{1}-T f^{2}\right\|_{\infty}=\max _{b, s}\left|T f^{1}(b, s)-T f^{2}(b, s)\right| \leq \beta|| f^{1}-f^{2} \|_{\infty} .
$$

Using the result of the previous Lemma, the following theorem establishes an equivalence between SSP payoffs and fixed points of the $\hat{T}$ operator.

Theorem 1. The functions $f=\left(f_{1}, f_{2}\right)$ are SSP payoffs if and only if $\hat{T} f=f$.

Proof. First, suppose that $f$ are SSP payoffs. Fix $(b, s) \in B \times S$. Suppose that no proposal is accepted at $(b, s)$, and the outside option is not taken. Then the SSP payoffs $f$ satisfy the relationships

$$
\begin{aligned}
& f_{1}(b, s)=u\left(e^{\text {def }}(s)\right)+\beta E\left[f_{1}\left(b, s^{\prime}\right) \mid s\right], \\
& f_{2}(b, s)=\delta E\left[f_{2}\left(b, s^{\prime}\right) \mid s\right] .
\end{aligned}
$$


If a proposal is accepted at $(b, s)$, it must be that it gives the agent who receives the proposal at least their reservation utility. If the debtor is proposing, then it must be that the proposal $\left(\tau, b^{\prime}\right)$ satisfies

$$
\tau+b^{\prime} q\left(b^{\prime}, s\right) \geq \min \left\{b, \delta E\left[f_{2}\left(b, s^{\prime}\right) \mid s\right]\right\}=\delta E\left[f_{2}\left(b, s^{\prime}\right) \mid s\right],
$$

while if the creditor is proposing, it must satisfy

$$
\begin{aligned}
& u\left(e^{\operatorname{def}}-\tau\right)+\beta E\left[V\left(b^{\prime}, s^{\prime}\right) \mid s\right] \\
\geq & \max \left\{u\left(e^{\operatorname{def}}(s)\right)+\beta E\left[f_{1}\left(b, s^{\prime}\right) \mid s\right], \begin{array}{c}
\max _{\tau, b^{\prime}} u\left(e^{\operatorname{def}}(s)-\tau\right)+\beta E\left[V\left(b^{\prime}, s^{\prime}\right) \mid s\right] \\
\text { s.t } \tau+b^{\prime} q\left(b^{\prime}, s\right) \geq b
\end{array}\right\} .
\end{aligned}
$$

Moreover, as the proposal is part of a SSP, it must give the proposer the largest payoff over all such feasible proposals. Hence, if the debtor proposes in a state where a proposal is accepted

$$
\begin{aligned}
f_{1}(b, s)= & \max _{\tau, b^{\prime}} u\left(e^{\text {def }}(s)-\tau\right)+\beta E\left[V\left(b, s^{\prime}\right) \mid s\right] \\
& \text { s.t. } \tau+b^{\prime} q\left(b^{\prime}, s\right) \geq \min \left\{b, \delta E\left[f_{2}\left(b, s^{\prime}\right) \mid s\right]\right\}
\end{aligned}
$$

while if a creditor proposes, it must be that

$$
f_{2}(b, s)=\min \left\{b, \begin{array}{l}
\max _{\tau, b^{\prime}} \tau+b^{\prime} q\left(b^{\prime}, s\right) \\
\text { s.t. } u\left(e^{\operatorname{def}}(s)-\tau\right)+\beta E\left[V\left(b^{\prime}, s^{\prime}\right) \mid s\right] \geq u\left(e^{\operatorname{def}}(s)\right)+\beta E\left[f_{1}\left(b, s^{\prime}\right) \mid s\right]
\end{array}\right\} .
$$

Finally, as the proposer can always guarantee themselves their reservation payoff (or the outside option in the case of the debtor) by proposing something that will not be accepted, it must be that

$$
f_{1}(b, s)=\max \left\{\begin{array}{c}
\max _{\tau, b^{\prime}} u\left(e^{\text {def }}(s)-\tau\right)+\beta E\left[V\left(b^{\prime}, s^{\prime}\right) \mid s\right] \\
s . t \tau+b^{\prime} q\left(b^{\prime}, s\right) \geq \min \left\{b, \delta E\left[f_{2}\left(b, s^{\prime}\right) \mid s\right]\right\}
\end{array}, u\left(e^{\text {def }}(s)\right)+\beta E\left[f_{1}\left(b, s^{\prime}\right) \mid s\right]\right\}
$$

when the debtor proposes, and

$$
\begin{aligned}
f_{2}(b, s)= & \max \left\{\operatorname { m i n } \left\{b, \quad \text { s.t } u\left(e^{\text {def }}(s)-\tau\right)+\beta E\left[V\left(b^{\prime}, s^{\prime}\right) \mid s\right] \geq u\left(e^{\operatorname{def}}(s)\right)+\beta E\left[f_{1}\left(b, s^{\prime}\right) \mid s\right]\right.\right. \\
& \left., \delta E\left[f_{2}\left(b, s^{\prime}\right) \mid s\right]\right\}
\end{aligned}
$$

when the creditor proposes. But then $\hat{T} f=f$.

Second, suppose that $\hat{T} f=f$. We will construct a SSP outcome $\left((B \times S)^{\mu}, \mu\right)$ for which $f=v^{\mu}$. We construct $(B \times S)^{\mu}$ by noting that, if for a given $(b, s)$ there exists $\left(\tau, b^{\prime}\right)$ such that

$$
\begin{aligned}
f_{1}(b, s) & =u\left(e^{\operatorname{def}}(s)-\tau\right)+\beta E\left[V\left(b^{\prime}, s^{\prime}\right) \mid s\right] \\
f_{2}(b, s) & =\tau+b^{\prime} q\left(b^{\prime}, s\right),
\end{aligned}
$$

then $(b, s)$ is an agreement state and hence $(b, s) \in(B \times S)^{\mu}$. Then for that state we let

$$
\mu(b, s)=\left(\tau, b^{\prime}\right) .
$$

Otherwise, we say $(b, s) \in(B \times S) \backslash(B \times S)^{\mu}$. 
We need to show that the value of the outcome $\left((B \times S)^{\mu}, \mu\right), v^{\mu}$, is equal to $f$ and that it is a SSP outcome. To show that the value of the outcome is $v^{\mu}$, consider any state $(b, s)$. Since $\hat{T} f=f$, for the non-proposing player we have

$$
\begin{aligned}
& f_{1}(b, s)=u\left(e^{\text {def }}(s)\right)+\beta E\left[f_{1}\left(b, s^{\prime}\right) \mid s\right], \\
& f_{2}(b, s)=\min \left\{b, \delta E\left[f_{2}\left(b, s^{\prime}\right) \mid s\right]\right\}
\end{aligned}
$$

while for the proposing country we have

$$
\hat{T} f_{1}(b, s)=\max \left\{\begin{array}{c}
\max _{\tau, b^{\prime}} u\left(e^{\operatorname{def}}(s)-\tau\right)+\beta E\left[V\left(b^{\prime}, s^{\prime}\right) \mid s\right] \\
s . t \tau+b^{\prime} q\left(b^{\prime}, s\right) \geq \delta E\left[f_{2}\left(b, s^{\prime}\right) \mid s\right]
\end{array}, u\left(e^{\operatorname{def}}(s)\right)+\beta E\left[f_{1}\left(b, s^{\prime}\right) \mid s\right]\right\},
$$

with an analogous result for the creditor. If $\tau+b^{\prime} q\left(b^{\prime}, s\right)=f_{2}(b, s)$, then $(b, s) \in(B \times S)^{\mu}$ by construction and

$$
f_{1}(b, s)=u\left(e^{\operatorname{def}}(s)-\tau\right)+\beta E\left[V\left(b^{\prime}, s^{\prime}\right) \mid s\right] .
$$

If $\tau+b^{\prime} q\left(b^{\prime}, s\right)<f_{2}(b, s)$, then $(b, s) \notin(B \times S)^{\mu}$ and

$$
f_{1}(b, s)=u\left(e^{\operatorname{def}}(s)\right)+\beta E\left[f_{1}\left(b, s^{\prime}\right) \mid s\right] .
$$

but in Lemma 1 we showed that $v^{\mu}$ was the unique function satisfying these conditions. Hence $f=v^{\mu}$.

Finally, to show that $\left((B \times S)^{\mu}, \mu\right)$ is a SSP outcome, consider a strategy designed as follows: (i) if $(b, s) \in(B \times S)^{\mu}$, then propose $\mu(b, s)$, otherwise propose an outcome that delivers the other player strictly less than $v^{\mu}(b, s)$; (ii) accept any proposal as long as it delivers at least $v^{\mu}(b, s)$. To see that this is a subgame perfect equilibrium, consider a node at which a player has yet to propose. $\mu(b, s)$ delivers at least $v^{\mu}(b, s)$ by the previous result and so will be accepted. Moreover, as $\hat{T} v^{\mu}=v^{\mu}$, this proposal maximizes the payoff of the proposer subject to delivering this utility level. Hence a proposer cannot gain by deviating to any other proposal. Next, consider a node at which a proposal has been made. If the proposal gives strictly less than $v^{\mu}(b, s)$, the player can only lose by accepting it. If the proposal gives exactly $v^{\mu}(s)$, then by construction it also delivers exactly the reservation payoff of the agent, which is the value they expect from rejecting the offer. Hence, a one stage rejection of a proposal gives the same expected payoff. Familiar arguments show that by iterating on this argument we can rule out finite stage deviations, while boundedness and discounting rule out infinite deviations.

\section{Existence and Uniqueness of SSP Equilibria of the Bargaining Model}

Next we show that an SSP equilibrium exists, and provide a condition under which the SSP equilibrium is unique. Existence is proven by demonstrating that our $\hat{T}$ mapping operates on a bounded set of functions, and is monotone. Let $\mathcal{F}(B \times S)$ be the space of all functions mapping $B \times S$ into $\mathbb{R}^{2}$, and let $\mathcal{B}(B \times S)$ be the subset of $\mathcal{F}(B \times S)$ that satisfies the following bounds

$$
\begin{aligned}
\min _{s \in S} \frac{u\left(e^{\text {def }}(s)\right)}{1-\delta} & \equiv V_{\min } \leq \min _{(b, s) \in B \times S} f_{1}(b, s) \leq \max _{(b, s) \in B \times S} f_{1}(b, s) \\
& \leq V_{\max } \equiv \max _{\left(b, s, s^{\prime}\right) \in B \times S \times S} u(e(s)-b)+\beta V\left(b, s^{\prime}\right), \\
b_{\min } & \equiv \min B \leq \min _{(b, s) \in B \times S} f_{2}(b, s) \leq \max _{(b, s) \in B \times S} f_{2}(b, s) \leq b_{\max } \equiv \max B .
\end{aligned}
$$


We endow $\mathcal{B}(B \times S)$ with the supremum (in this case, maximum) norm.

Lemma B. 2. The operator $\hat{T}$ maps $\mathcal{B}(B \times S)$ into itself.

Proof. To see that if $f \in \mathcal{B}(B \times S)$ then $\hat{T} f \in \mathcal{B}(B \times S)$, first consider the creditors continuation value function. Fix $b$. Then if $s$ is such that the debtor proposes

$$
\hat{T}_{2}\left(f_{1}, f_{2}\right)(b, s)=\min \left\{b, \delta E\left[f_{2}\left(b, s^{\prime}\right) \mid s\right]\right\} \in\left[b_{\min }, b_{\max }\right] .
$$

If $s$ is such that the creditor proposes

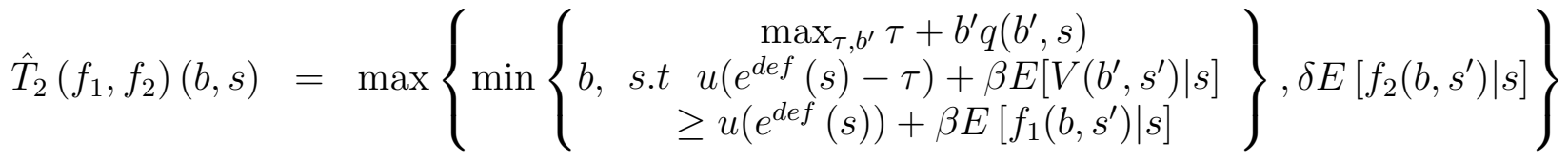

$$
\begin{aligned}
& \leq \max \left\{b, \delta E\left[f_{2}\left(b, s^{\prime}\right) \mid s\right]\right\} \leq b_{\max }
\end{aligned}
$$

and

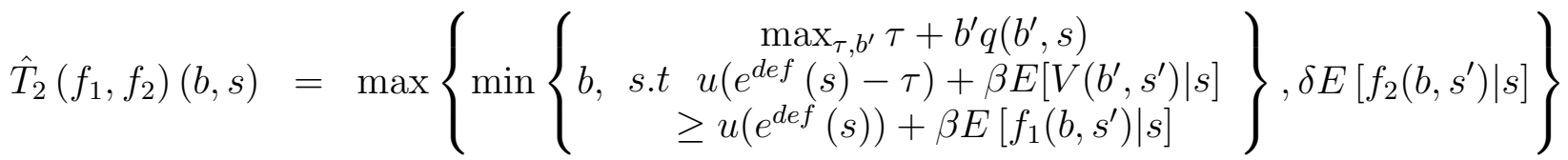

$$
\begin{aligned}
& \geq \delta E\left[f_{2}\left(b, s^{\prime}\right) \mid s\right] \geq b_{\min },
\end{aligned}
$$

since $b_{\min } \leq 0$

Next consider the debtor's continuation value function. Fix $b$. Then if $s$ is such that the creditor proposes

$$
\begin{aligned}
& \hat{T}_{1}\left(f_{1}, f_{2}\right)(b, s) \\
= & \max \left\{u\left(e^{\text {def }}(s)\right)+\beta E\left[f_{1}\left(b, s^{\prime}\right) \mid s\right], \begin{array}{c}
\left.\max _{\tau, b^{\prime}} u\left(e^{\text {def }}(s)-\tau\right)+\beta E\left[V\left(b^{\prime}, s^{\prime}\right) \mid s\right]\right\} \\
\text { s.t } \tau+b^{\prime} q\left(b^{\prime}, s\right) \geq b
\end{array}\right\} \\
\leq & \max \left\{u\left(e^{\text {def }}(s)-b_{\min }\right)+\beta V_{\max }, V_{\max }\right\} \leq V_{\max },
\end{aligned}
$$

and

$$
\begin{aligned}
\hat{T}_{1}\left(f_{1}, f_{2}\right)(b, s) & =\max \left\{u\left(e^{\operatorname{def}}(s)\right)+\beta E\left[f_{1}\left(b, s^{\prime}\right) \mid s\right], \begin{array}{c}
\max _{\tau, b^{\prime}} u\left(e^{\operatorname{def}}(s)-\tau\right)+\beta E\left[V\left(b^{\prime}, s^{\prime}\right) \mid s\right] \\
\text { s.t } \tau+b^{\prime} q\left(b^{\prime}, s\right) \geq b
\end{array}\right\} \\
& \geq u\left(e^{d e f}(s)\right)+\beta E\left[f_{1}\left(b, s^{\prime}\right) \mid s\right] \geq V_{\min } .
\end{aligned}
$$

If $s$ is such that the debtor proposes

$$
\begin{aligned}
& \hat{T}_{1}\left(f_{1}, f_{2}\right)(b, s) \\
= & \max \left\{\begin{array}{c}
\max _{\tau, b^{\prime}} u\left(e^{\operatorname{def}}(s)-\tau\right)+\beta E\left[V\left(b^{\prime}, s^{\prime}\right) \mid s\right] \\
s . t \quad \tau+b^{\prime} q\left(b^{\prime}, s\right) \geq \min \left\{b, \delta E\left[f_{2}\left(b, s^{\prime}\right) \mid s\right]\right\},
\end{array}, u\left(e^{\operatorname{def}}(s)\right)+\beta E\left[f_{1}\left(b, s^{\prime}\right) \mid s\right]\right\} \\
\geq & u\left(e^{\operatorname{def}}(s)\right)+\beta E\left[f_{1}\left(b, s^{\prime}\right) \mid s\right] \geq V_{\min },
\end{aligned}
$$


and

$$
\begin{aligned}
& \hat{T}_{1}\left(f_{1}, f_{2}\right)(b, s) \\
= & \max \left\{\begin{array}{c}
\max _{\tau, b^{\prime}} u\left(e^{\text {def }}(s)-\tau\right)+\beta E\left[V\left(b^{\prime}, s^{\prime}\right) \mid s\right] \\
s . t \tau+b^{\prime} q\left(b^{\prime}, s\right) \geq \min \left\{b, \delta E\left[f_{2}\left(b, s^{\prime}\right) \mid s\right]\right\},
\end{array}, u\left(e^{\text {def }}(s)\right)+\beta E\left[f_{1}\left(b, s^{\prime}\right) \mid s\right]\right\} \\
\leq & \max \left\{V_{\max }, u\left(e^{\operatorname{def}}(s)-b_{\min }\right)+\beta V_{\max }\right\} \leq V_{\max } .
\end{aligned}
$$

Lemma B. 3. The operator $\hat{T}$ is monotone. That is, if there exists functions $f_{1}, f_{1}^{\prime}, f_{2}, f_{2}^{\prime} \in$ $\mathcal{F}(B \times S)$ such that $f_{1}>f_{1}^{\prime}$ and $f_{2}^{\prime}>f_{2}$ then

$$
\hat{T}_{1}\left(f_{1}, f_{2}\right) \geq \hat{T}_{1}\left(f_{1}^{\prime}, f_{2}^{\prime}\right) \text { and } \hat{T}_{2}\left(f_{1}, f_{2}\right) \leq \hat{T}_{2}\left(f_{1}^{\prime}, f_{2}^{\prime}\right) .
$$

Proof. Take the functions $f_{1}, f_{1}^{\prime}, f_{2}, f_{2}^{\prime}$ as given. Fix $b$ and consider a state $s$ in which the debtor proposes. Then it follows immediately that the creditor's value satisfies

$$
\hat{T}_{2}\left(f_{1}, f_{2}\right)(b, s)=\min \left\{b, \delta E\left[f_{2}\left(b, s^{\prime}\right) \mid s\right]\right\} \leq \min \left\{b, \delta E\left[f_{2}^{\prime}\left(b, s^{\prime}\right) \mid s\right]\right\}=\hat{T}_{2}\left(f_{1}^{\prime}, f_{2}^{\prime}\right)(b, s) .
$$

For the debtor's value, we have

$$
\begin{aligned}
& \hat{T}_{1}\left(f_{1}, f_{2}\right)(b, s) \\
= & \max \left\{\begin{array}{c}
\max _{\tau, b^{\prime}} u\left(e^{\text {def }}(s)-\tau\right)+\beta E\left[V\left(b^{\prime}, s^{\prime}\right) \mid s\right] \\
s . t \tau+b^{\prime} q\left(b^{\prime}, s\right) \geq \min \left\{b, \delta E\left[f_{2}\left(b, s^{\prime}\right) \mid s\right]\right\},
\end{array}, u\left(e^{\text {def }}(s)\right)+\beta E\left[f_{1}\left(b, s^{\prime}\right) \mid s\right]\right\} \\
\geq & \max \left\{\begin{array}{c}
\max _{\tau, b^{\prime}} u\left(e^{\operatorname{def}}(s)-\tau\right)+\beta E\left[V\left(b^{\prime}, s^{\prime}\right) \mid s\right] \\
s . t \tau+b^{\prime} q\left(b^{\prime}, s\right) \geq \min \left\{b, \delta E\left[f_{2}^{\prime}\left(b, s^{\prime}\right) \mid s\right]\right\},
\end{array}, u\left(e^{\text {def }}(s)\right)+\beta E\left[f_{1}^{\prime}\left(b, s^{\prime}\right) \mid s\right]\right\} \\
= & \hat{T}_{1}\left(f_{1}^{\prime}, f_{2}^{\prime}\right)(b, s) .
\end{aligned}
$$

As this is true for all $(b, s)$, monotonicity holds for this region of the state space.

Now consider $s$ such that the creditor proposes. The debtor's value satisfies

$$
\begin{aligned}
& \hat{T}_{1}\left(f_{1}, f_{2}\right)(b, s) \\
= & \max \left\{u\left(e^{\text {def }}(s)\right)+\beta E\left[f_{1}\left(b, s^{\prime}\right) \mid s\right], \begin{array}{c}
\max _{\tau, b^{\prime}} u\left(e^{\operatorname{def}}(s)-\tau\right)+\beta E\left[V\left(b^{\prime}, s^{\prime}\right) \mid s\right] \\
\text { s.t } \tau+b^{\prime} q\left(b^{\prime}, s\right) \geq b
\end{array}\right\} \\
\geq & \max \left\{u\left(e^{\operatorname{def}}(s)\right)+\beta E\left[f_{1}^{\prime}\left(b, s^{\prime}\right) \mid s\right], \begin{array}{cc}
\max _{\tau, b^{\prime}} u\left(e^{\operatorname{def}}(s)-\tau\right)+\beta E\left[V\left(b^{\prime}, s^{\prime}\right) \mid s\right] \\
\text { s.t } \tau+b^{\prime} q\left(b^{\prime}, s\right) \geq b
\end{array}\right\} \\
= & \hat{T}_{2}\left(f_{1}^{\prime}, f_{2}^{\prime}\right)(b, s) .
\end{aligned}
$$


Similarly, the creditor's value satisfies

$$
\begin{aligned}
& \hat{T}_{2}\left(f_{1}, f_{2}\right)(b, s) \\
& =\max \left\{\min \left\{\begin{array}{c}
\max _{\tau, b^{\prime}} \tau+b^{\prime} q\left(b^{\prime}, s\right) \\
\text { s.t } u\left(e^{\operatorname{def}(s)-\tau)+\beta E\left[V\left(b^{\prime}, s^{\prime}\right) \mid s\right]}\right. \\
\geq u\left(e^{\operatorname{def}(s))+\beta E\left[f_{1}\left(b, s^{\prime}\right) \mid s\right]}\right.
\end{array}\right\}, \delta E\left[f_{2}\left(b, s^{\prime}\right) \mid s\right]\right\} \\
& \leq \max \left\{\min \left\{\begin{array}{c}
\max _{\tau, b^{\prime}} \tau+b^{\prime} q\left(b^{\prime}, s\right) \\
b, \text { s.t } u\left(e^{\operatorname{def}}(s)-\tau\right)+\beta E\left[V\left(b^{\prime}, s^{\prime}\right) \mid s\right] \\
\geq u\left(e^{\operatorname{def}}(s)\right)+\beta E\left[f_{1}\left(b, s^{\prime}\right) \mid s\right]
\end{array}\right\}, \delta E\left[f_{2}^{\prime}\left(b, s^{\prime}\right) \mid s\right]\right\} \\
& \leq \max \left\{\min \left\{\begin{array}{c}
b, \text { s.t } u\left(e^{\operatorname{def}(s)-\tau)+\beta E\left[V\left(b^{\prime}, s^{\prime}\right) \mid s\right]}\right. \\
\geq u\left(e^{\operatorname{def}}(s)\right)+\beta E\left[f_{1}^{\prime}\left(b, s^{\prime}\right) \mid s\right]
\end{array}\right\}, \delta E\left[f_{2}^{\prime}\left(b, s^{\prime}\right) \mid s\right]\right\} \\
& =\hat{T}_{2}\left(f_{1}^{\prime}, f_{2}^{\prime}\right)(b, s),
\end{aligned}
$$

where the last inequality comes from the fact that $f_{1}^{\prime} \leq f_{1}$ which loosens the constraint on the creditor's maximization problem and thus weakly increases the value of the program.

The proof of existence then follows by applying the $\hat{T}$ operator to a suitable initial $f^{0}$ within the space $\mathcal{B}(B \times S)$.

Theorem 2. An SSP equilbrium exists.

Proof. Choose $f^{0}=\left(f_{1}^{0}, f_{2}^{0}\right)$ such that for all $(b, s), f_{1}^{0}(b, s)=V_{\max }$ and $f_{2}^{0}(b, s)=b_{\min }$ and successively apply the operator $\hat{T}$ to obtain the sequence of functions $\left\{f^{n}\right\}_{n=0}^{\infty}$ where $f^{n+1}=$ $\hat{T} f^{n}$. By Lemma $4 \hat{T}$ is monotone, and by Lemma $3 \hat{T}$ maps $\mathcal{B}(B \times S)$ into itself, so that this is a monotone sequence of functions in $\mathcal{B}(B \times S)$. Hence, the sequence converges to a SSP equilibrium values and by Theorem 2 and Lemma 1 there exists a SSP equilibrium.

The following theorem provides bounds on the rate at which resources can be transformed into utility, and the rate at which utility can be transformed into resources which, if satisfied, are sufficient to establish uniqueness of this fixed point.

Theorem 3. Let $u: \mathbf{R} \rightarrow \mathbf{R}$ be differentiable. If there exists $K_{L}>\beta$ and $K_{U}<1 / \delta$ such that $K_{L} \leq u^{\prime}(c) \leq K_{U}$, for all $c$, then the $S S P$ equilibrium values are unique.

Proof. Let $f^{1}=\left(f_{1}^{1}, f_{2}^{1}\right)$ and $f^{2}=\left(f_{1}^{2}, f_{2}^{2}\right)$ be elements of $\mathcal{B}(B \times S)$. To establish the result, we need to show that there exists a $\gamma \in(0,1)$ such that

$$
\begin{aligned}
& \left\|\hat{T} f^{1}-\hat{T} f^{2}\right\|_{\infty} \\
= & \max _{(b, s) \in B \times S}\left\{\max \left\{\left|\left(\hat{T} f_{1}^{1}\right)(b, s)-\left(\hat{T} f_{1}^{2}\right)(b, s)\right|,\left|\left(\hat{T} f_{2}^{1}\right)(b, s)-\left(\hat{T} f_{2}^{2}\right)(b, s)\right|\right\}\right\} \\
\leq & \gamma \max _{(b, s) \in B \times S}\left\{\max \left\{\left|f_{1}^{1}(b, s)-f_{1}^{2}(b, s)\right|,\left|f_{2}^{1}(b, s)-f_{2}^{2}(b, s)\right|\right\}\right\} \\
\leq & \gamma\left\|f^{1}-f^{2}\right\|_{\infty} .
\end{aligned}
$$


The argument varies according to whether the outside offer is taken, no proposal is accepted, or a proposal is accepted.

First, fix $(b, s)$ and consider the case in which $s$ is such that the debtor proposes. If the outside option is taken for both $f^{1}$ and $f^{2}$, then we have

$$
\left|\left(\hat{T} f^{1}\right)(b, s)-\left(\hat{T} f^{2}\right)(b, s)\right|=0
$$

since the creditor's payoff is $b$, and the debtor's payoff solves

$$
\begin{gathered}
\max _{\tau, b^{\prime}} u\left(e^{\text {def }}(s)-\tau\right)+\beta E\left[V\left(b^{\prime}, s^{\prime}\right) \mid s\right] \\
\text { s.t } \tau+b^{\prime} q\left(b^{\prime}, s\right) \geq b,
\end{gathered}
$$

neither or which depends on the continuation values $f^{1}$ and $f^{2}$.

If no proposal is accepted for both $f^{1}$ and $f^{2}$, then we have

$$
\left|\left(\hat{T} f_{2}^{1}\right)(b, s)-\left(\hat{T} f_{2}^{2}\right)(b, s)\right|=\left|\delta E\left[f_{2}^{1}\left(b, s^{\prime}\right) \mid s\right]-\delta E\left[f_{2}^{2}\left(b, s^{\prime}\right) \mid s\right]\right| \leq \delta\left\|f_{2}^{1}-f_{2}^{2}\right\|_{\infty},
$$

for the creditor's continuation value function, and

$$
\begin{aligned}
& \left|\left(\hat{T} f_{1}^{1}\right)(b, s)-\left(\hat{T} f_{1}^{2}\right)(b, s)\right| \\
= & \left|u\left(e^{\operatorname{def}}(s)\right)+\beta E\left[f_{1}\left(b, s^{\prime}\right) \mid s\right]-u\left(e^{\operatorname{def}}(s)\right)-\beta E\left[f_{1}\left(b, s^{\prime}\right) \mid s\right]\right| \\
= & \beta\left|E\left[f_{1}\left(b, s^{\prime}\right) \mid s\right]-E\left[f_{1}\left(b, s^{\prime}\right) \mid s\right]\right| \\
\leq & \beta\left\|f_{1}^{1}-f_{1}^{2}\right\|_{\infty} .
\end{aligned}
$$

for the debtor's continuation value function.

If a proposal is accepted for both $f^{1}$ and $f^{2}$, consider first the case in which $s$ is such that the debtor proposes. In this case, the creditor's continuation values satisfy

$$
\left|\left(\hat{T} f_{2}^{1}\right)(b, s)-\left(\hat{T} f_{2}^{2}\right)(b, s)\right|=\left|\delta E\left[f_{2}^{1}\left(b, s^{\prime}\right) \mid s\right]-\delta E\left[f_{2}^{2}\left(b, s^{\prime}\right) \mid s\right]\right| \leq \delta|| f_{2}^{1}-f_{2}^{2} \|_{\infty} .
$$

Using this fact, the debtor's continuation values satisfy

$$
\begin{aligned}
& \left|\left(\hat{T} f_{1}^{1}\right)(b, s)-\left(\hat{T} f_{1}^{2}\right)(b, s)\right| \\
& =\mid \begin{array}{c}
\max _{\tau, b^{\prime}} u\left(e^{\operatorname{def}}(s)-\tau\right)+\beta E\left[V\left(b^{\prime}, s^{\prime}\right) \mid s\right] \\
\text { s.t } \tau+b^{\prime} q\left(b^{\prime}, s\right) \geq \delta E\left[f_{2}^{1}\left(b, s^{\prime}\right) \mid s\right]
\end{array} \\
& { }_{-} \max _{\tau, b^{\prime}} u\left(e^{\operatorname{def}}(s)-\tau\right)+\beta E\left[V\left(b^{\prime}, s^{\prime}\right) \mid s\right] \\
& \text { s.t } \tau+b^{\prime} q\left(b^{\prime}, s\right) \geq \delta E\left[f_{2}^{2}\left(b, s^{\prime}\right) \mid s\right] \\
& \leq \mid \begin{array}{c}
\max _{\tau, b^{\prime}} u\left(e^{\text {def }}(s)-\tau\right)+\beta E\left[V\left(b^{\prime}, s^{\prime}\right) \mid s\right] \\
\text { s.t } \tau+b^{\prime} q\left(b^{\prime}, s\right) \geq \delta E\left[f_{2}^{2}\left(b, s^{\prime}\right) \mid s\right]+\delta\left\|f_{2}^{1}-f_{2}^{2}\right\|_{\infty}
\end{array} \\
& \begin{array}{c}
\max _{\tau, b^{\prime}} u\left(e^{\operatorname{def}}(s)-\tau\right)+\beta E\left[V\left(b^{\prime}, s^{\prime}\right) \mid s\right] \\
\text { s.t } \tau+b^{\prime} q\left(b^{\prime}, s\right) \geq \delta E\left[f_{2}^{2}\left(b, s^{\prime}\right) \mid s\right]
\end{array} \mid .
\end{aligned}
$$

Now suppose that $\left(\tau^{2}, b^{2}\right)$ attain the maximum for $f_{2}^{2}$. Then exploiting the fact that $U$ is defined over negative consumptions and that its slope is bounded we can find a feasible $\hat{\tau}$ 
such that

$$
\hat{\tau}=\tau^{2}+\delta\left\|f_{2}^{1}-f_{2}^{2}\right\|_{\infty}
$$

yielding

$$
\begin{aligned}
& \left|\left(\hat{T} f_{1}^{1}\right)(b, s)-\left(\hat{T} f_{1}^{2}\right)(b, s)\right| \\
\leq & \mid u\left(e^{\operatorname{def}}(s)-\tau^{2}+\delta\left\|f_{2}^{1}-f_{2}^{2}\right\|_{\infty}\right)+\beta E\left[V\left(b^{2}, s^{\prime}\right) \mid s\right]-u\left(e^{\operatorname{def}}(s)-\tau^{2}\right) \\
& -\beta E\left[V\left(b^{2}, s^{\prime}\right) \mid s\right] \mid \\
\leq & \left|u\left(e^{\operatorname{def}}(s)-\tau^{2}\right)+u^{\prime}\left(e^{\operatorname{def}}(s)-\tau^{2}\right) \delta\left\|f_{2}^{1}-f_{2}^{2}\right\|_{\infty}-u\left(e^{\operatorname{def}}(s)-\tau^{2}\right)\right| \\
\leq & \delta K_{U}\left\|f_{2}^{1}-f_{2}^{2}\right\|_{\infty} .
\end{aligned}
$$

Next consider the case in which $s$ is such that the creditor proposes. In this case, the debtor's continuation values satisfy

$$
\begin{aligned}
& \left|\left(\hat{T} f_{1}^{1}\right)(b, s)-\left(\hat{T} f_{1}^{2}\right)(b, s)\right| \\
= & \left|\beta E\left[f_{1}^{1}\left(b, s^{\prime}\right) \mid s\right]-\beta E\left[f_{1}^{2}\left(b, s^{\prime}\right) \mid s\right]\right| \leq \beta\left\|f_{1}^{1}-f_{1}^{2}\right\|_{\infty} .
\end{aligned}
$$

Using this fact, the creditor's continuation values satisfy

$$
\begin{aligned}
& \left|\left(\hat{T} f_{2}^{1}\right)(b, s)-\left(\hat{T} f_{2}^{2}\right)(b, s)\right| \\
& =\left|\begin{array}{cc}
\max _{\tau, b^{\prime}} \tau+b^{\prime} q\left(b^{\prime}, s\right) & \max _{\tau, b^{\prime}} \tau+b^{\prime} q\left(b^{\prime}, s\right) \\
\text { s.t } u\left(e^{\operatorname{def}}(s)-\tau\right)+\beta E\left[V\left(b^{\prime}, s^{\prime}\right) \mid s\right] & -s . t \\
\geq u\left(e^{\operatorname{def}}(s)\right)+\beta E\left[f_{1}^{1}\left(b, s^{\prime}\right) \mid s\right] & \geq u\left(e^{\operatorname{def}}(s)\right)+\beta E\left[f_{1}^{2}\left(b, s^{\prime}\right) \mid s\right]
\end{array}\right| \\
& \leq \mid \begin{array}{c}
\max _{\tau, b^{\prime}} \tau+b^{\prime} q\left(b^{\prime}, s\right) \\
\text { s.t } u\left(e^{\text {def }}(s)-\tau\right)+\beta E\left[V\left(b^{\prime}, s^{\prime}\right) \mid s\right] \\
\geq u\left(e^{\text {def }}(s)\right)+\beta E\left[f_{1}^{1}\left(b, s^{\prime}\right) \mid s\right]
\end{array} \\
& \begin{array}{c}
\max _{\tau, b^{\prime}} \tau+b^{\prime} q\left(b^{\prime}, s\right) \\
\text { s.t } u\left(e^{\operatorname{def}}(s)-\tau\right)+\beta E\left[V\left(b^{\prime}, s^{\prime}\right) \mid s\right] \\
\geq u\left(e^{\operatorname{def}}(s)\right)+\beta E\left[f_{1}^{1}\left(b, s^{\prime}\right) \mid s\right]+\beta\left\|f_{1}^{1}-f_{1}^{2}\right\|_{\infty}
\end{array}
\end{aligned}
$$

Now suppose that $\left(\tau^{1}, b^{1}\right)$ attain the maximum for $f_{1}^{1}$. Then there exists a $\hat{\tau}$ such that

$$
\left|\hat{\tau}-\tau^{1}\right| \leq \beta K_{L}\left\|f_{1}^{1}-f_{1}^{2}\right\|_{\infty}
$$

and that $\left(\hat{\tau}, b^{2}\right)$ is feasible for $f_{1}^{1}$ and so

$$
\left|\left(\hat{T} f_{2}^{1}\right)(b, s)-\left(\hat{T} f_{2}^{2}\right)(b, s)\right| \leq \beta \frac{1}{K_{L}}\left\|f_{1}^{1}-f_{1}^{2}\right\|_{\infty} .
$$

It remains to consider cases that involve combinations of the outside option, no proposal being accepted, and a proposal being accepted. Suppose the outside option is taken for one of the $f^{i}$ and no proposal is accepted for $f^{-i}$. The argument is analogous regardless of whether the debtor proposes or the creditor proposes at $s$. Without loss of generality we 
can order the creditor's continuation value functions such that

$$
\begin{aligned}
\left|\left(\hat{T} f_{2}^{1}\right)(b, s)-\left(\hat{T} f_{2}^{2}\right)(b, s)\right| & =\left|b-\delta E\left[f_{2}^{2}\left(b, s^{\prime}\right) \mid s\right]\right| \\
& \leq\left|\delta E\left[f_{2}^{1}\left(b, s^{\prime}\right) \mid s\right]-\delta E\left[f_{2}^{2}\left(b, s^{\prime}\right) \mid s\right]\right| \\
& \leq \delta\left\|f_{2}^{1}-f_{2}^{2}\right\|_{\infty},
\end{aligned}
$$

while for the debtor, if we define

$$
V^{o o}(b, s)=\begin{gathered}
\max _{\tau, b^{\prime}} u\left(e^{\text {def }}(s)-\tau\right)+\beta E\left[V\left(b^{\prime}, s^{\prime}\right) \mid s\right] \\
\text { s.t } \tau+b^{\prime} q\left(b^{\prime}, s\right) \geq b
\end{gathered}
$$

we have

$$
\begin{aligned}
& \left|\left(\hat{T} f_{1}^{1}\right)(b, s)-\left(\hat{T} f_{1}^{2}\right)(b, s)\right| \\
= & \left|V^{o o}(b, s)-u\left(e^{\operatorname{def}}(s)\right)+\beta E\left[f_{1}^{2}\left(b, s^{\prime}\right) \mid s\right]\right| \\
\leq & \left|u\left(e^{\operatorname{def}}(s)\right)+\beta E\left[f_{1}^{2}\left(b, s^{\prime}\right) \mid s\right]-u\left(e^{\operatorname{def}}(s)\right)-\beta E\left[f_{1}^{1}\left(b, s^{\prime}\right) \mid s\right]\right| \\
\leq & \beta\left\|f_{1}^{1}-f_{1}^{2}\right\|_{\infty} .
\end{aligned}
$$

where the first inequality follows from the fact that the debtor did not take the outside option for $f^{2}$ and the fact that the value of the outside option is independent of the continuation values.

Now suppose the outside option is taken for one of the $f^{i}$ and a proposal is accepted for $f^{-i}$. If $s$ is such that the debtor proposes, then the argument for the creditor is the same as in the previous case since they earn their autarky value from an accepted proposal. For the debtor, we have

$$
\begin{aligned}
& \left|\left(\hat{T} f_{1}^{1}\right)(b, s)-\left(\hat{T} f_{1}^{2}\right)(b, s)\right| \\
& =\left|\begin{array}{c}
\max _{\tau, b^{\prime}} u\left(e^{\text {def }}(s)-\tau\right)+\beta E\left[V\left(b^{\prime}, s^{\prime}\right) \mid s\right] \\
s . t \tau+b^{\prime} q\left(b^{\prime}, s\right) \geq \delta E\left[f_{2}^{1}\left(b, s^{\prime}\right) \mid s\right]
\end{array}-V^{o o}(b, s)\right| \\
& \leq\left|\begin{array}{cc}
\max _{\tau, b^{\prime}} u\left(e^{\operatorname{def}}(s)-\tau\right)+\beta E\left[V\left(b^{\prime}, s^{\prime}\right) \mid s\right] & \max _{\tau, b^{\prime}} u\left(e^{\operatorname{def}}(s)-\tau\right)+\beta E\left[V\left(b^{\prime}, s^{\prime}\right) \mid s\right] \\
\text { s.t } \tau+b^{\prime} q\left(b^{\prime}, s\right) \geq \delta E\left[f_{2}^{1}\left(b, s^{\prime}\right) \mid s\right] & \text { s.t } \tau+b^{\prime} q\left(b^{\prime}, s\right) \geq \delta E\left[f_{2}^{2}\left(b, s^{\prime}\right) \mid s\right]
\end{array}\right| \\
& \leq \delta K_{U}\left\|f_{2}^{1}-f_{2}^{2}\right\|_{\infty},
\end{aligned}
$$

where the first inequality follows from the fact that the debtor did not take the outside option for $f^{2}$. If $s$ is such that the creditor proposes, the argument for the debtor's continuation value function is the same as in the previous case because the debtor receives their autarky value from an accepted proposal. For the creditor, the result follows from an argument similar to the debtor proposer case.

Finally, consider the case where no agreement occurs for $f^{1}$ and an agreement occurs for $f^{2}$. Non-proposers receive their autarky values in both cases, implying no difference in continuation value functions under the $\hat{T}$ operator. For the proposer, the fact that no agreement is chosen over agreement for $f^{2}$ means we can apply the same argument as in the previous case.

Since the result holds for arbitrary $(b, s)$, the operator $T$ is a contraction with modulus

$$
\gamma=\max \left\{\delta, \beta, \delta K_{U}, \beta / K_{L}\right\}
$$




\section{B Solution to the Borrowing Problem}

In this subsection, we prove the following theorem:

Theorem 4. Given $\left(\tilde{V}^{D}(b, s), \tilde{W}(b, s)\right) \in \mathcal{B}(B \times S)$ and $q(b, s) \in \mathcal{Q}(B \times S)$, there exists a value function for the country, $V(b, s)$, and an equilibrium bond price function $q(b, s) \in$ $\mathcal{Q}(B \times S)$, that solve the borrowing problem.

The proof proceeds by establishing the following two Lemmata. The first takes the bond price function as given and establishes the existence of a unique solution to the country's problem.

Lemma B. 4. Given $\left(\tilde{V}^{D}(b, s), \tilde{W}(b, s)\right) \in \mathcal{B}(B \times S)$ and $q(b, s) \in \mathcal{Q}(B \times S)$, there exists a unique solution to the country's borrowing problem, $V(b, s)$.

Proof. Let $\mathcal{G}(B \times S)$ be the space of all real functions on $B \times S$, bounded below by $\tilde{V}^{D}(b, s)$, and above by $U\left(\max _{s \in S} e(s)-b_{\max }+b_{\min } /\left(1+r^{w}\right)\right) /(1-\beta)$. It is straightforward to show that $T^{V}$ maps $\mathcal{G}(B \times S)$ into itself.

For any $f \in \mathcal{G}(B \times S)$ define the operator $T^{V}$ by

$$
\left(T^{V} f\right)(b, s)=\max \left\{\begin{array}{c}
\max _{c, b^{\prime} \in B} U(c)+\beta \sum_{s^{\prime} \in S} \pi\left(s^{\prime} \mid s\right) f\left(b^{\prime}, s^{\prime}\right), \tilde{V}^{D}(b, s) \\
\text { s.t. } c-q\left(b^{\prime}, s\right) b^{\prime} \leq e(s)+b .
\end{array}\right.
$$

First, we show that the operator $T^{V}$ is monotone. Let $f^{1}, f^{2} \in \mathcal{G}(B \times S)$ such that $f^{1} \geq f^{2}$. Then for all $(b, s)$

$$
\begin{aligned}
\left(T^{V} f^{1}\right)(b, s) & =\max \left\{\begin{array}{c}
\left.\max _{c, b^{\prime} \in B} U(c)+\beta \sum_{s^{\prime} \in S} \pi\left(s^{\prime} \mid s\right) f^{1}\left(b^{\prime}, s^{\prime}\right), \tilde{V}^{D}(b, s)\right\} \\
\text { s.t. } c-q\left(b^{\prime}, s\right) b^{\prime} \leq e(s)+b .
\end{array}\right. \\
& \geq \max \left\{\begin{array}{c}
\left.\max _{c, b^{\prime} \in B} U(c)+\beta \sum_{s^{\prime} \in S} \pi\left(s^{\prime} \mid s\right) f^{2}\left(b^{\prime}, s^{\prime}\right), \tilde{V}^{D}(b, s)\right\} \\
\text { s.t. } c-q\left(b^{\prime}, s\right) b^{\prime} \leq e(s)+b .
\end{array}\right. \\
& \geq\left(T^{V} f^{2}\right)(b, s) .
\end{aligned}
$$

Next, we show that the operator $T^{V}$ satisfies the discounting property. Let $a \in R$. Then for all $f \in \mathcal{G}(B \times S)$ and all $(b, s)$ we have

$$
\begin{aligned}
& \left|T^{V}(f+a)(b, s)-T^{V}(f)(b, s)\right| \\
& =\left|\max \left\{\begin{array}{c}
\max _{c, b^{\prime} \in B} U(c)+\beta \sum_{s^{\prime} \in S} \pi\left(s^{\prime} \mid s\right) f\left(b^{\prime}, s^{\prime}\right)+\beta a \\
\text { s.t. } c-q\left(b^{\prime}, s\right) b^{\prime} \leq e(s)+b
\end{array}, \tilde{V}^{D}(b, s)\right\}-T^{V}(f)(b, s)\right| \\
& \leq\left|\max \left\{\begin{array}{c}
\max _{c, b^{\prime} \in B} U(c)+\beta \sum_{s^{\prime} \in S} \pi\left(s^{\prime} \mid s\right) f\left(b^{\prime}, s^{\prime}\right), \tilde{V}^{D}(b, s) \\
\text { s.t. } c-q\left(b^{\prime}, s\right) b^{\prime} \leq e(s)+b
\end{array}\right\}+\beta a-T^{V}(f)(b, s)\right| \\
& =\beta a \text {. }
\end{aligned}
$$

Hence, $T^{V}$ is a contraction with modulus $\beta$, and there exists a unique fixed point in $\mathcal{G}(B \times S)$.

The second Lemma constructs a new operator and shows that, in combination with the result of the first Lemma, that the composition of these operators is monotone, and hence that an equilibrium exists. 
Lemma B. 5. Given $\left(\tilde{V}^{D}(b, s), \tilde{W}(b, s)\right) \in \mathcal{B}(B \times S)$, there exists an equilibrium bond price function $q(b, s) \in \mathcal{Q}(B \times S)$.

Proof. For any $g^{n} \in \mathcal{Q}(B \times S)$, define the operator $T^{q}$ as follows. First, given $g^{n}$, apply the operator $T^{V}$ (which is defined for a given $g$ ) until convergence to $V^{n}$ with associated $\left(V^{R}\right)^{n}$. Then define

$$
\phi^{n}(b, s)=\left\{\begin{array}{ll}
1 & \text { if } \quad \tilde{V}^{D}(b, s)>\left(V^{R}\right)^{n}(b, s) \\
0 & \text { if } \quad \tilde{V}^{D}(b, s) \leq\left(V^{R}\right)^{n}(b, s)
\end{array},\right.
$$

which embodies the behavioral assumption that when indifferent between default and repayment the country always repays, from which can be constructed the default probability

$$
p^{n}(b, s)=\sum_{b \in B, s^{\prime} \in S} \phi^{n}\left(b, s^{\prime}\right) \pi\left(s^{\prime} \mid s\right)
$$

and a new bond price function

$$
g^{n}(b, s)=\frac{1-p(b, s)+p(b, s) \sum_{s^{\prime} \in S} \pi\left(s^{\prime} \mid s\right) \tilde{W}\left(b, s^{\prime}\right) / b}{1+r^{w}},
$$

which is an element of $\mathcal{Q}(B \times S)$ given the bounds on $\tilde{W}(b, s)$.

Then define the sequence $\left\{g^{n}\right\}_{n=0}^{\infty}$ by applying $T^{q}$ successively from the initial $g^{0}=$ $1 /\left(1+r^{w}\right)$. To see that this is a monotone sequence in $\mathcal{Q}(B \times S)$, note that $g^{1} \leq g^{0}$ and moreover that $\phi^{n}(b, s)=0$ whenever $b \leq 0$. Hence, the interest rate on borrowings is increasing at each stage, while the interest rate on savings is unchanged, and consequently the fixed points of the associated $T^{V}$ operators are ordered. But this produces an ordered sequence of default probabilities $p^{n}$ and, given our restriction on $\tilde{W}(b, s)$, a monotonically decreasing sequence of $g^{n}$. As this sequence is bounded below by zero, it converges to a fixed point in $\mathcal{Q}(B \times S)$.

\section{C Existence of Equilibrium}

Theorem 5. There exists an equilibrium of our borrowing economy.

Proof. Let $q \in \mathcal{Q}(B \times S)$ and $\left(V^{D}, W\right) \in \mathcal{B}(B \times S)$. We construct the first part of our mapping, $\mathcal{H}_{1}\left(V^{D}, q\right)$ as follows. Fix $(b, s)$ and think of the $q\left(b^{\prime}, s\right)$ and $V^{D}(b, s)$ as a set of $N_{b}+1$ parameters for the country's borrowing problem. Let $C(X)$ be the set of continuous and bounded functions defined on $X=\left[0,1 /\left(1+r^{w}\right)\right]^{N_{b}+1} \times\left[V_{\min }, V_{\max }\right]$. Let $f \in \mathcal{C}(X)$ and define the operator $\hat{T}^{V}$ by

$$
\left(\hat{T}^{V}\right) f=\max \left\{\max _{b^{\prime} \in B} u\left(e(s)-b+b^{\prime} q\left(b^{\prime}, s\right)\right)+\beta E\left[V\left(b^{\prime}, s^{\prime}\right) \mid s\right], \tilde{V}^{D}(b, s)\right\} .
$$

Next define $H_{1}\left(T^{V}, q\right)$ as the fixed point of the bargaining operator, given a default value of $T^{V}$ and a bond price of $q$.

The finiteness of $B$ ensures that a solution to the country's borrowing problem exists, and that it is bounded, while the Theorem of the Maximum implies that $\left(\hat{T}^{V}\right) f$ is continuous in $x$. For any $f^{1}, f^{2} \in \mathcal{C}(X)$ analogues of the arguments provided above ensure that the fixed points of the bargaining operator defined on $\mathcal{C}(X)$ are also continuous in $X$. Select the largest 
such fixed point. Then the mapping $\mathcal{H}_{1}\left(V^{D}, q\right)(b, s)$ is a continuous (and hence upper hemicontinuous) single valued, and hence compact and convex valued, correspondence. From this, we can construct the product correspondence

$$
\mathcal{H}_{1}\left(V^{D}, q\right)=\prod_{(b, s) \in B \times S} \mathcal{H}_{1}\left(V^{D}, q\right)(b, s) .
$$

By Theorem 17.28 of Aliprantis and Border (2006), this product correspondence is continuous and compact valued.

Now consider the second part of our mapping $\mathcal{H}_{2}\left(V^{D}, W, q\right)$ defined as follows. First, think of the $q\left(b^{\prime}, s\right), V^{D}(b, s)$ and $W(b, s)$ as a finite set of parameters for the country's borrowing problem, with each $q\left(b^{\prime}, s\right)$ belonging to the compact interval $\left[0,1 /\left(1+r^{w}\right)\right]$, each $V^{D}(b, s)$ belonging to $\left[V_{\min }, V_{\max }\right]$, and each $W(b, s)$ belonging to $\left[b_{\min }, b_{\max }\right]$. Let $\mathcal{C}(X)$ be the space of all continuous functions defined on

$$
X=\left[0,1 /\left(1+r^{w}\right)\right]^{N_{b} \times N_{e}} \times\left[V_{\min }, V_{\max }\right]^{N_{b} \times N_{e}} \times\left[b_{\min }, b_{\max }\right]^{N_{b} \times N_{e}} .
$$

Let $f \in \mathcal{C}(X)$ and define the operator $\hat{T}^{V}$ be defined by

$$
\left(\hat{T}^{V}\right) f=\max \left\{\max _{b^{\prime} \in B} u\left(e(s)-b+b^{\prime} q\left(b^{\prime}, s\right)\right)+\beta E\left[V\left(b^{\prime}, s^{\prime}\right) \mid s\right], \tilde{V}^{D}(b, s)\right\} .
$$

As above, the fixed point $V$ is continuous on $X$; the calculations also define the function $V^{R}(b, s)$.

Define the default indicator correspondence

$$
\Phi(b, s)=\left\{\begin{array}{ccc}
1 & \text { if } & \tilde{V}^{D}(b, s)>V^{R}(b, s) \\
0 & \text { if } & \tilde{V}^{D}(b, s)<V^{R}(b, s) \\
{[0,1]} & \text { if } & \tilde{V}^{D}(b, s)=V^{R}(b, s)
\end{array} .\right.
$$

From this we can define a default probability correspondence, $P\left(b^{\prime}, s\right)$, as the set of all $p\left(b^{\prime}, s\right)$ constructed as

$$
p\left(b^{\prime}, s\right)=\sum_{s^{\prime} \in S} \phi\left(b^{\prime}, s^{\prime}\right) \pi\left(s^{\prime} \mid s\right),
$$

for some $\phi\left(b^{\prime}, s^{\prime} ; x\right) \in \Phi\left(b^{\prime}, s^{\prime} ; x\right)$., Hence, for any fixed $\left(b^{\prime}, s\right)$ we can define the bond price correspondence from points in $X$ to $\left[0,1 /\left(1+r^{w}\right)\right]$ as

$$
\mathcal{H}_{2}\left(V^{D}, W, q\right)\left(b^{\prime}, s\right)=\left\{y: y=\frac{1-p+p \sum_{s^{\prime} \in S} \pi\left(s^{\prime} \mid s\right) \tilde{W}\left(b^{\prime}, s^{\prime}\right) / b}{1+r^{w}} \text { for some } p \in P\left(b^{\prime}, s\right)\right\}
$$

where $\tilde{W}\left(b^{\prime}, s^{\prime}\right)$ was defined above.

It is straightforward to show that for $\left(b^{\prime}, s\right)$ and $\left(V^{D}, W, q\right)$ fixed, this is a closed interval contained in $[0,1]$. Hence, it is compact valued. A straightforward adaptation of App Lemma 8 from Chatterjee, Corbae, Nakajima and Rios-Rull (2002) shows that it is also upper-hemi continuous. Therefore, viewed as a correspondence from points in $X$ to $\left[0,1 /\left(1+r^{w}\right)\right]$ this is upper-hemi continuous. Then for any $\left(V^{D}, W, q\right)$, we can define the 
product correspondence

$$
\mathcal{H}_{2}\left(V^{D}, W, q\right)=\prod_{(b, s) \in B \times S} \mathcal{H}_{2}\left(V^{D}, W, q\right)(b, s) .
$$

By Theorem 17.28 of Aliprantis and Border (2006), this product correspondence is continuous and compact valued.

Finally, form

$$
\mathcal{H}\left(V^{D}, W, q\right)=\left[\mathcal{H}_{1}\left(V^{D}, q\right), \mathcal{H}_{2}\left(V^{D}, W, q\right)\right]
$$

By Theorem 17.23 of Aliprantis and Border (2006), $\mathcal{H}$ is upper hemi-continuous. Using the fact that $\mathcal{H}_{1}$ is single valued, it is also straightforward to show that it is convex valued. Hence, by Kakutani's fixed point theorem there exists a fixed point of $\mathcal{H}$.

Using the fixed points for $q^{*}$ and $V^{D *}$, we can then iterate to convergence to find $V^{*}$. The collection $V^{*}, V^{D *}, W^{*}$ and $q^{*}$ satisfies the definition for an equilibrium of our borrowing economy, and hence there exists an equilibrium for our borrowing economy.

\section{Appendix C: Data}

In this appendix, we tabulate our data on delays and haircuts, and study the relationship between our estimates of haircuts and those computed by other authors. We also discuss the some issues that arise with the use of World Bank debt stock data.

\section{A Data on Haircuts}

The data on haircuts are presented in Figure 15, for all ninety defaults and settlements. Table 12 then presents the correlations between our measures of haircuts, and those computed by other authors for smaller samples of countries. As shown in Table 12, the correlation with the World Bank and Cline estimates is around 0.9, which presumably follows from the similar sources of data. The correlation with the Sturzenegger and Zettelmeyer preferred estimate (calculated as a debt value weighted average over the estimates for all instruments in a restructuring) is also 0.86. Interestingly, the correlations with the market estimates of Sturzenegger and Zettelmeyer, and with the estimates produced by the Global Committee of Argentine Bondholders, are the smallest.

The differences in estimates result for a number of reasons. One reason is the rate of discounting. Another is that not all estimates subtract "new money" (new loans made as part of a restructuring), although as pointed out by Cline (1995 p. 236), new money typically amounted to less than two per-cent of the debt stock, and should have little impact on the results. Another reason is that some estimates are intended as estimates of the reduction in total debt, rather than just the debts owed to private sector creditors. For example, the World Bank (1993) estimates of "debt reduction equivalents" for nine countries subtract the value of new loans by the official sector. The estimates of the private sector Global Committee of Argentine Bondholders, 2004, were intended as evidence in support of their claim that the restructuring of Argentine debts after the 2001 default was particularly severe. Since the methodology for their computation was not reported, it is not possible to verify whether or not they focused on measures that would tend to understate the estimates. Finally, the World Bank estimates also focus on the reduction in the face value of the debt, which neglects the effect of any extension of the maturity of the loans being rescheduled. The most rigorous measurement is by Sturzenegger and Zettelmeyer (2005, 2007), who provide careful instrument-by-instrument estimates of creditor losses for 246 debts, but for only six defaults, 
and who are careful to adjust for the effect of maturity extensions. The high correlation between their estimates and ours suggests that this adjustment is often not significant.

Table 12 also presents results for the relationship between delays and the different measures of haircuts. As shown in the table, the range of estimates brackets the one produced for the large sample (0.66). The most reliable estimates, produced by Sturzenegger and Zettelmeyer, have the highest correlation with delays at 0.88 .

\section{B Data on Debt}

In its Global Development Finance (GDF) publication, the World Bank publishes estimates of the face value of sovereign debt of a country, which is defined to be the sum of all future principal repayments on the debt. This creates a problem when matching the model to the data because different debt contracts with precisely the same payment stream will have different face values depending on the way the payments streams are divided into 'principal' and 'interest'.

To see this in the context of our model, note that we have assumed that all debts take the form of a zero-coupon discount bond. The face value of such a bond is therefore equal to the amount $b$ of payments promised in the next period, since all payments for such a bond are regarded as principal. An alternative contract that produces the same payment stream as these zero-coupon discount bonds would be a bond issued at par (a 'par-bond') in the amount $b q(b, s)$ and that bore a coupon of $(1-q(b, s))$ per bond, generating total interest payments of $b(1-q(b, s))$. For such a contract, face value of the debt outstanding would be reported as $b q(b, s)$, which is the market value of the debt. Of course, there are also a continuum of other equivalent contracts that divide debt service into principal and interest in different proportions, and that have face values that lie between $b q(b, s)$ and $b$.

In the data, over the period we study, there has been a shift away from bank loans, which are typically issued at par, towards bonds issued at a discount. There are also difference in the financing mix across countries. As a consequence, we examine the models implications for both the face value and the market value of debt, before comparing both to the GDF data.

Table 12: Comparison of Alternate Haircut Estimates

\begin{tabular}{|c|c|c|c|c|c|}
\hline & \multirow{2}{*}{$\begin{array}{c}\text { World Bank } \\
(1993)\end{array}$} & \multicolumn{4}{|c|}{ Sturzenegger and Zettelmeyer } \\
\hline & & $(1995)$ & Preferred & Market & $(2004)$ \\
\hline no. obs. & 13 & 17 & 6 & 6 & 17 \\
\hline $\begin{array}{c}\text { Correlation } \\
\text { with Authors' } \\
\text { Estimates }\end{array}$ & 0.87 & 0.90 & 0.86 & 0.77 & 0.50 \\
\hline $\begin{array}{c}\text { Correlation } \\
\text { with } \\
\text { Delay }\end{array}$ & 0.40 & 0.55 & 0.88 & 0.72 & 0.42 \\
\hline
\end{tabular}


Figure 15: Data on Delays and Haircuts

\begin{tabular}{|c|c|c|c|c|c|c|c|c|c|c|c|}
\hline \multirow[b]{2}{*}{ Country } & \multirow[b]{2}{*}{$\begin{array}{l}\text { Country } \\
\text { Code }\end{array}$} & \multirow[b]{2}{*}{$\begin{array}{l}\text { Default } \\
\text { Code }\end{array}$} & \multicolumn{3}{|c|}{ Length (Years) } & \multirow[b]{2}{*}{$\begin{array}{l}\text { Authors } \\
\text { Estimate }\end{array}$} & \multirow[b]{2}{*}{$\begin{array}{l}\text { World Bank } \\
\text { (1993) }\end{array}$} & \multirow[b]{2}{*}{$\begin{array}{l}\text { Cline } \\
(1995)\end{array}$} & \multicolumn{2}{|l|}{ Haircuts (\%) } & \multirow[b]{2}{*}{$\begin{array}{l}\text { GCAB } \\
(2004) \\
\end{array}$} \\
\hline & & & $\begin{array}{c}\text { Default } \\
\text { Start }\end{array}$ & $\begin{array}{l}\text { Default } \\
\text { End }\end{array}$ & $\begin{array}{l}\text { Default } \\
\text { Length }\end{array}$ & & & & $\begin{array}{c}\text { Sturzenegger } \\
\text { Preferred }\end{array}$ & $\begin{array}{c}\text { Zettelmeyer (2005) } \\
\text { Market }\end{array}$ & \\
\hline Albania & ALB & ALB91 & 1991 & 1995 & 4.6 & 38 & & & & & \\
\hline Algeria & DZA & DZA91 & 1991 & 1996 & 5.2 & 0 & & & & & \\
\hline Angola & AGO & AG085 & 1985 & 2004 & 19.0 & 69 & & & & & \\
\hline Argentina & ARG & ARG82 & 1982 & 1993 & 11.2 & 30 & 32 & 29 & & & 35 \\
\hline Argentina & ARG & ARG01 & 2001 & 2005 & 3.6 & 63 & & & 55 & 63 & 63 \\
\hline Bolivia & $\mathrm{BOL}$ & BOL80 & 1980 & 1993 & 12.4 & 58 & 78 & & & & \\
\hline Brazil & BRA & BRA83 & 1983 & 1994 & 11.2 & 21 & 18 & 28 & & & 35 \\
\hline Bulgaria & BGR & BGR90 & 1990 & 1994 & 4.3 & 46 & 44 & 50 & & & 50 \\
\hline Burkina Faso & BFA & BFA83 & 1983 & 1996 & 13.0 & 61 & & & & & \\
\hline Cameroon & CMR & CMR85 & 1985 & 2003 & 18.0 & 61 & & & & & \\
\hline Cape Verde & CPV & CPV81 & 1981 & 1996 & 15.7 & 46 & & & & & \\
\hline Central African Republic & CAF & CAF83 & 1983 & 2004 & 21.0 & 66 & & & & & \\
\hline Chile & $\mathrm{CHL}$ & CHL83 & 1983 & 1990 & 7.4 & 46 & & & & & \\
\hline Colombia & $\mathrm{COL}$ & COL85 & 1985 & 1991 & 5.3 & 2 & & & & & \\
\hline Costa Rica & CRI & CRI83 & 1983 & 1990 & 6.7 & 43 & 62 & 61 & & & \\
\hline Croatia & HRV & HRV92 & 1992 & 1996 & 4.0 & 0 & & & & & \\
\hline Dominica & DMA & DMA03 & 2003 & 2004 & 1.0 & 0 & & & & & \\
\hline Dominican Republic & DOM & DOM83 & 1983 & 1994 & 10.9 & 47 & 63 & 50 & & & \\
\hline Ecuador & ECU & ECU82 & 1982 & 1995 & 12.3 & 23 & & 45 & & & 45 \\
\hline Ecuador & ECU & ECU99 & 1999 & 2000 & 1.7 & 34 & & & 27 & 60 & \\
\hline Ecuador & ECU & ECU00 & 2000 & 2001 & 1.1 & 0 & & & & & 40 \\
\hline El Salvador & SLV & SLV81 & 1981 & 1996 & 15.0 & 64 & & & & & \\
\hline Ethiopia & ETH & ETH91 & 1991 & 1999 & 8.1 & 44 & & & & & \\
\hline Gabon & GAB & GAB86 & 1986 & 1994 & 7.4 & 42 & & & & & \\
\hline Gabon & GAB & GAB99 & 1999 & 2004 & 4.7 & 85 & & & & & \\
\hline Gambia & GMB & GMB86 & 1986 & 1990 & 4.2 & 63 & & & & & \\
\hline Guatemala & GTM & GTM89 & 1989 & 1989 & 0.0 & 14 & & & & & \\
\hline Guinea & GNB & GNB86 & 1986 & 1988 & 2.3 & 8 & & & & & \\
\hline Guinea & GNB & GNB91 & 1991 & 1998 & 8.0 & 14 & & & & & \\
\hline Guinea-Bissau & GIN & GIN83 & 1983 & 1996 & 13.0 & 70 & & & & & \\
\hline Guyana & GUY & GUY82 & 1982 & 2004 & 21.5 & 85 & & 86 & & & \\
\hline Haiti & $\mathrm{HTI}$ & HTI82 & 1982 & 1994 & 12.0 & 65 & & & & & \\
\hline Honduras & HND & HND81 & 1981 & 2004 & 23.0 & 72 & & & & & \\
\hline Ivory Coast & CIV & CIV83 & 1983 & 1998 & 15.2 & 52 & & & & & \\
\hline Ivory Coast & CIV & CIV00 & 2000 & 2004 & 4.0 & 41 & & & & & \\
\hline Jamaica & JAM & JAM87 & 1987 & 1993 & 6.1 & 60 & & & & & \\
\hline Jordan & JOR & JOR89 & 1989 & 1993 & 4.1 & 44 & 42 & 33 & & & 35 \\
\hline Kenya & KEN & KEN94 & 1994 & 2004 & 10.0 & 85 & & & & & \\
\hline Macedonia & MKD & MKD92 & 1992 & 1997 & 5.2 & 60 & & & & & \\
\hline Madagascar & MDG & MDG81 & 1981 & 2002 & 20.1 & 68 & & & & & \\
\hline Mauritania & MRT & MRT92 & 1992 & 1996 & 4.7 & 48 & & & & & \\
\hline Mexico & MEX & MEX82 & 1982 & 1990 & 7.9 & 34 & 35 & 30 & & & 35 \\
\hline Moldova & MDA & MDA98 & 1998 & 1998 & 0.0 & 15 & & & & & \\
\hline Moldova & MDA & MDA02 & 2002 & 2002 & 0.5 & 42 & & & & & \\
\hline Mongolia & MNG & MNG97 & 1997 & 2000 & 3.0 & 0 & & & & & \\
\hline
\end{tabular}


Figure 15 (Continued): Data on Delays and Haircuts

\begin{tabular}{|c|c|c|c|c|c|c|c|c|c|c|c|}
\hline \multirow[b]{3}{*}{ Country } & \multirow{3}{*}{$\begin{array}{c}\text { Country } \\
\text { Code }\end{array}$} & \multirow{3}{*}{$\begin{array}{c}\text { Default } \\
\text { Code }\end{array}$} & \multicolumn{3}{|c|}{ Length (Years) } & \multirow{3}{*}{$\begin{array}{l}\text { Authors } \\
\text { Estimate }\end{array}$} & \multirow{3}{*}{$\begin{array}{c}\text { World Bank } \\
\text { (1993) }\end{array}$} & \multirow{3}{*}{$\begin{array}{c}\text { Cline } \\
(1995)\end{array}$} & \multicolumn{2}{|l|}{ Haircuts (\%) } & \multirow{3}{*}{$\begin{array}{l}\text { GCAB } \\
\text { (2004) }\end{array}$} \\
\hline & & & Default & Default & Default & & & & Sturzenegger & Zettelmeyer (2005) & \\
\hline & & & Start & End & Length & & & & Preferred & Market & \\
\hline Morocco & MAR & MAR86 & 1986 & 1990 & 4.6 & 42 & & & & & \\
\hline Mozambique & MOZ & MOZ83 & 1983 & 1992 & 10.0 & 57 & & 58 & & & \\
\hline Myanmar & MMR & MMR97 & 1997 & 2003 & 6.0 & 43 & & & & & \\
\hline Nicaragua & NIC & $\mathrm{NIC79}$ & 1979 & 2003 & 24.0 & 75 & & & & & \\
\hline Niger & NER & NER83 & 1983 & 1991 & 7.9 & 89 & & 82 & & & \\
\hline Nigeria & NGA & NGA82 & 1982 & 1992 & 10.4 & 70 & 80 & 49 & & & \\
\hline Nigeria & NGA & NGA02 & 2002 & 2002 & 0.0 & 8 & & & & & \\
\hline Pakistan & PAK & PAK98 & 1998 & 1999 & 1.6 & 29 & & & 31 & 30 & \\
\hline Panama & PAN & PAN83 & 1983 & 1996 & 12.7 & 34 & & & & & 45 \\
\hline Paraguay & PRY & PRY86 & 1986 & 1993 & 7.6 & 62 & & & & & \\
\hline Paraguay & PRY & PRY03 & 2003 & 2004 & 1.4 & 0 & & & & & \\
\hline Peru & PER & PER80 & 1980 & 1980 & 0.9 & 0 & & & & & \\
\hline Peru & PER & PER83 & 1983 & 1997 & 14.4 & 29 & & & & & 45 \\
\hline Philippines & $\mathrm{PHL}$ & PHL83 & 1983 & 1992 & 9.6 & 35 & 44 & 36 & & & \\
\hline Poland & POL & POL81 & 1981 & 1994 & 12.9 & 42 & 58 & 45 & & & 45 \\
\hline Romania & ROM & ROM81 & 1981 & 1983 & 1.5 & 9 & & & & & \\
\hline Russia & RUS & RUS91 & 1991 & 1997 & 6.0 & 32 & & & & & \\
\hline Russia & RUS & RUS98 & 1998 & 2000 & 2.3 & 32 & & & 53 & 65 & 38 \\
\hline Rwanda & RWA & RWA95 & 1995 & 1995 & 0.0 & 0 & & & & & \\
\hline Sao Tome and Principe & STP & STP87 & 1987 & 1994 & 7.7 & 48 & & & & & \\
\hline Senegal & SEN & SEN90 & 1990 & 1990 & 0.7 & 3 & & & & & \\
\hline Senegal & SEN & SEN92 & 1992 & 1996 & 5.0 & 10 & & & & & \\
\hline Serbia and Montenegro & SER & SER92 & 1992 & 2004 & 12.0 & 57 & & & & & \\
\hline Seychelles & SYC & SYCOO & 2000 & 2002 & 2.0 & 12 & & & & & \\
\hline Sierra Leone & SLE & SLE86 & 1986 & 1995 & 9.7 & 85 & & & & & \\
\hline Sierra Leone & SLE & SLE97 & 1997 & 1998 & 1.0 & 51 & & & & & \\
\hline Solomon Islands & SLB & SLB96 & 1996 & 2004 & 8.0 & 90 & & & & & \\
\hline South Africa & ZAF & ZAF93 & 1993 & 1993 & 0.7 & 0 & & & & & \\
\hline Sri Lanka & LKA & LKA96 & 1996 & 1996 & 0.0 & 4 & & & & & \\
\hline Tanzania & TZA & TZA84 & 1984 & 2004 & 20.3 & 63 & & & & & \\
\hline Thailand & THA & THA97 & 1997 & 1998 & 0.5 & 0 & & & & & \\
\hline Togo & TGO & TG091 & 1991 & 1997 & 7.0 & 66 & & & & & \\
\hline Trinidad and Tobago & TTO & TTO88 & 1988 & 1989 & 2.0 & 4 & & & & & \\
\hline Uganda & UGA & UGA80 & 1980 & 1993 & 13.2 & 90 & & 76 & & & \\
\hline Ukraine & UKR & UKR98 & 1998 & 2000 & 1.4 & 1 & & & 18 & 28 & \\
\hline Uruguay & URY & URY90 & 1990 & 1991 & 1.1 & 16 & 41 & 31 & & & \\
\hline Uruguay & URY & URY03 & 2003 & 2003 & 0.0 & 0 & & & 16 & 29 & \\
\hline Venezuela & VEN & VEN90 & 1990 & 1990 & 1.0 & 14 & 23 & 20 & & & 30 \\
\hline Venezuela & VEN & VEN95 & 1995 & 1997 & 2.0 & 2 & & & & & \\
\hline Venezuela & VEN & VEN98 & 1998 & 1998 & 0.0 & 0 & & & & & \\
\hline Venezuela & VEN & VEN05 & 2005 & 2005 & 0.1 & 0 & & & & & \\
\hline Vietnam & VNM & VNM85 & 1985 & 1998 & 14.0 & 58 & & & & & \\
\hline Yemen & YEM & YEM85 & 1985 & 2001 & 16.5 & 35 & & & & & \\
\hline Zambia & $\mathrm{ZMB}$ & ZMB83 & 1983 & 1994 & 10.5 & 45 & & & & & \\
\hline Zimbabwe & ZWE & ZWE00 & 2000 & 2004 & 4.0 & 19 & & & & & \\
\hline
\end{tabular}

